\title{
Studies in community-based education : programme implementation and student assessment at the Faculty of Medicine, University of Gezira, Sudan
}

Citation for published version (APA):

Magzoub, M. E. (1994). Studies in community-based education : programme implementation and student assessment at the Faculty of Medicine, University of Gezira, Sudan. [Doctoral Thesis, Maastricht University]. Rijksuniversiteit Limburg. https://doi.org/10.26481/dis.19941130mm

Document status and date:

Published: 01/01/1994

DOI:

10.26481/dis.19941130mm

Document Version:

Publisher's PDF, also known as Version of record

Please check the document version of this publication:

- A submitted manuscript is the version of the article upon submission and before peer-review. There can be important differences between the submitted version and the official published version of record.

People interested in the research are advised to contact the author for the final version of the publication, or visit the DOI to the publisher's website.

- The final author version and the galley proof are versions of the publication after peer review.

- The final published version features the final layout of the paper including the volume, issue and page numbers.

Link to publication

\footnotetext{
General rights rights.

- You may freely distribute the URL identifying the publication in the public portal. please follow below link for the End User Agreement:

www.umlib.nl/taverne-license

Take down policy

If you believe that this document breaches copyright please contact us at:

repository@maastrichtuniversity.nl

providing details and we will investigate your claim.
}

Copyright and moral rights for the publications made accessible in the public portal are retained by the authors and/or other copyright owners and it is a condition of accessing publications that users recognise and abide by the legal requirements associated with these

- Users may download and print one copy of any publication from the public portal for the purpose of private study or research.

- You may not further distribute the material or use it for any profit-making activity or commercial gain

If the publication is distributed under the terms of Article 25fa of the Dutch Copyright Act, indicated by the "Taverne" license above, 


\title{
Studies in Community-based Education
}

\author{
Programme implementation and student assessment
} at the Faculty of Medicine, University of Gezira, Sudan 



\section{Studies in Community-based Education}

Programme implementation and student assessment at the Faculty of Medicine, University of Gezira, Sudan

\section{Proefschrift}

ter verkrijging van de graad van doctor aan de Rijksuniversiteit Limburg te Maastricht, op gezag van de Rector Magnificus, Prof.dr. H. Philipsen, volgens het besluit van het College van Dekanen, in het openbaar te verdedigen op woensdag,

30 november 1994 om 16.00 uur

door

Mohi Eldin Magzoub

geboren te Fadasi, Gezira,

Sudan, in 1957 


\section{Promotor:}

Prof.dr. H.G. Schmidt

\section{Beoordelingscommissie:}

Prof.dr. A.C. Nieuwenhuijzen Kruseman (voorzitter)

Dr. Ch. Boelen, World Health Organisation, Geneva, Switzerland Prof.dr. H.F.J.M. Crebolder

Prof.dr. G.J. Kok

Dr. C.P.M. van der Vleuten

Produktie: Uniprint / Universitaire Drukkerij, Maastricht

Mohi Eldin Magzoub, Maastricht, 1994

CIP-gegevens Koninklijke Bibliotheek, Den Haag,

Magzoub, Mohi Eldin

Studies in Community-based Education:

Programme implementation and student assessment at the

Faculty of Medicine, University of Gezira, Sudan,

Mohi Eldin Magzoub - Maastricht:

Universitaire Drukkerij,

Rijksuniversiteit Limburg Maastricht -

Thesis Maastricht - With ref. - With summaries in Dutch and Arabic.

ISBN: 90-5398-030-X

Subject headings: Community-based Education /

Assessment in Community Settings. 


\section{Contents}

1. Introduction

2. Eleven Steps of Community-based Education at Gezira Medical School

Co-authors: B.O. Ahmed and S.T. Salih

Published in Annals of Community-oriented Education, 5, 11-17, 1992

3. The Rural Residency Course

Co-authors: M.M. Magzoub and A.A. Saead

Published in Annals of Community-oriented Education, 5, 27-31, 1992

4. A Comprehensive Approach to Student Assessment in Community Settings (1) Description of Methods

Co-authors: H.G. Schmidt and S. E. Mustafa

Submitted for Publication in Medical Education

5. A Comprehensive Approach to Student Assessment in Community Settings (2) Measures of reliability and validity Co-authors: H.G. Schmidt, A. A. Abdel-Hameed and, D. Dolmans Submitted for Publication in Medical Education

6. Assessing Students in Community Settings:

The Role of Peer Evaluation

Co-authors: H.G. Schmidt, D. Dolmans and A. A. Abdel-Hameed

Submitted for Publication in Medical Education 
7. The Impact of a Community-based Programme on the Community

Co-author: H.G. Schmidt

Submitted for Publication in Medical Education

8. Problems Facing Graduates from Network Institutions:

Experience from Sudan

Published in Annals of Community-oriented Education, 105-110, 1992

9. Summary and Conclusion

Samenvatting

Summary in Arabic

Curriculum Vitae 


\section{Acknowledgement}

The studies described on this thesis, is the final product of a learning process and fruitful collaboration with several people.

My promoter, Prof. dr. Henk Schmidt, played an important role in this project. His enthusiasm, personal interest in the topic and his continuous support always allowed for timely advice and suggestions, despite his overburdened schedule. This thesis benefited greatly from his ideas, suggestions and comments. I would like to thank also my co-authors and the reviewers for their contribution to this work. My thanks goes to the students of the Faculty of Medicine, University of Gezira (FMUG) who were involved in these studies. Their contributions were indispensable. A thesis concerning community-based education at the FMUG should not be considered completed without acknowledging the founding dean, Professor Bashir Hamad to whom I pass my respect and indebtedness.

I would like to thank my colleagues at both the FMUG and at the Department of Educational Development and Research, University of Limburg, whom I often consulted about some issues concerning the studies and analysis. I would like to mention a few names: Bushra $\mathrm{O}$. Ahmed, Ahmed A. Abdel-Hameed, Sirageldin Mustafa, Omer A. Mirghani and Sayed M. Ahmed (FMUG). Diana Dolmans, Cees van der Vleuten, Peter Bouhuijs, Irma Kokx, Ineke Wolfhagen and Bert Kerkhofs (Maastricht). My thanks also go to Tonnie de Vries-Spaen, Fien van Deurse and Pauline Vluggen who facilitated my stay in Maastricht.

I am grateful to the University of Gezira, University of Limburg, the World Health Organization, the Population Council and the Network of Community-Oriented Educational Institutions for Health Sciences for their financial assistance. 
Finally my gratitude goes to my parents and my brothers for their moral support and continuous encouragement. And last but not least the company of my wife Ayat and my lovely daughters Razan and Rania was supportive in finishing this work, although at the expense of many family hours.

Mohi Eldin Magzoub

October 1994 


\section{Introduction}

\section{Historical background}

In the history of medical education three periods can roughly be distinguished: Pre-Flexner period (-1910), in which the apprenticeship model of medical education was prevalent; and the Flexner era (1910-1970), which introduced the biomedical approach into the educational process. More recently, a new approach is advocated: the community-oriented model of medical education.

The Flexner report of 1910 convinced the US medical community, that the apprenticeship nature of medical education was not sufficient to produce high-quality physicians and that there was a need to increase the scientific knowledge and emphasis of medical practice (Bannerman 1985). The curricular model underlying Flexner's ideas was based on philosophical ideas which were developed in Germany in the early 19th century (Bouhuijs 1987). Flexner's model has been adopted widely by universities in both developing and developed countries. The model has led to an increased emphasis on factual knowledge in medicine and a discipline-based approach to health problems. Consequently, the amount of knowledge medical students have to acquire and the number of specialists who have to teach this knowledge have increased as well (Bannerman 1985). Almost all the teaching is done in classes, laboratories and tertiary-care university hospitals. As a result, graduates from such institutions know little about the prevailing community problems and are not prepared to work in rural or remote areas (Magzoub et al, 1992). 
Education as discipline started to make a contribution to medical curricula in the early 1960s (Bouhuijs, 1987). At the same time, in developed countries, societal values began to change. The human right movement called for equal rights in all areas of human existence, including health (White 1983). Governments became aware of the inequity of access to services to their population, and established social security and welfare departments with the aim of giving equal health services to all individuals regardless of their socio-economic, age or ethnic backgrounds (Report of WHO Study Group, 1987).

In the early seventies staff from a number of medical schools in developing countries came to the conclusion that the prevalent model of medical education was not optimal for producing graduates who are able to respond to local community health needs. The question of relevance of medical education to the health needs of the nation is, for instance, clearly explicated in the objectives set for Obafemi Awollowo medical school in Nigeria, which was established in 1972. These objectives were, (1) to train a health team of graduates with considerable knowledge and skills to work effectively in both rural and urban areas of the state and the nation, and (2) to provide comprehensive health care to a defined geographical area of the state and involve members of the community in the provision of health care to their communities. To realize these objectives the faculty adopted a defined geographical area, where services were delivered through staff and student postings (Jinadu, 1992).

The worldwide awareness of the importance of primary health care and equity in service delivery reached an advanced stage in 1978, following the Alma Ata declaration in primary health care and the worldwide acceptance of the "Health for all by the year 2000" objectives (WHO, 1978).

The Alma Ata conference confirmed the need for a new look at health profession education. The global awareness of the world's health problems and, subsequently, the promotion of health for all by the year 2000 through primary health care brought with it a growing concern of the necessity to adjust health manpower development to the real health needs and demands of the populations. This resulted in what is called the "health manpower development concept" (Fulop, 1985).

Quite some institutions for health professions education adopted the community-based education (CBE) approach even before a definition, goals and strategies were explicitly formulated and before the establishment of the Network of Community-Oriented Educational Institutions for Health Sciences (Network) (Richards \& Fulop, 1987). The Network was a voluntary organization of, mostly, medical schools sharing the idea of relevance for health professions education. It played an important role in disseminating the idea of CBE widely. It also made considerable efforts in 
collaboration with the World Health Organization in conceptualizing innovative approaches to health professions education such as CBE and problem-based learning, through international meetings and publications (Schmidt et al, 1991).

Community-based education is now recognized as a an important addition to the methods available in medical education, because the skills of graduates are needed in the community, more than in the tertiary hospital. Unfortunately, research in this area is still in its infancy. Most of the studies conducted in $\mathrm{CBE}$ are descriptive in nature. In the following sections of this introduction issues related to $\mathrm{CBE}$ will be briefly discussed. Then, a taxonomy of CBE will be presented followed by a discussion of the different dimensions along which CBE programmes can be distinguished, and finally an overview of the thesis is provided.

\section{Issues related to community-based education}

In this section, some concepts relevant to an understanding of what $\mathrm{CBE}$ is, will be discussed. In addition, some implications of our conceptualization of $\mathrm{CBE}$ will be presented.

\section{Health manpower development concept}

According to Fulop (1985) the quality and quantity of health manpower has to be planned in response to the specific needs of national health systems and through this to the health needs and demands of the population. In order to reach this goal, health personnel should be trained according to these plans, which means placing the right kind of manpower in the right numbers at the right time in the right place (Fulop, 1985). This is not as obvious as it sounds. Health manpower training is largely left to the schools themselves, without reference to specific needs. In the US, for instance, this has led to overproduction of physicians, while in the Sudan, this has led to maldistribution of health services, i.e., concentration of physicians in big cities.

\section{Community-oriented education}

Community-oriented education is defined as a type of training of health personnel that focuses on both population groups and individuals and that takes into account the health needs of the community concerned. (First meeting of the Network of Community-Oriented Educational Institutions for Health Sciences, 1979). Again, this is not self evident. Medical education as it is practised all over the world is quite skewed towards the cure of 
individuals in tertiary health care, whose problems represent only the tip of the ice berg of the prevailing community health problems.

\section{Community-based education}

CBE is defined as a means of achieving educational relevance to community needs and, consequently, as a way of implementing a community-oriented educational programme. It consists of leaming activities that utilize the community extensively as a leaming environment in which not only students, but also teachers, members of the community, and representatives of other sectors are actively involved throughout the educational experience. Community-based education activity is an educational activity that takes place within a community or in any of a variety of health services settings at the primary and secondary care level. An educational programme, or a curriculum, can be called communitybased if, for its entire duration, it consists of an appropriate number of learning activities in a balanced variety of educational settings (WHO Study Group Report, 1987).

The distinction between community-oriented and community-based education is not very clear, even for institutions involved in both. Therefore, the following suggestions for a distinction is offered here: Community orientation is referring to the objectives of the school and their relevance to community health needs. These objectives are reflected in the content of the curriculum. This means that the subject-matter studied by the students has direct relevance with regard to the priority health problems of the society for which these students are trained. Community-based education, on the other hand, refer to learning activities that take place in a particular setting, the community settings. The activities undertake in that setting may, or may not, be relevant to community health needs. Let us take the following two examples. A medical school in a developed country has objectives that can be labelled community-oriented and the curriculum content is properly reflecting these objectives, as indicated by the type of subject-matter selected which is related to the priority health problems in that particular country. However, the students stay in the university and only minimal learning takes place in the community setting. This curriculum can be described as community-oriented, without being community-based. Take, on the other hand one, a curriculum for community health nursing, in one of the developing countries. The staff sends its students on home visits regularly to follow-up on children with rare congenital anomalies. This curriculum can be considered community-based without being communityoriented. Hence, one may conclude that an entirely relevant curriculum should be community-oriented as well as community-based. 
This point of view needs further clarification. First, community-based education is a set of leaming activities that takes place outside the classroom. This may require a special approach to learning and instruments for student and programme assessment adapted to the peculiarities of the environment and the specific objectives pursued. These features make CBE difficult to implement and control, compared to classroom teaching. Second, since this type of education depends to a large extent on community settings, that is: settings beyond the university's control, institutions involved have to seek close collaboration with the community itself and with the government. Third, each new programme has to be unique in its approach because local circumstances and situations tend to be unique. Carbon copies of other programmes tend not to work.

In the fourth place, community-based education is not synonymous with what community medicine or public health departments tend to do in conventional education. Although these departments may play a key role in the implementation, $\mathrm{CBE}$ should be the responsibility of the whole school and preferably also of other institutions outside the school e.g., the government, other faculties, etc. The shared responsibility ensures the commitment of staff, students and the collaborating institutions to CBE. In addition, it is a safeguard towards the sustainability of the programme. Finally, an institution involved in CBE should not consider the community as just another laboratory for training where students are to collect data. The community should see positive changes as a result of services provided during the process of training.

\section{Rationale of community-based education}

The rationale of $\mathrm{CBE}$ can be summarized in a number of distinct points:

1. Community-based education may contribute to the solution of the problem of inequity in service delivery. Education in community settings seems to be an important approach to train doctors who are willing and able to work in the underserved areas, particularly rural communities (Harris, 1982; Emey, 1991; Magnus, 1993). In the Sudan, for instance, not unlike many other developing countries, more than $60 \%$ of the physicians work in the capital, Khartoum, a city where only $10 \%$ of the total population lives. Moreover, the total number of physicians working in the Sudan, has never increased over the last 20 years despite the fact that every year 400 new doctors are joining the Ministry of Health. This is mainly due to the drain of physicians to the Arabian Gulf. In addition, the health expenditures are mainly allocated to curative services in communities where most of health problems are, in fact, preventable. The problem of maldistribution of health personnel and services, is felt even in industrialized countries such as the United States (Starfield, 1991) and Norway (Magnus, 1993). Community- 
based education offers students and faculty the chance to appreciate these challenges and face them by working in the underserved areas (Magnus, 1993). In addition, CBE may contribute in a positive way to the improvement of the health system by resolving health priority problems (Abdel Rahim, 1992).

2. Two of the rationales mentioned by Schmidt (1983) for problembased learning are also applicable in community-based education. First, the closer the resemblance between the situation in which something is learned and the situation in which it is applied, the better the performance. CBE provides unique opportunities to learn in an environment that typically resembles what students will encounter in later professional life. Second, information is better understood, processed and retrieved if students have opportunities to elaborate on that information. $\mathrm{CBE}$ provides a chance for elaborating on information. Since students will be considered as experts by the community, they will be asked questions, deliver talks about health education, discuss its problems with the community, and try to explain different phenomena observed in the community. In this way communitybased education can enhance learning in much the same way as in problembased learning.

3. Community-based education may not only provide answers to maldistribution of services by graduating health professionals who are committed to the community. In fact, many community-based programmes make health services available to the community as soon as students begin to learn in that community. These services range from curative services to community-development activities. Often these programmes serve as models to be replicated by local governments, non governmental organizations (NGOs) or the international community.

4. Community-based education may equip students with competencies which they will never learn otherwise e.g., leadership skills, the ability to work in a team, and the capability to interact with the community. During their field work students will have a unique opportunity to apply these skills, essential for their later professional life. Also, CBE provides an opportunity to consolidate skills learned in other parts of the curriculum, including problem-solving, clinical and managerial skills.

5. Community-based education may provide opportunities for improving student and programme assessment. As the community dispenses a site for learning, it also provides a chance for assessing important student competencies in context, eg., communication, management and leadership skills. Also, the community is a source of independent assessors for both students and the programme, such as community leaders or health personal working in primary health care units. 
6. The importance of working as a harmonious tean including all health professions is very important. This can not be achieved without the recognition and appreciation of each team member's role and shared respect between the team members. CBE offers the students an opportunity to learn and work with other health professionals in for instance, primary care units (Magzoub, 1992).

7. Health is defined as a complete physical, mental and social state of well-being and not merely absence of disease (WHO 1978). This definition implies a holistic and multidisciplinary approach to health care. The contribution of other sectors to the improvement of health status of the population is a well established fact. Europe, for instance, experienced a drop in mortality through the dissemination of methods of hygiene both personal and environmental, before the invention of modern health care. The rate of tuberculosis dropped well before Koch's discovery of its cause and decades before the advent of specific antibiotic therapies (McKeown, cited by Lipkin, 1989). Data resulting from the World Fertility Survey demonstrated that maternal education is the most important single variable negatively correlating with fertility and child mortality (Cochaine et al, 1980). These findings suggest the importance of involvement of other sectors in solving health problems. While students are posted in villages or assigned to work in rural health facilities they have opportunities to practice a multidisciplinary and holistic approach to health care (Hamad, 1982).

8. Working in the community will put the academic institution in touch with community and political leaders and other influential persons in the community around. This may help in strengthening the school in many areas, politically, financially and morally. In this, the school may acquire a platform to play an influential role, through its staff, students and graduates, in regional health policy development. To give an example: In the Beer Sheeva experiment, the dean was assigned as a director of the health services in the Negev, Israel, where the school made an important contribution to health services delivery in their catchment area (WHO Study Group, 1987).

9. Furthermore, and not unimportant, CBE brings a school in contact with a number of international organizations such as the World Health Organization and the Network of Community-Oriented Educational Institutions for Health Sciences. This may give the school credit locally and a safeguard against forces who may want to step back or do away the community-oriented approach.

10. CBE, may also be a means of developing and updating the curriculum using health priority data that come from continuous assessment conducted by the students and staff during their field work in the community setting. The main goal of curriculum updating is to meet the 
needs of the changing patterns of health and other community problems and, consequently, to respond to the changing needs of the community (Neufeld, 1989).

11. CBE, in addition, renders opportunities for partnership between the community, university and government. This is an advanced step of collaboration between the three parties. Partnership means institutionalization of the relationship by assigning a specific role to each partner. The advantage of this approach is that it gives the school political and moral support to realize its objectives and to play an essential role in decision making concerning the promotion of the health system and services in the community. (This approach is, in particular, advocated by the Network of Community-oriented Educational Institutions for Health Sciences.)

\section{Approaches to Community Based Education}

This section deals with a taxonomy of CBE and the different dimensions of community-based programmes as described in the literature. The section starts with a rationale for a CBE taxonomy and with the difficulties involved in creating it. Subsequently, our taxonomy will be presented. This taxonomy includes three major classifications and six subclassifications, which will be described in some detail. Finally, a number of dimensions are presented by which community-based programmes can be distinguished.

\section{Why classifying community-based programmes?}

Classification of community-based education is important for the following reasons. First, one of the criticisms voiced against community oriented, community-based education, is that this type of learning does not have a scientific basis (Hamad, 1991). Having a taxonomy that describes all community-based programmes may encourage the development of a more systematic approach to the study of community-based education. Second, having this approach of classification may help in developing guidelines for implementation of community-based programmes. When discussing the problem of implementation of CBE Programmes, Nooman (1989) stresses the need for comparative studies on how different programmes face the problems of implementation and the importance of exchange of experience. Therefore, classification of programmes and the definition of dimensions on which these may differ, may help in sharing experiences among those involved on this kind of education. 


\section{Previous attempts at classification of community-based programmes}

There have been a few attempts at classifying community-based programmes. Most of these attempts were directed towards differentiating between community-based curricula and conventional approaches by the department of community medicine and family health for instance. The first attempt on this line, was the one that distinguished between communitybased curriculum and community-based activity (Report of WHO study group, 1987). The former is described as learning activities that utilize the community extensively throughout the educational experience. The latter is a short and isolated educational activity that take place on the community setting.

Jinadu (1992), addresses the same issue in a slightly different way. He identified two models, the conventional or traditional model and the experiential community-based model The latter is characterised by utilization of the entire social environment for learning, use of inductive, non-directive learning processes and deep level approaches to learning. Another attempt was based on the classification of objectives and their assessment of the institutions belonging to the Network according to geographical regions (Engel et al, 1991). Mauksch (1980)) has divided the educational programmes that address the problems of underserved population in the US into programmes that focus on the geographic maldistribution of health services and others that focus on culturally and socially identified groups of undeserved population. However, there is not yet a comprehensive review of community-based education for the purpose of the classification. What follows, will be a first approximation.

\section{Problems facing the creation of a taxonomy}

First, for obvious reasons, the implementation of various programmes by different community-based health professions institutions is quite diverse. Each school has a unique approach to CBE, although it may share general goals and some experiences with others. The main reason, of course, is, that the learning is based in communities and communities can be quite distinct. Even within one country, varieties of communities can be found, with different levels in terms of development, health, socio-economic status and culture. Some communities may enjoy good coverage of health services, others may lack basic resources for survival. Some communities may be quite open and well accepting outsiders; others may be reluctant to accept visitors. Furthermore, the national educational system within which the school is operating, and the administrative and political set-up of the institution, are important factors in planning and implementation and ultimately shaping the community-based education programmes. The resources allocated to community-based education are different for various 
programmes. Thus, country, community, regional and institutional factors all shape the CBE programme in one institution and give it its identity. This feature make it difficult to group these diverse programmes in a simple taxonomy that encapsulates this diversity.

The second problem is related to data availability regarding these programmes. In recent years, quite some descriptive studies of communitybased programmes have been published. Unfortunately, some of these articles are lacking important descriptive information, e.g., how these programmes are organized, what its contents are, and how they are evaluated. This lack of information makes it difficult to classify these programmes based on only the existing literature. However, even a standard questionnaire study faced problems with the interpretation of answers to questions and the definition of terms (Engel et al, 1991; Richards \& Fulop 1987). For the purpose of our classification the published literature was used.

The third problem has to do with the interpretation of the available data. Different terms carry different meanings for different institutions. This difficulty was also felt by other authors (Richards \& Fulop 1987; Engel, et al 1991; Hamad, 1991). These reviews demonstrated that different schools have different interpretations even for basic concepts, such as "community-orientation", "community-based experience" or even what is a "community."

The last problem, is whether a review should be based on the objectives as stated by an institution or on the actual application of these objectives. For instance, some traditional institutions, e.g., the University of khartoum medical school in the Sudan explicitly include the community-oriented approach as one of its objectives, but does hardly implement it. Therefore, we have chosen an empirical approach to classification. We have only looked at the actual implementation of $\mathrm{CBE}$ and have ignored programmes that only state that they are community-based.

\section{Taxonomy of community-based programmes}

Here we propose a taxonomy that has three main categories: It distinguishes between programmes that are primarily service-oriented, programmes that are research-oriented and programmes that are training-focused. In addition it introduces six subclassifications. The taxonomy is based on the nature of activities carried out by the students in the community, in addition to the level of community and faculty involvement in the programme (see Figure 1). 


\section{Service-oriented programmes}

The programmes included in this category, are focusing on service delivery through their students and staff. The services may range from restricted curative services in primary care units to broader community development services through community mobilization. In most of the programmes reviewed services are based on prior needs and resources assessment. Almost all programmes in this category are located in developing countries.

\section{Research-oriented programmes}

In this category, students and staff are mainly involved in studying the problems of community health. The research aims at informed decisionmaking, addressing, for instance, a health care delivery problem. Many of these programmes are located in developed countries.

\section{Training-focused programmes}

The programmes included in this category are focusing on student training in the community setting be it a primary care unit, a defined community or a working environment. The main challenge for these programmes is to produce physicians who are able to work in underserved areas. These programmes are located in both developing and developed countries.

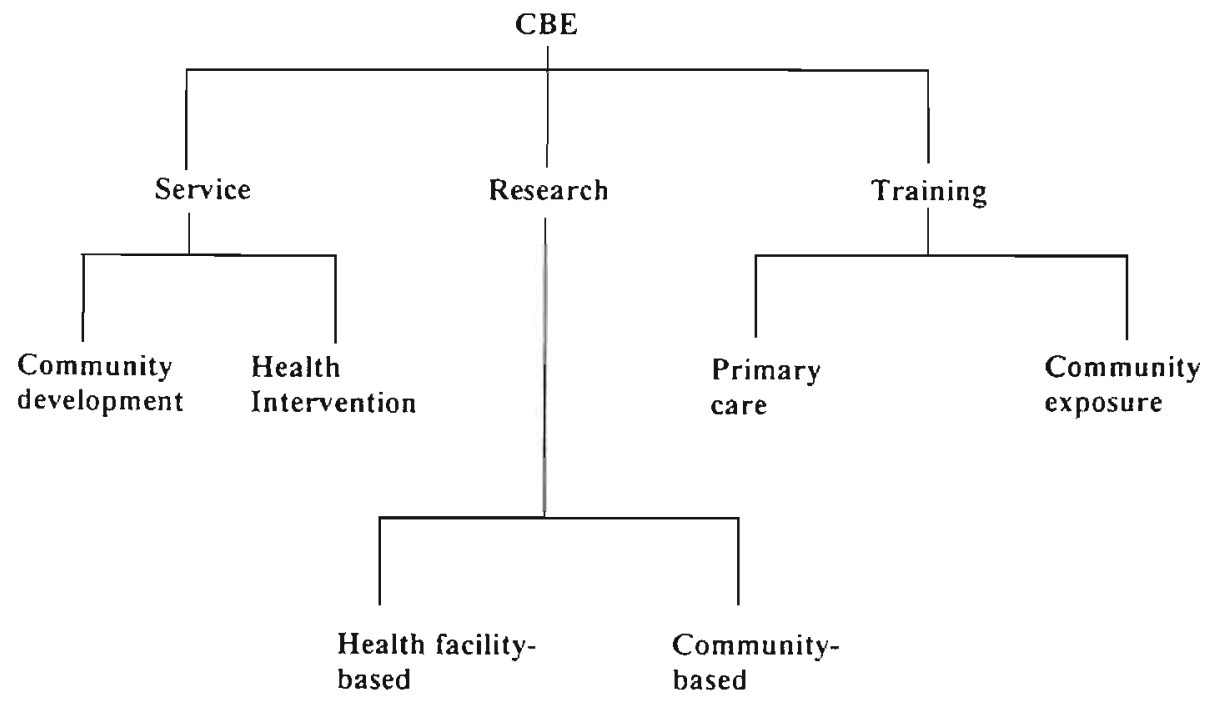

Figure 1:

Classification of community-based educational programmes 


\section{Subclassification and examples}

The service-oriented programmes can be further subdivided in health intervention programmes and community development programmes. In the former, the main focus is on health services delivery including curative services in rural health centres and preventive services such as health education activities, water supply and environmental sanitation programmes at the level of the community. An example of a programme falling in this subcategory is the community-based experience and service (COBES) programme in llorin Nigeria. We include a somewhat longer excerpt from an article by Bollag et al (1982) to give an impression of what a programme falling in this category looks like. It is a report of a group of students.

"While we had seen cases with Guinea-worm infection in October 1978, it happened that, during our second COBES rotation in April 1979, the community of Dekala. a hamlet situated some $35 \mathrm{~km}$ west of Babana, called for our help. What an ideal learning situation for us; Guinea-worm infection, a problem suffered by the people themselves on one hand could be coupled with the stated objective to look in the problem of infectious diseases during COBES on the other.

The transmission cycle of Guinea-worm infection (Source, vector, host) was known to us from the reading which had been assigned to us by the tutors prior to leaving for Dekala.

All of the 109 cases reported were located at Dekala; 52 males and 57 females were found to be infected. Thus the disease did not seem to distinguish between the sexes. Among those infected, the ages range from 2 to 60 years, but only three children of less $<5$ were included. We attributed this to the fact that the very young were not yet sent to fetch water and therefore, did not get in close touch with the source of infection.

Interviews held with some members of the community, disclosed that the Guinea-worm infection was believed to have been introduced from the neighbouring hamlets through intermarriage. By further enquiries we learned that there were two families, one of them the family of the 'Sariki' (The community leader), who had not had any Guinea-worm infection. These families boiled their drinking water. As a matter of fact, the Sariki had a transistor radio, and had listened from time to time to broadcast lessons. That is how he had learned never to drink any unboiled or untreated water. We wondered whether the power of the Sariki as leader of the community could not be utilized to change the hazardous habits of his people. We argued further that the presence of medical professional from a University would certainly had a favourable effect on the credibility of his educational talk. Fortunately, he agreed with our idea and so gathered 
all the villagers under a huge tree and delivered a speech to them emphasizing the necessity of boiling any water for drinking purposes.

The only water source at Dekala was a dirty pond. Microscopic examination of a specimen of the water showed the causative agent of the disease, the Cyclops. We mounted our microscope on the bonnet of our vehicle and encouraged the people to look at the organism responsible for all their suffering. Now they were even better to grasp the Sariki's waming never to wade into the pond with the contaminated water.

Many patients presented with super-infected wound where the worm has found its way out. We cleansed the lesions and in some cases administered some antibiotic drugs to control secondary infection.

At the end of the day one of the tutors demonstrated how a tiny fraction of Dettol sufficed to kill the cyclops. If this measure were to be applied in regular 2-3 month intervals, and if all infected people were treated successfully or the worm was absorbed or extruded, dissemination of the disease could be stopped. We instructed the teacher in the village to repeat the disinfection of water with Dettol, a bottle of which we left with him." (Bollag et al, 1983, pp 285-286).

As we have mentioned before, community-based service programmes need not only be confined to health intervention, they can also include fullfledged community development programmes. For a CBE programme to be classified in this subcategory it should be organized at least at the level of the university or in partnership with external partners. As development takes time, an extensive follow up is required. Therefore, the programme onset should be early and continuous or in multirounds, with active involvement of the community, the students and the university. The amount of time allotted to the activities should be reasonable in relation to other academic activities. In most instances, a well-defined community will be taken and followed up for at least three years. Examples of community development programmes are the EL. Tel Alkabeer project in Suez Canal University Ismailia, Egypt (Nooman, 1989), the Interdisciplinary Field Training Research and Rural Development Programme in Gezira, Sudan (Hamad, 1982), and the Community-Oriented Programme in the Christian Medical College, Vellore, India (Moses, 1990).

The following example describes a community development programme in one of the villages of central Sudan. This programme is initiated by one of the professors in the Faculty of Medicine, University of Gezira, and then adopted by the university as a whole.

"Elkaraiba is a small village lying south-east of Wad Medani. In the early phases of this programme, illiteracy high infant and child mortality due to malnutrition and diarrhoea, deteriorating cotton and dura yield per feddan ( 1 feddan $=1.4$ acres) were identified as 
priority community problems. These problems were ascertained by a group of students, using different sources of data collection. The community perception played an important role in the selection of a priority problem. In the second phase, following discussion with the governmental departments concerned, an interdisciplinary committee was formed and a community development centre was suggested to be established in Elkaraiba to deliver integrated development services and training for community members. The community offered the building for the centre, the health and social welfare departments offered the staff, while the university participated technically though its students and staff.

The services delivered by the centre included an adult education programme for mothers focusing on literacy, nutrition, tailoring, handcrafts and income generating projects, e.g., poultry farms and the introduction of back-yard gardens for growing vegetables. The duration of the course is six months. Also training courses were organized for farmers on how to apply the technical packages recommended by the agricultural research corporation for increasing the yield per feddan.

University staff and students from various faculties were and still participating in service, research and training activities. After five years of programme operation in this village the outputs were: $80 \%$ of the 400 mothers had participated in the training course, all farmers were trained, severai income generating projects were established. Significant improvement of health indicators were found. A remarkable contribution of this programme is the invention of Isma and Niama, two meals used as weaning food made of local and cheap ingredients available to all Sudanese families. The meals are easy to prepare and they are nutritionally balanced. Now these meals are popular and widely used in the area."

The research-oriented programmes can be subdivided in: community-based research programmes and health facility-based programmes. The only difference between them is the site for research. In this approach, the students conduct research in the respected site. They collect data to locate and delineate a major health problem plaguing the particular community. Mostly, such programmes are offered relatively late in the curriculum. It may be a one-shot programme or the students may return at several occasions to measure changes. The amount of time spent on such programmes is not exceeding $14 \%$ in relation to the curriculum in most of the programmes reviewed. Community involvement would not necessarily be active. The role of the student is mainly confined to that of observer or data collector while the university role is largely technical.

Below an example showing the kind of activities carried out in such programmes, taken from an article written by Schmidt et al, (1991). 
Schistosomiasis is a major endemic disease in Egypt. Half of the population is exposed to this infection through daily contact with the canal of the Nile River, which are infested with an intermediate host, a snail. Several years ago, as part of national development plans for the Bedouin-inhabited Sinai Desert, water for irrigation was channelled from the Nile Valley to canals constructed in Sinai to feed new agricultural projects. What is the public health impact of bringing the Sinai Bedouins in contact with the snail-infested Nile water to which they have never been exposed before? Have prophylactic measures been taken and, if so, how efficiently? Such were the questions that a group of six fourth-year students of the faculty of medicine at Suez Canal University, bordering Sinai, decided to answer during their six weeks elective by designing and implementing a field study. They defined the demographic features of the community, examined the canals for infected snails, interviewed the population at risk, and examined the residents' excreta for parasite eggs. They found that in spite of prophylactic measures, the canals harboured infected snails and that the Bedouins were infected. The students reported their findings to the regional health authorities, with whom they discussed the recommended prophylactic measures." (Schmidt et al, 1991 pp 260).

The training-focused programmes can be further divided in: primary carebased programmes and community exposure programmes. The former is mainly for clinical training of students taking place in primary health care facilities. The contribution of this type of community-based education to the curriculum may amount to $50 \%$ of all activities (that was at least the case in one of the programmes Kantrowitz, 1987). The primary care-based programmes may offer some services through their students and staff and may contribute to the improvement of health facilities utilized by the programme.

The example below described the experience of the author, being a fourth year medical student at the Faculty of Medicine, University of Gezira, Sudan.

"I was posted in Eljunaid rural hospital as part of the rural residency course which is offered by my school at semester seven, i.e. immediately following the completion of the system courses and before the clinical clerkships. I used to start my working day in the outpatient department. I worked with the medical assistant who was running the outpatient department. His job was to treat most of the attending patients and to decide who should be referred to the doctor inside the hospital. He told me that he has an experience of 30 years in this job. It was the furst time that he was requested to assist in training a medical student. For him this was an honourable chance 
that he was triumphantly appreciating. For me it was an enjoyable experience, because I always felt comfortable and free to raise questions and initiate discussion. He was constantly supporting his arguments by examples from his rich experience in all parts of the Sudan. During my work I observed that many cases of schistosomiasis were coming from Elhegaileag village, which is 10 $\mathrm{km}$ north of the hospital. I suggested to the medical assistant that we should make a field visit to the village to see what the underlying causes may be. For him this was a strange request, because the responsibility of prevention belongs to the public health overseer, located in the town council. Following a long discussion to convince him, he agreed. We asked the overseer to join us. The three of us made a visit to the village, we discovered that the village is surrounded by canals from three sides. One was a major canal and the other two were minor. The community health workers told us that because, the water pump was not working for a long time, the villagers use the canal water for domestic purposes and the children enjoyed swimming in the canals. The community health worker told us that he observed that the families near the main canal has less prevalence of schistosomiasis. In his opinion this is mainly due to the rapid stream of the major canal compared to the semi stagnant minor canals. We admired this observation. We raised this problem to the authorities in the rural council to make the necessary action.

This was an experience I will never forget. I valued working with, and learning from para medical personnel. This experience built in me positive attitudes towards these personnel. In the future this will help me to work jointly with them in a homogeneous health team."

Community exposure represents the second subcategory of training programmes. In this approach, usually time to relate to a community is minimal compared to other approaches. The students mostly are observers or might be involved in data collection of other tasks of limited duration e.g., measuring blood pressure of community members in a day or two. The organization is mostly department-based. The site for student training often is close to the university, be it a community or a primary health care unit, the amount of time spent in the community is so limited that one could speak of "community sight-seeing."

The following is an example of activities in this category, it represents an experience of a group of second year medical students at the Faculty of Medicine, University of Gezira (The author among them).

"During the summer of 1980, the Faculty of Medicine of Gezira University decided to expose their second year medical students (the most senior class at that time) to the community. They could observe the different activities carried out by the Ministry of Health to control 
a cholera epidemic, occurring at that time. The faculty was convinced that this was a unique opportunity for their students to gain a practical experience in cholera control, despite of the fact that they were in the early stages of their education. This conviction was grounded in the fact that cholera epidemics are relatively rare in the Sudan, the last epidemic being ten years ago. The students were distributed to the most affected villages in the area following a three days seminar prepared by the students themselves on the different aspects of cholera.

Three students decided to go to Mahala village, which is located $100 \mathrm{~km}$ south of Wad Medani. They introduced themselves to the health authorities in the headquarters of the province. The official of the province suggested that the students could join the mobile team which was responsible for stool specimens collection. The students wanted to stay in the village but they were told by the health authority that the village was too infected. In addition, there was no latrine and safe water supply. The students decided to spend a long working day in the village so as to observe as many activities as possible. The students joined the mobile team to the village. They found that it was severely affected by cholera, children as well as adults complaining of rice water diarrhoea, a cardinal symptom of cholera. As part of rural people hospitality, the students were offered tea and juice. It was, of course dangerous to drink from the water in this infected village. On the other hand, it would be embarrassing to the community and may create a barrier if the students would refuse to accept what they were offered by the villagers. Fortunately, they learned that they could put some lemon which would make the juice more acidic, a media in which the cholera will never survive. They put some lemon in and asked the villagers to do the same. A quarantine area was established in the primary school. The patients were treated with tetracyclines. Very ill patients were referred to the nearby hospital. The students observed all the activities carried out by the community health worker in the village. They asked themselves why this village was so infected compared to the neighbouring vil]ages. It came to their mind there must be a common source of infection that all the villagers use. It didn't take much time and effort to identify the water source as a likely cause. They decided to take a sample of water to be tested for the presence of the infective agent. They took a container from the village and sent it to the university lab. It was found positive for vibrio cholera. However, upon return they were informed that this was not the proper way of taking a sample of water for lab investigation. They were instructed that special sterilized container with peptone water should be used. Subsequently, a sample was taken in the proper way and again it was positive. The results were communicated to the health authority. Immediately, the tank of the water was cleaned and sterilized and in the mean time the villagers were provided with safe water from the town. The prevalence of cholera was rapidly decreasing." 


\section{A classification of 32 community-based programmes}

The above mentioned classification is not aiming at some sort of evaluation of the existing programmes. Each category of activities is adapted to meet particular objectives considering the local situation and realities. For example, services programmes are located mostly in developing countries, where any kind of service is likely to improve the condition of the population in need. This classification is mainly based on the main focus of each programme. One may find some programmes that include all the activities mentioned in various categories. Also within one school the focus may pass through different categories, e.g., it might start with simple community exposure and then develop to full-fledged community development.

Thirteen programmes could be classified as service-oriented programmes. Eight programmes as research-oriented programmes, and eleven as training-focused programmes (Table 1).

\section{Dimensions of the existing community-based educational programme}

By reviewing the 32 community-based programmes, a number of dimensions can be identified that describe the diversities of these programmes. Examples are timing, duration of the community-based programme in relation to other curricular activities. level of community involvement, responsibility of the organization etc. In this section, the various dimensions will be discussed along with the criteria that differentiate CBE Programmes within each of them.

\section{Timing}

This dimension refers to two issues. The first is: When do students have their first community experience? Is it already during the first year? Is it part of the clerkship years? Or somewhere in-between? The second is: Are the students exposed only once to the community or is it a multiround exposure?

Timing can be considered as a consequential dimension in describing community-based programmes, because it is an important discriminating variable distinguishing community-based curricula and conventional curricula including some community-based activities. In the latter, CBE is a fairly isolated activity where the former can be defined as a programme that "for its entire duration, consists of a number of learning activities in a balanced varieties of educational settings" (WHO study group, 1987). 


\section{Level of community involvement}

Community participation is a well recognized factor in the success of all community-based programmes (Hamad, 1982; Bryant, 1991; Alausa, 1988; Magzoub, 1992). This is important for the sustainability, as well as for the political support for such programmes. The level of success of CBE programmes can be measured by the level of community involvement. The measurement of community participation, however, is quite difficult. The difficulty arises from the fact that the issue of participation itself is rather ambiguous. For the purpose of this classification community participation will be classified crudely in active participation and passive participation.

\section{Level of student involvement}

The importance of active involvement of students in their own learning is a well documented fact by all schools adopting community-based and problem-based strategies for health profession education. Community-based education is a method for stimulating self-directed learning by students through exposure to "real life" community problems (Magzoub, 1992; Alausa, 1988). While reviewing the literature four levels of student involvement were observed. The first level is the student as observer. This is mainly the case when the school arranges a visit, for instance to a factory or an existing community development project for practical application of what already is learned. The second level is the student as data collector for problem identification purposes as part of a research project of faculty, for instance. At this level more interaction with the community is needed and, of course, students tend to spend more time on site. At the third level of involvement the student acts as a health provider. Activities included provision of health services, for instance in primary health care units or in villages, such as health education or immunization services. At the highest level of involvement the student acts as community development worker or as change agents. Here the student is assigned to a specific community and follows it up for a long time through a multidisciplinary approach, trying to bring about lasting improvements in the life of the community members.

\section{Level of university involvement}

University involvement is also another important dimension that distinguishes community-based programmes. The university involvement can either be technical i.e., it can be involved in design, planning and offering of the programme; or it can be financial, by providing assistance to students services, such as buying drugs or meeting latrine projects costs. 
Distribution of community-based programmes in the different categories of the proposed taxonomy (is continued on the next page).

Services programmes

Community develop.

CBE Programme

Faculty of Medicine

University of Gezira

Sudan (Hamad, 1982)

\section{CBE Programme}

Faculty of Medicine

Suez Canal University

Egypt (Nooman, 1989)

\section{CBE Programme \\ Christian Medical \\ College (India) \\ (Moses, 1990)}

Faculty of Health

Sciences, Agha Khan

University, Pakistan

(Bryant, 1990)

Institute of Medicine

Tribhuvan University

Katmandu, Nepal

(Upadhayay, 1990)
Health intervention

Community-based Education

\& Service Programme (COBES)

Faculty of Health Sciences

Nigeria (Bollag et al, 1983)

Community-based Medical

Education \& Service Prog.

(CBMESP) Bayero University

Kano, Nigeria (Ominisi, 1992)

Community-based Medical

Education Prog. University

of Maiduguri, Nigeria

(Omotara et al, 1992)

Rural Comprehensive Health

Prog. Obafemi Awolowo Univ.

Dle-Ife, Nigeria (Jinadu \&

Davies-Adetugbo, 1992)

Institute of Health Sciences

University of Philippines, The

Philippines (Siegia-Sune \&

Varana, 1987)

The Area Health Education Centre (AHEC) Morehouse

School of Medicine. Atlanta

Georgia (Blumenthal, 1990)

Undergraduate Education in Rural PHC, University of Zimbabwe Medical School (Vaz \& Gona, 1992)

University Centre for

Health Sciences, Yaounde,

Cameroon (Monekosso, 1992)
Research programmes

Community-based

Community \& Family

Case Study (CFCS)

Universiti Sains Malaysia

(Jaafar \& Hassan, 1990)

Family \& Community Health Prog. Sultan

Qaboos Univ. Sult. of

Oman (Musgrove, 1990)

Community-Oriented

Primary Care, Univ. of North Carolina, USA

(Landis et al, 1990)

University of Newcastle Medical School,

Australia

(Hamilton, 1991)

Community Needs and Student Research (Burbach, 1992)

Gadjah Mada University Yogykarta, Indonesia (Geefhuysen \& Radjiman, 1990)

Community-based proj. in Rural Internships

B. J. Medial college Maharashta, India (Praindhi et al, 1992) 
Table 1

Continuation of Table 1: Distribution of community-based programmes in the different categories of the proposed taxonomy.

Research programmes

Health facility-based

The Family study

Univ. Newcastle

UK (Foster et al, 1992)
Training programmes

Primary care

Community-exposure

Chiang Mali University

Chiang Mali Tailand

(Swander, 1990)

Community-based

Teaching Project Univ.

Wales, UK (Pill, 1993)

Beer Sheeva Experiment

Ben Grion University

of the Negev, Israel

(Glick \& Margolis, 1991)

Mental Health in the

Community, University

of Liverpool UK

(Graham-Jones, 1992)

The General Integrated Medical

Prog. (GIMP), (A36) Univ. of

Autonmous New Mexico, Mexico

(Valle et al, 1987)

The Upper Peninsula Medical

Educ. Prog. (UPMEP) Michigan

State Univ. USA (Brazeau et al, 1987)

Family Practice Preceptorship

Prog. Univ. of Limburg, Maastricht,

The Netherlands (Bouhuijs, 1991)

Faculty of health Sciences

Linkoping University

(Berghahl et al, 1991)

Minando State University College

of Medicine, Marawi city, The

Philippines (Manalo, 1990)

Public Sector Medicine Prog. (PSMP)

University of South Florida College

of Medicine (Herold et al, 1993)

Institute of Clinical Medicine, University of Tromso School of

Medicine, Norway (Magnus \&

Tollan, 1992) 


\section{Responsibility of the organization}

Responsibility for the organization of $\mathrm{CBE}$ also varies in different schools. Four levels of responsibilities can be identified: Department-based, facultybased, university-based and partnership-based.

Department-based programmes are offered mainly by community medicine or family health departments (Omatara, 1992). In faculty-based programmes various departments are involved such as, community medicine, paediatrics, obstetrics and internal medicine (Ajyedun, 1992). Most of the programmes are operated through a committee headed by a senior staff member, e.g., the dean. In university-based programmes other faculties e.g., economics or agriculture are involved through their staff and students (Hamad, 1982). CBE is considered to be most sustainable if other sectors outside the university share the responsibility for its organization in the form of partnerships between community committees, health services and other related governmental departments (Nooman 1990). The higher the level of involvement, the more sustainable a programme is considered to be. Programmes that eventually failed, were often run by only a few interested staff (Jinadu, 1992).

\section{The training site}

It is erroneous assumption that CBE focuses exclusively on primary health care in rural areas. In fact, many sites are used by different programmes. These sites could consist of primary health care facilities, families, rural and district hospitals. urban slums, villages and urban communities (Benor et al 1989; Magzoub at al, 1992)

\section{Number of courses offered}

Some programmes offer their community-based learning activity in one course such as the Community-oriented Primary Care (COPC) programme at North Carolina USA (Landis, et al 1992). Other programmes offer more than one community-based course e.g., the University of Gezira, the Sudan has six community-based courses (Rahim, 1990).

\section{Time allotted to CBE}

This is the percentage of time allotted to community-based education in relation to other activities. This percentage varies in different programmes between 5 and $50 \%$. Some authors assume that the quality of graduates as community-oriented health professionals is explained by the amount of time spent in community-based activities, during the undergraduate curriculum (Magnus, 1993). For instance, the high rating given by external assessors to Gezira graduates with respect to attitude and the ability to work with colleagues and other members of the health team is mainly attributed to the 
early exposure of the community and the amount of time spent in community health units. This offers the students the chance to work with a wider range of health workers than those in traditional curricula. (Abdel Rahim, 1992).

\section{Is the programme residential?}

Do students live in the community for the entire duration of the activity or do they return to the university at night? It is assumed that the longer the students spend in the community, the more opportunities they will have to understand the community and meet different community members, for instance, those who retum home late from work, In addition, the community may sometimes have meetings or other activities in the evenings that may be important to students.

\section{Review of the existing programmes according to the above mentioned dimensions}

Out of the 32 programmes 27 programmes were found to be having sufficient data. These programmes were reviewed according to the above mentioned dimensions. Three schools offered their CBE in a single occasion. Fourteen schools offered their programmes on two or more occasions, whereas nine programmes are offered on a continuous basis. Nineteen schools introduce their programme at an early stage of education mainly the first two years. Four are midcurricular, and only one is offered at a late stage. Twelve programmes were identified as eliciting passive community involvement, and sixteen are involving the community in an active fashion. In five programmes the students were classified as data collectors, in eleven as health providers and in only three programmes students were classified as community development workers. In almost twenty programmes the role of the university is only technical and in seven programmes the role is (financially) supportive. The organization of the programmes in seven schools is department-based. Eleven programmes are organized through the school; only one programme is organized at the university level; while four programmes are organized on a partnership bases. Twelve schools offer their programme in one course, whereas seven offer their programme in different courses. Primary care sites are used by eighteen programmes, six use families as a site for student training, and fourteen operate their programmes in communities. The amount of time spent ranges from five to fifty percent in relation to other academic activities. 


\section{Overview of this thesis}

One of the criticism of CBE is that it is based on a weak scientific basis (Hamad, 1991). It is envisioned as a branch of the social and behavioral sciences which, by many within the medical school, not in the least the students themselves, are considered incompatible with biomedical science. And indeed, few attempts have been made, until today, to provide CBE with a solid philosophy that would justify its existence and necessity. In addition, there is no authoritive source available in the literature that would help teachers to implement (forms of) CBE. In Chapter 2, a first attempt is made to describe a more structured approach to CBE in "eleven steps".

A second problem bothering those who try to implement CBE is that guidelines on how to do it hardly exist (Nooman, 1989). Community-based programmes are addressing local community problems, that may be different for different communities. This makes it difficult to copy models of CBE developed elsewhere. Of course, these programmes have at least some features in common, and tend to agree in terms of objectives (Nooman, 1989). The real challenge is the translation of these objectives into educational programmes that work.

Community-based learning activities are difficult to control compared to class teaching. CBE requires much effort in terms of supervision and follow up. and logistic support such as transportation and student accommodation. The effort required may sometimes be too big for an institution in the sense that the implementation of crucial activities in the CBE course are hindered by logistic limitations e.g., lack of transport vehicle to bring students to the field. This may lead to student frustration and disinterest, which may actually be reflected in their attitudes to CBE (Jinadu, 1992). Facing the problem of implementation of community-based education the university of Gezira provides an example of the rural residency course, which demonstrate just how a medical school in the Sudan can affect change in the local health system, so that it really does provide opportunities for promotive and preventive, as well as curative care, (Editorial, Annals of Community-oriented Education, 1992). This course is described along with the attitudes of students and graduates towards its implementation and learning outcome in Chapter 3.

Assessing students in community setting is another challenge for CBE. This problem arises from the difficulty of controlling field conditions. Students tend to be posted in different locations, having a dissimilar environment and dissimilar problems, and, at the same time students are required to attain the same objectives and conduct more or less uniform activities. In addition, the assessment needs heavy logistical preparation in terms of transportation of supervisors, preparation of evaluation forms, 
which make it expensive. Many difficult-to-assess skills need to be assessed, which require the involvement of many raters and different assessment methods, this may affect the reliability and validity of the assessment.

The above mentioned problems force many schools to take student assessment in the community setting less seriously compared to other academic activities. Some schools are not assessing students at all. Others use a subjective evaluation approach. Irrelevant assessment at the end of a learning experience will be reflected in students' enthusiasm, which is an important issue in the operation and success of the leaming activities carried out in the context of CBE. Chapter 4 and 5 presents a comprehensive approach to student assessment in community settings adapted to the particular difficulties encountered. Chapter 6 continues on this issue by presenting how peers could contribute to the objective assessment of students in community settings.

A fourth important problem, is that the community-based education approach heavily utilize families, primary care settings and communities as training sites to stimulate student learning. A legitimate question, then, is what the community gets in return. It is true that many CBE programmes provide services while they are run in the community. It is not uncommon that some communities might request the university to include their localities as part of the programme. Some programmes have gone further and involved themselves in community development services. The question then, is whether there is any impact on the population health and even better: on other indices of physical and social well-being as a result of $\mathrm{CBE}$. An answer to these questions stumbles over robust methodological problems, including the selection of appropriate study design and the control of confounding variables. As universities are not the only services providers and interventions tend to take several years, it is really difficult to study the impact of these programmes in the health status of the population. The University of Gezira attempted an approach using consumer satisfaction as measured by interviewing community leaders. The finding are presented in chapter 7 .

The last and most important problem is that even if community-oriented schools succeed to produce different products able to respond to their community needs, and prepared to work in the underserved areas, the health system must allow this type of graduate to apply the competencies learned in their schools, including problem solving and a population-based approach to health problems. Unfortunately the existing health systems are not at all attractive for these graduates, let alone that they would play an influential role in the development of the system (Schmidt et al, 1991). Health systems in many countries, particularly in developing ones are cure-oriented with 
minimal support to rural health. The primary health care services are delivered disintegrated at the level of primary health care units. Young doctors are competing for specialization in more attractive clinal specialities where they can gain prestige and financial amenities. Primary care delivery and general practice in such an environment is only for the stupid. Many migrate to rich countries. This may cause the present system with its above mentioned problems to negatively affect the attitudes of graduates in order to survive in such environment. In Chapter 8 an experience of a graduate with the health system will be reviewed along with the efforts exerted by Gezira University to influence the health system positively. In the last Chapter a discussion and conclusion is presented. 


\section{References}

Abdelrahim I.M., Mustafa, A.E. \& Ahmed B.O. (1992). Performance evaluation of graduates from a community-based Curriculum: The housemanship period at Gezira. Medical Education, 26, 233-240.

Ajyedun B.A. (1992). Community-based Experience and Service (COBES) Programme. Annals of Community-Oriented Education, 5, 61-68.

Alausa O.K. (1988). Community-based medical education In Nigeria: The cuse of Bayemo University. Annals of Community-oriented Education, 1, 5-12.

Anon (1979). Report of the First Inaugural Meeting, Kingston, Jamiaca, 48 June, 1979. HMD/ 79.4. Geneva. Switzerland: World Health Organization.

Bannerman J. (1985). Community-based education programmes; A literature survey. Chicago, Illinois, Centre for Educational Development. University of Illinois.

Benor D.E., Hobfoll S.E, \& Prywes M. (1989). Important issues in community-oriented medical education. In H G. Schmidt, M. Lipkin, Jr. M. W. de Vries \& J. M. Greep (Eds.) New Directions for Medical Education: Problem-Based Learning and Community-Oriented Education. New York, NY: Springer-Verlag.

Begdahl B., Ludvigsson J., Koch M. \& Messman J. (1991). Undergraduate medical education in Sweden: A case study of the Faculty of Health Sciences at Linkoping University. Teaching and Learning in Medicine, 3(4), 203-309.

Blumenthal D.S., (1990). The area health education centre: A model of communitybased health sciences education. Annals of Community-Oriented Education, 3, 8590.

Bouhuijs P.A., (1986). The University of Limburg family practice preceptorship programme. Family Practice, 3(4), 251-8.

Bouhuijs P.A. \& Sajid A.W. (1987) Curriculum planning models in medical education. Joumal of Higher Education Studies, 2(1), 2-5.

Bollag U., Schmidt H.G., Fryes T. \& Lawani J. (1982) Medical Education in Action: Community-based experience and service in Nigeria. Medical education, 16, 282289.

Brazeau N.K., Jones J.W., Hickner J.M. \& Vantassel J.L. The Upper Peninsula medical education programme and the problem-based preclinical alternative: In $\mathbf{M}$. Kantrowitz,A. Kaufman, S. Mennin, T. Fulop \& J. J. Guilbert (Eds). Innovative Tracks at Established Institutions for the Education of Health Personnel An Experimental Approach to Change Relevant to Health Needs. WHO Offset Publication No. 101, Geneva, Switzerland: World Health Organization.

Bryant J.H. \& Thobani NM. (1990). Interactions of academic institutions and health systems as partners in health development. Annals of community-oriented education, 3(II), 37-52.

Burbach C.A.L., Baldwin P. (1992). Linking community needs with student research experiences. Nurse Educator, 17(3), 37-42.

Cochaine S. H., O'Haa D. J. \& Leslee J. (1980). The effects of education on health. World Bank staff working paper. No. 405. World Bank, Washington D.C.

Dowrick C., Graham-Jones S. \& Stanley I. (1992). Mental health in the community. Medical Education, 26, 145-152.

Engel C.E., et al (1991). Community-based/Oriented medical education: Its objectives and their assessment. Annals of Community-Oriented Education, 4, 139-148. 
Erney S.L., Allen D.L. \& Siska K.F. (1991). Effect of a year long primary care clerkship on graduate selection of family practice residencies. Academic Medicine, 66, 234236

Fulop T. (1985). Health personnel for tomorrow; the great challenge of the health for all movement, WHO, WRP/HMD/INF.4. Regional Office for the Westem Pacific. 27 March, 1985.

Foster D.P., Drinkwater C.K., Corradine A. \& Cowely K. (1992). The family study: a model for integrating the individual and community perspective in medical education. Medical education, 26 110-115.

Geefhuysen C. J. \& Radjiman (1990). Education for health in transition. The response of Medical education at Gadjah Mada University. Annals of Community-Oriented Education, 3, 61-72.

Glick S. \& Margolis C., (1991). Medical education in Israel: Directions and challenges. Teaching and Learning in Medicine, 3(4). 195-199.

Hamad B. (1982). Interdisciplinary field training research and rural development programme. Medical Education, 16, 105-107.

Hamad B. (1991). Community-oriented education revised, community-oriented medical education: What is it? Medical education, 25, 16-22.

Hamilton J. (1991). The Australian experience. Teaching and Learning in Medicine, 3(4), 182-197.

Harris D.L., Coleman M., \& mallea M. (1982). Impact of participation in a family practice track programme on student career development. Journal of Medical Education, 57. 698-614.

Herold A.H., Woodward L.J., Pamies R.J., Roetzheim R.G., Van Dure D J. \& Micceri T. (1993). Influence of a longitudinal primary care training on medical students' speciality choices. Academic Medicine, 68(4), 281-300.

Jaafar R. \& Hassan M.H.M. (1990). Community and Family Case Study Programme at the Universiti Sains Malaysia: An experience in self-directed, contract, Learning. Annals of Community-Oriented Education, 3(II) 129-132.

Jinadu K.M. (1992). Model of experiential community-based education for health care professionals: Implications for developing countries. Annals of Community-Oriented Education 5, 19-26.

Jinadu K.M. \& Davies-Adetugbo A. (1992). Ife experience in community-based education for health professionals. Annals of community-oriented Education, 5, 5560.

Lipkin M. (1989). Towards the education of doctors who care for need of the people: Innovative approaches in medical education. In : H.G. Schmidt, M. Lipkin, Jr. M. W.de Vries, \& J. M. Greep (Eds.) New Direction for Medical Education: Problembased Learning and Community-oriented Medical Education. New York, NY: Springer-Verlag.

Landis S.E., Summerlin H. \& Oslon P.R. (1992). Training of students on the principles of community oriented primary care in the rural Southern United States. Annals of Community-Oriented Education, 5, 81-95.

Magnus J.H. \& Tollan A. (1993). Institute of clinical medicine. Rural doctor recruitment: does medical education in rural districts recruit doctors to rural areas. Medical Education, 27, 250-253.

Manalo A.H. (1990) The Minando State University College of Medicine communitybased medical curriculum. Annals of Community-Oriented Education, 3, 91-104. 
Magzoub M.M.A., Ahmed B.O., Salih S.T. (1992). Eleven steps of community-based education as applied at Gezira Medical School. Annals of Community-Oriented Education, 5, 11-17.

Magzoub M.E.M.A., Magzoub M.M.A. \& Saeed A.A. (1992). The rural residency course. Annals of Community-Oriented Education, 105-110.

Mauksch H.O. (1980). Can future doctors be educated to care for underserved people. Public Health Report, 95, 1, 41-44

Monekoso G.L. (1993). The teaching of medicine at the University Centre for Health sciences Yaounde, Cameroon: its concordance with the Edinburgh Deceleration on Medical Education. Medical Education, 27, 304-320.

Moses B.M., Joseph A. \& Rajaratna A. (1990). Co-operation between academic institutions and health care system, The Christian Medical College, Vellore model. Annals of Community-oriented Education, 3(II) 143-144.

Musgrove J.P. (1990). Family and community health in a new medical school. Medical Education, 24, 124-128.

Neufeld V.R., (1989). Community-based medical education: Some recent initiatives towards making medical education more responsive to national health priorities. Annals of Community-Oriented Education, 2, 65-84.

Nooman Z., Refaat A.H. \& Esmat E.S. (1990). Experience in community-based education at the faculty of medicine, Suez Canal University: In Z. M. Nooman, H. G. Schmidt, \& E. S. Ezzat (Eds). Innovation in medical education: An evaluation of its present status. Springer publishing company, New York.

Nooman Z.M. (1989). Implementation of a community-oriented curriculum. The tasks and the problems: In H. G. Schmidt, M. Lipkin, Jr. M. D. de Vries, J. M. Greep, (Eds). New Directions for Medical Education, Problem-based Learning and Community-Oriented Medical Education. New York, NY: Springer-verlag.

Omonisi M.K., Alausa O.K., Ennin M.A. \& Bichi L.A. (1992) Preparation for the first community-based programme of Bayerno University. Annals of Community-oriented Education, 5, 69-80.

Omatara B.A., Padonu M.K.O., Bassi A.P. \& Amodu M.O. (1992). Community-based medical education: The University of Maiduguri experience. Annals of communityoriented education, 5, 41-46.

Pill R.M \& Tapper-jones M. (1993). An unwelcome visitor? The opinions of mothers involved in a community-based undergraduate teaching project. Medical Education, $27,238-244$.

Pratinidhi A.K., Joshi J.K., Bawik S.P \& Javediekar S.J., (1992). Community-based projects in rural internships: an altemative approach. Medical Education, 26, 36871.

Rahim I.A.M., Abdeen A.Z.A., Faki B.A., Mustafa A.E. \& Nadler S. (1987). Introducing training in primary health care programme management into the curriculum. Medical Education, 21, 288-292.

Richards R., \& Fulip T. (1987). Innovative schools for health personnel. Report on ten schools belonging to the Network of Community-Oriented Educational Institutions for Health Sciences. WHO Offset Publication No. 102. Geneva, Switzerland: World Health Organization.

Schmidt H.G. (1983). Problem-based learning: rationale and description. Medical Education, 17, 11-16. 
Schmidt H.G., Neufeld V.R., Noomam Z.M. \& Ogunbode T. (1991). Network of Community-Oriented Educational Institutions for Health Sciences. Academic medicine, 66, 5, 259-263.

Siega-Sur J.L., Varona Z.C. Elements of institutionalization of the University of the Philippines, Institute of Health Sciences at Palo, Leyte: In M. Kantrowitz, A. Kaufman, S. Mennin, T. Fulop \& J. J. Guilbert (Eds). Innovative Tracks at Established Institutions for the Education of Health Personnel. An Experimental Approach to Change Relevant to Health Needs. WHO Offset Publication No. 101, Geneva, Switzerland: World Health Organization.

Starfield B. (1991). Primary care and health. Journal of the American Medical Association, 226, 2268-2271.

Suwanwela C., Varavit C., Ruamsuke S. The medical education for students from rural areas project (MESRAP): In M. Kantrowitz, A. Kaufman, S. Mennin, T. Fulop \& J. J. Guilbert (Eds.) Innovative Tracks at Established Institutions for the Education of Health Personnel. An Experimental Approach to Change Relevant to Health Needs. WHO Offset Publication No. 101, Geneva, Switzerland: World Health Organization.

Updhyay M.P. \& Tamsang J. (1990). Academic institutions in health care development: A Nepalese experience. Annals of Community-Oriented Education 3, 205-210.

Vale F.C., Siorida V.E., Wood H.G., Carnicer J.V., de la Vega A.R., Garcia L.C., Durazo A.L. \& Silva P.M. National Autonomous University of Mexico, Mexico. The General Integrated Medical Programme (A-36) : In M. Kantrowitz, A. Kaufman, S. Mennin, T. Fulop \& J. J. Guilbert (Eds.) Innovative Tracks at Established Institutions for the Education of Health Personnel An Experimental Approach to Change Relevant to Health Needs. WHO Offset Publication No. 101, Geneva, Switzerland: World Health Organization.

White K. "Life and Death and Medicine". Scientific American, 229(3), 23-33.

World Health Organization (1987). Deceleration of Alma-Ata. Report of the Intemational Conference on Primary Health Care, Alma-Ata, USSR 6-12 september 1978. "Health for all" Series No.1, Geneva WHO.

World Health Organization (1987). Community-based education of health personnel. Report of a WHO study group. Technical Report Series No. 746, Geneva Switzerland: World Health Organization. 


\section{Eleven Steps of Community-Based Education at Gezira Medical School}

\section{Abstract}

This paper suggests clear steps in community-based learning (CBL) as in problem-based learning. These steps follow the management cycle or problem solving cycle. The steps include selection of a community unit, identification of investigation tools, data collection, analysis, listing of problems, prioritization of problems, plan of action, implementation of the plan, follow up, evaluation and reporting. The features of these steps and how they are applied by the Gezira Medical School are discussed.

\section{Introduction}

A major objective of medical schools is to prepare their students to resolve the problems of their communities at the level of individuals, families and the community. In addition the students have to be prepared to continue their education following graduation to become life long learners. The realization of these goals has been the subject of numerous initiatives and innovations. Now many innovative schools follow the clear steps of problem-based learning as described in the nine steps (Schmidt, 1983). There is a need to create similarly clear steps for community-based learning (CBL).

Community-oriented medical education (COME) is defined as "education which is focused on population groups and individual persons taking into account the health needs of the community concerned" (Network of 
Community-Oriented Educational Institutions for Health Sciences, First Meeting, 1979). Community-based education "is the means by which COME can be achieved". Community-Based Learning "is the specific learning activities in community setting" (Hamad, 1991). From these definitions we conclude that $\mathrm{CBL}$ is learning activities that use individuals, families and communities as units for learning. Our steps in CBL exclude individuals because here the problem solving or problem-based strategies are applied. However, the aggregate data of individuals attending primary health units, for instance, will constitute a major resource in our steps for CBL. Our focus is thus on CBL using groups of individuals in primary health units, families and communities. Care of these groups calls for special competencies that students have to acquire, in order to become community-oriented problem solvers.

\section{The Need for Clear Steps in CBL}

As more educational institutions come to adopt $\mathrm{CBL}$ as a main educational strategy, clear steps will facilitate the sharing of experiences which will in turn be reflected in the further development and progress of CBL. Many institutions involved in CBL have similar community-based programmes e.g., Gezira, Suez Canal, Ilorin, Aga Khan Universities. This will make it easier to agree on uniform steps in CBL. One of the criticism of COME and CBL is that they are based on "soft science" and not on "scientific grounds" (Hamad, 1982). The defining of these steps may help in conceptualising CBL in a uniform framework which may contribute to making CBL more scientifically based. Specifying the steps will define students' leaming objectives which should facilitate teaching and learning activities and contribute to more objective assessment of students and evaluation of programmes.

\section{Main Features of the Proposed Steps}

These steps follow the management cycle or problem solving approach, where students progress through different stages, including planning, implementation and evaluation. The students are exposed to real and practical community field experiences. In contrast to problem-based learning in the class room, with its heavy reliance on written and simulated problems, the students are offered the chance of real life exposure to community problems and to apply their knowledge and skills. As community participation is an integral part of the educational process, it is not specified as a separate step. Most of the steps are followed by provisional report writing; however the final report is listed as the 
final step as important in its own right and because it includes many learning objectives. An important feature of these steps is that it is not always essential to go through all the steps for every problem. Selection of steps and their sequences could be adapted according to the available resources, time and programme objectives.

\section{Step one. Selection of Community Units (Family or Community)}

In most instances the selection is the responsibility of the Medical School. This selection is determined by logistics, access to transport, programme objectives and the willingness of the community to accept students and to participate actively in the programme. A variety of community units will be selected in terms of development, size, ethnic and geographical background, so that the students can share experiences between and within different groups. At this stage the learning objectives include introduction to community and family structure and function, and the impact on the health of individuals, the importance of a multidisciplinary approach and inter-sectorial collaboration in health.

\section{Step two. Identification of Investigation Tools}

The students are expected to identify and design all the tools of investigation for collecting data from the community units. Students work independently in small groups under the supervision of staff members. The learning objectives here are to recognize, apply and evaluate the strength and weaknesses of each instrument, and the data collection which may include questionnaires, direct interviews with community leaders, and observations. Also at this stage the students will have the chance to use and advance their knowledge of sampling procedures and of the conduct of surveys.

\section{Step Three. Collection of Data}

The students collect data from their community units during one or several visits. The students will be offered the chance to take full responsibility in approaching the community leaders and arranging their stay in the community. The learning objectives are: to be able to administer the data collection instruments, to use and develop their knowledge and skills in communication, how to make use of community participation and to become acquainted with 
rural life and the difficulties and constraints associated with projects in the field.

\section{Step Four. Analysis of Information}

At this stage the students come to the university campus to analyze and interpret the data they have collected. They work individually or in small groups with the assistance of their tutors, the library and senior peers. By the end of this step the students are expected to be able to recognise all the stages of data processing which include coding, entry, cleaning, manipulation, analysis and presentation. The students will also have the opportunity of applying their knowledge of statistics and to learn more about statistical procedures. The students are introduced to the use of computers in data analysis.

\section{Step Five. Listing the Problems}

The students are asked to list the problems and classify them in a presentable format, e.g., according to problems of health status, health service problems and community problems. The learning objectives are: to recognise basic features of a problem, problem classification and presentation.

\section{Step Six. Prioritization of Problems}

The students list the problems in order of priority and follow their priority problem through the subsequent steps. Also at this stage the students include in their report general recommendations about all the problems according to their findings. The criteria for selecting a priority problem may include frequency, seriousness, preventability and the community's perception of the problem. Our experience has shown that the most important criterion is the community's perception of the problem. This encourages active community participation and thus the proper implementation of the intervention.

\section{Step Seven. Plan of Action}

The students write a detailed plan of action for the resolution of the problem. During this process the students will be helped by their tutors. The plan will be taken to the community for discussion and final approval. With the help of the community, the students will approach funding agencies to finance their 
suggested interventions. The learning objectives here are: how to write a project proposal including objectives, strategies, implementation planning, follow up and evaluation. How to approach funding agencies.

\section{Step Eight. Implementation of the Plan}

This is the implementation of the suggested plan of action, with as much participation by, and financial support as possible from the community. This is the only way to ensure sustainability of the project. Here the students will learn implementation with a real experience of working with villagers through their participation.

\section{Step Nine. Follow-up}

Students follow their project up on a regular basis, either through regular visits or meeting community leaders during their visits to the town. Students use a checklist to follow their activities. The learning objectives are: to acquaint students with the importance of supervision and supervisory skills. The results of supervision will be used for decision making and evaluation.

\section{Step Ten. Evaluation}

This is where the students evaluate their project by using different evaluation tools to determine the degree of achievement of the objectives of the project. The learning objectives here are: to recognise and apply different tools of evaluation, assess the advantages and disadvantages of these tools, and use the results of evaluation to inform decision making.

\section{Step Eleven. Reporting}

Reporting may accompany all the above steps. However, the final report is the most important one. Here, the students describe the whole process including all the steps. This report will be discussed with the community. During this step the students learn how to write a scientific report. 


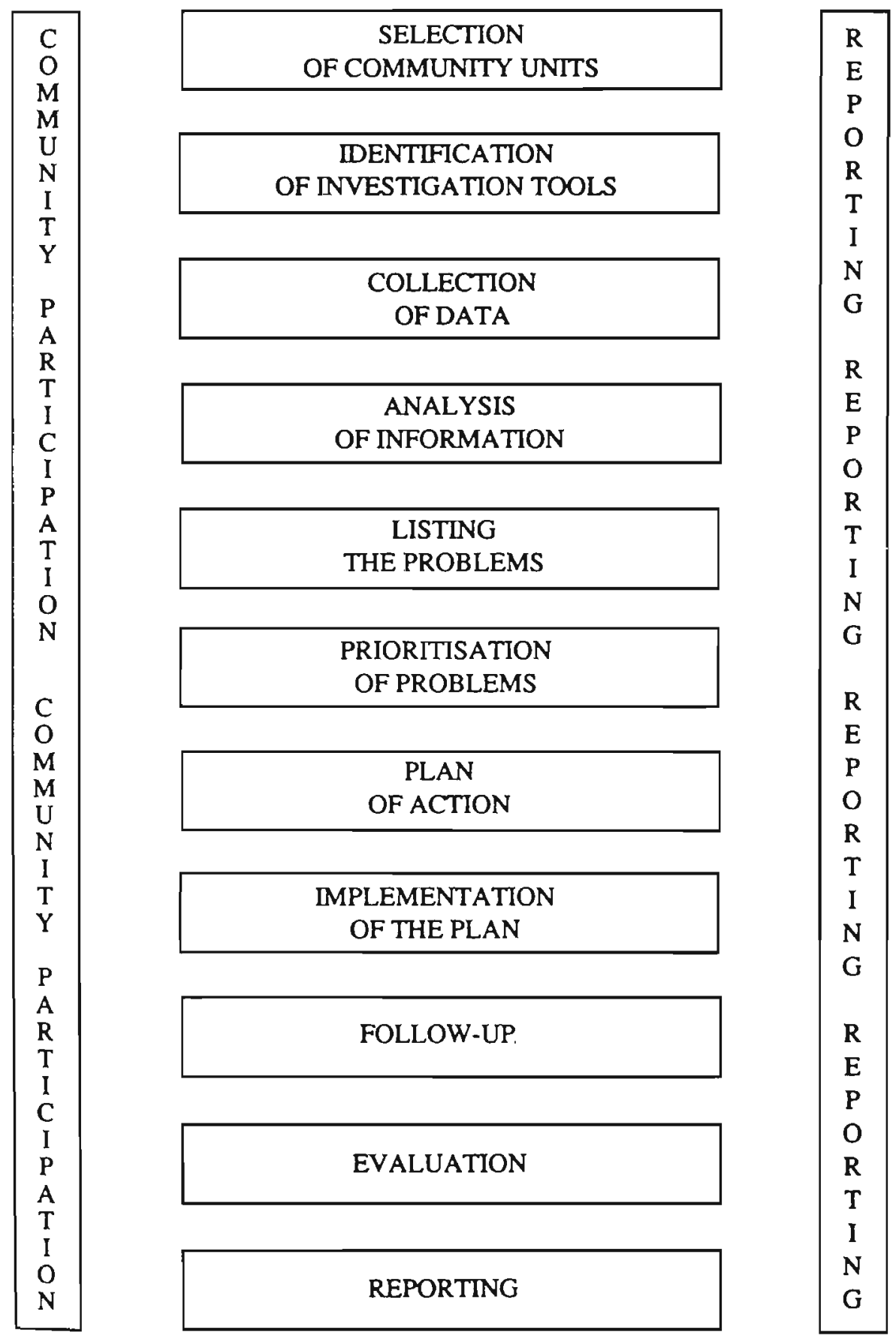

Figure 1

The eleven steps of community-based education as applied in Gezira medical school 


\section{Application of these Steps at Gezira}

These steps are applied gradually and built on throughout the undergraduate course. Application starts in the first introductory part of the curriculum, the introduction to medicine course. Here the students are given community problems and asked to analyze them by using existing records, making visits, and conducting simple interviews. This exercise includes Steps 1 to 7. Subsequently the students experience all the steps in depth under close supervision by the staff. This fits in with the interdisciplinary field training research, rural development and the family health courses. Later on the students have more autonomy and responsibility and less support from the staff. Here the students are left free to choose the community units themselves and tailor the steps and sequence to the problem which they have selected. This is part of the rural residency course.

\section{An Example}

We are a group of four students. Abbara village was selected for us during the summer field training. Our first task was to identify problems in this village. We decided to collect the data through a structured questionnaire, interviews with community leaders, and an observation checklist. These tools were developed with the help of our tutors, senior colleagues and colleagues from the Faculties of Agriculture and Economics. It took us one week to develop these tools. It was hard work but it was interesting. We used public transport to reach the village. In the bus we met many people from the village, who introduced us to the Sheikh, the village chief. We had a warm welcome from the Sheikh, he asked his son and one of the few educated ladies to be our guide during our one week stay in the village. We lived in the Sheikh's house which was a wonderful experience. We accomplished the task of data collection successfully. We returned to the University main campus for data analysis and listed all health and health related problems of the village. The findings were discussed with our tutors, colleagues and the community leaders. With the criteria for prioritizing problems we selected childhood diarrhoea as our priority problem. In the second phase of our community-based education we chose a latrine construction programme as an intervention to address this priority problem. The objective was to increase the availability of latrines by $30 \%$ in one year. We submitted a joint project with the village health committee to the Blue Nile Health Project. They agreed to provide slabs for any completed four meter depth latrine. Our role was to encourage families to dig their four meter pit. It was difficult to convince families to change their 
behaviour, i.e. not to get rid of their excreta in the open air. Through time and personal contact we convinced the Sheikh to make a start. In far less time than we had expected our target was achieved, and the programme was evaluated in the last phase. There was a significant reduction in the incidence of diarrhoea when compared with the base line data. During the presentation of our work, we were criticised, as the reduction of diarrhoea incidence might not have been due to our intervention. It might have been the result of other factors which we had not controlled, including improved socioeconomic status and water supply. At first this was a disappointing comment but it has stimulated us to read more about study design and the control of confounding variables. We concluded that we could not be sure the reduction was due to our intervention. What we can be sure about is that the community and we ourselves were satisfied with our inputs, and we learned a lot from this experience. 


\section{References}

Anon (1979). Report of the inaugural meeting. Kingston, Jamaica, 4-8 June, 1979, HMD/79.4. Geneva, Switzerland: World Health Organization.

Bryant J.H. \& Thobani N.M. (1990). Interaction of academic institutions and health care system as partners in health development. Annals of Community-Oriented Education, 3(II), 37-51. Maastricht, The Netherlands: Network of Community-Oriented Educational Institutions for Health Sciences.

Hamad B. (1982). Interdisciplinary field training research and rural development. Medical Education, 16, 105-107.

Hamad B. (1991). Community-oriented medical education: What is it? Medical Education, $25,16-22$.

Rahim I.A.M. (1989). Six strategies for effective and relevant medical education as applied in Gezira medical school. Saudi Medical Journal, 10, 391-395.

Schmidt H.G. (1983). Problem-based leaming: Rationale and description. Medical Education, 17, 11-16. 



\title{
The Rural Residency Course
}

\begin{abstract}
This paper presents the student and graduate experience of the rural residency course which aims to improve the performance of doctors in rural hospitals. A questionnaire was distributed to the final and penultimate final year students, and to graduates working at the Wad Medani Teaching Hospital. The response rate was $57 \%$. The results have shown that the course was well received by the students and graduates. Positive educational experiences were mentioned by both students and graduates. Problems facing this course and how these may be resolved are discussed.
\end{abstract}

\section{Introduction}

Sudan is the largest country in Africa with an area of one million square miles. As one of the least developed countries, Sudan exhibits all the features of poor development, such as a high birth rate, high infant mortality rate, rapid growth and low gross national product, as well as predominance of epidemic and endemic infectious diseases. The majority of the population lives in rural areas $(75 \%)$ and $11 \%$ are nomadic. Yet more than $80 \%$ of the doctors work in big cities, predominantly in the capital city, serving only $14 \%$ of the total population.

This problem is mainly due to undergraduate education which is focused primarily on practice in big teaching hospitals. These hospitals are relatively well equipped and staffed. The health problems dealt with by these hospitals 
do not represent the commonest problems in the community; they are just the tip of the iceberg. A doctor with this background, when asked to work in rural areas, finds that $s /$ he is inadequately prepared to perform the tasks that are required of him/her, let alone be able to contribute to the improvement of rural health services. These tasks include supervision of all primary health care units in the catchment area. In addition, s/he will be responsible for managing his own hospital, including staff, equipment and finance. These duties require administrative and managerial skills which he lacks. In most cases the doctor either delegates these responsibilities to senior auxiliary staff or becomes frustrated while waiting eagerly to finish his/her compulsory one year rural residency period. The only motivation for him/her to stay is the permission to pursue postgraduate studies.

The Gezira Medical School was established in 1978 and adopted an innovative curriculum based on problem-based, community-oriented and community-based education. Emphasis is on primary health care and rural health. With this background the school addresses the above human resource problem through a variety of educational activities. One important activity is the rural residency which aims to acquaint the student with rural hospital situation and consequently improve his future performance in rural hospitals.

\section{The Rural Residency}

The course is offered to semester 7 students after they have studied all the body system in integrated blocks. This one month course is designed to expose the students to real life situations in rural areas and to the nature and responsibilities of the physician working in a rural hospital.

The course objectives are attained by students observing, assisting, or performing different activities in the rural hospital and other health facilities in the community.

In the rural hospital the students observe, assist, or perform different clinical and laboratory procedures in a real life situation with the limited resources that are available in the rural hospital. These activities are performed under close supervision by the doctor in charge. The students may also live with the doctor or other senior health personnel and work closely with them in service administration and management activities.

The students are also exposed to working situation in other health facilities, including health centres and primary health care units. The students are expected to appreciate that health services are rendered at different facilities by different health personnel working as a team. 
The students carry out a community-based survey addressing a priority health problem or health related problem. The purpose is to train the students in the application of criteria for selecting a priority problem, as well as to design, conduct and analyze a survey. In addition students write a final report in which they describe their experience at the rural hospital.

The course is preceded by a workshop in which students, staff and government officials participate. The workshop discusses course objectives, logistic support and evaluation of the course. The students choose their hospital, and only one or two students go to each hospital. The university offers a transport and catering allowance. Accommodation is the responsibility of the host hospital and of community leaders in rural areas. The course was offered for the first time in 1981. Since then ten rotations have been conducted.

\section{Methods}

A questionnaire was distributed to the final and penultimate final year students, who had completed the course, and to all Gezira graduates who were working at Wad Medani Teaching Hospital; some of the graduates completed their rural residency assignment as doctors. 80 students and graduates responded to the questionnaire, a response rate of $57 \%$. Structured long interviews were conducted with a few students. Also the personal experiences of the first author as former student and the second author as course coordinator were further sources of information.

The questionnaire covered organization of the course, attainment of the objectives, students' perception of the educational impact of the course, and graduates' perception of the educational impact of the course on their performance at rural hospitals. The response to each question was rated from 1 to 5 , where 5 represented strong agreement.

\section{Results}

$54(66.7 \%)$ of the respondents were students and $26(23.3 \%)$ were graduates of whom 15 had completed their rural residency as newly qualified doctors. $63 \%$ were males, and $37 \%$ were females. The combined mean responses and the standard deviation for each question are shown in Table 1. 
Table 1

Attitudes of students and graduates towards the rural residency course

\section{Course Organisation}

Enough help from the course coordinator

Enough help from the doctor at the rural hospital

Duration of the course was adequate

Mean

Adequate allowance

$\begin{array}{ll}2.7 & 1.3 \\ 4.1 & 1.0 \\ 3.5 & 1.3 \\ 1.7 & 1.2\end{array}$

\section{Course Objectives}

Clarity and relevance of objectives

Recognition of the role of the doctor

in the rural hospital

$\begin{array}{ll}3.5 & 1.4\end{array}$

Recognition of the role of the rural hospital

Familiarity with the rural hospital environment

$3.8 \quad 1.1$

\section{Educational impact on students}

Learning community interaction

Learning team work

$3.6 \quad 1.2$

Mastering skills (manual and communication)

$3.8 \quad 1.9$

Learning research skills

$3.1 \quad 1.3$

\section{Educational impact on graduates}

Help in the rural hospital as a doctor

Performed less well as a rural doctor if $s / h e$

did not participate in the rural residency course

\section{Discussion}

There was no significant difference between the responses of students and graduates. The above results indicate that this course was well received by the students and graduates who responded to the questionnaire. Positive educational impact was mentioned by both students and graduates. The relatively high standard deviation on some of the variables might be explained by the wide variation in rural hospitals situation and the support they received from the resident doctor. The reasons behind the interest shown by these students may well have been this enhanced opportunity to practice the skills 
they had learned; many respondents mentioned that this had been the first time for them to perform particular skills, e.g., abscess drainage, paracentesis.

Although gender was not an important factor, there had been some difficulties with the accommodation of female students in small rural hospitals. All the respondents complained about inadequate subsistence allowance. Some of the doctors in the rural hospitals were not interested in helping students and considered this task an additional workload. This aspect was compounded by the rapid turnover of doctors in rural hospitals. As Sudan is a large country with many transport problems, some of the students had to travel from 4 to 6 days to reach their hospital. This greatly handicapped the students' supervision by Faculty staff members. This was also obvious from the low rating when the students were asked about help provided by the staff coordinator. However, this course represents the third phase of the community-based experience, and the main educational aim is to give students autonomy and responsibility and to provide less support from the staff when compared with the students' two earlier experiences. As with other community-based courses, assessment was a problem. Variability of facilities at rural hospitals and of the doctors' interest in helping students prevented standardisation and created an element of subjectivity.

\section{Conclusion}

Suggestions to solve these problems include the assignment of students to hospital where Gezira graduates are working, as these graduates are oriented about the course objectives and their assessment. This would hopefully improve the quality of supervision and assessment. Also, students should be encouraged to choose rural hospitals with ready access to transport and accommodation facilities conducive to proper supervision and follow up.

It is here important to mention that this study has only evaluated the students' and graduates' satisfaction with the course. It did not assess the actual impact of the course on the performance of graduates in rural hospital which is the ultimate goal of the course. This is an area for further research. 


\section{References}

Hassan F., Hassan A. \& Ezzat E. (1990). Students' perception of field projects. Annals of Community-Oriented Education, 3, (II), 303-310, Maastricht, The Netherlands: Network of Community-Oriented Educational Institutions for Health Sciences.

Rahim I.A.M., Abdeen A.Z.A., Faki B.A., Mustafa, A.E., \& Nadler S. 1987). Introducing training primary health care programme management into the curriculum. Medical Education, 211, 288-292.

Saeed A.A. (1984). The rural residency course in the Faculty of Medicine, University of Gezira, Sudan. Sudan Medical Journal, 20, 39-52. 


\section{A comprehensive Approach to Student Assessment in Community Settings (1) Description of Methods}

\section{Abstract}

Student assessment in community settings presents certain problems to medical teachers, e.g., difficulties in assessing the contribution of individual members to group work, and lack of test standardization due to the lack of control over field conditions. The Faculty of Medicine, University of Gezira, which is a community-oriented, community-based medical school, adopted a comprehensive approach to student assessment in community settings, using various methods, including peer assessment, a supervisory checklist, community feedback, student reports, short essay questions (SEQs) and multiple choice questions (MCQs), student oral and poster presentations and assessment of logbooks. Each method focuses on a specific part of the objectives of the community-based program and is weighted in the final grade according to the extent of its coverage of the objectives. This assessment program stands in sharp contrast to the teachercentred, and unisource conventional approach. The Gezira approach to assessment focuses on the process of community-based learning, considers the effect on the community as well, provides some measures of student attitudes, has a strong participatory component, is cost-effective, uses various sources, is practical and the method is continuously monitored and improved using various sources of information.

It is concluded that a comprehensive approach has several advantages over the conventional approach and is strongly recommended for assessing students and programs in community settings. 


\section{Introduction}

As more institutions for health professions education are coming to adopt community-based education (CBE) as one of their educational strategies to graduate health personnel able to respond to community health needs (Schmidt et al, 1990), new problems arise. One of the most pressing problems is how to assess student performance in community settings. The community setting is, in principle, an environment difficult to control if one interested in measuring to what extent students reach the objectives set for this kind of education. Therefore, relevant assessment of students in community settings is a real challenge to these institutions. Facing this challenge is crucial for four reasons.

First, community-based work competes with other extensively assessed academic activities. Since it is generally complicated to assess students in the community setting, each individual contribution to group work is difficult to assess and the field conditions lack standardization, most institutions use informal, more or less subjective assessment of these important activities. The result may be that both students and staff consider community-based work as less important or secondary to the 'core' curriculum. This attitude will reflect itself in their commitment to the community-based activities.

Second, assessment is known to be a strong stimulator for student learning and has a large influence on what they do and how well they do it. Successful learning in the context of a community depends to a large extent on students' motivations and enthusiasm. Irrelevant assessment may induce less motivation and hence irrelevant activities and negative attitudes.

Third, student assessment and student feedback are important elements often used for program evaluation. If the assessment is largely irrelevant to the program's primary goals, the results of the assessment will reflect directly in the way the programme is operated and further developed. To give an example, if students are assessed on knowledge only, ignoring their performance during the field posting, the results of student assessment will not provide any information about field conditions, such as logistics problems and problems with accommodation, that may have hindered student learning and the attainment of programme objectives.

Fourth, relevant assessment provides opportunities to identify outstanding students who may be future leaders in the health care system and, at the same time, identify students who need assistance. Identification of those two groups through objective assessment is important for informed decision making. In the Sudan, for instance, doctors are expected to be health team leaders almost immediately after graduation. 
To meet these challenges, the Faculty of Medicine, University of Gezira (FMUG) uses a comprehensive approach to student assessment in community settings. In this article we will discuss, in some detail, this approach and its features. First, however, we will briefly review the community-based courses conducted at the FMUG, in particular with regards to their objectives. This is done to indicate which objectives are pursued and, therefore which objectives should be assessed.

\section{The FMUG community-based courses}

The FMUG was established as part of the University of Gezira in 1978. The objectives set for the school are in line with the University philosophy which focuses on community needs and rural development in its educational, research and services activities. The FMUG adopted an innovative curriculum and implemented an educational programme based on the following elements: (1) Student-centred and problem-solving learning (2) a community-oriented approach and community-based training, (3) integration of basic, clinical, and social sciences learning in the curriculum (4) training within the existing health care facilities as opposed to training exclusively within campus and teaching hospital. (5) intra-and inter-sectoral collaboration in training with health services departments and other university faculties (6) team work, staff development and democratic decision-making (Abdel Rahim, 1989).

Community-based courses play a significant role in implementing the educational strategies in Gezira. These courses represent $20 \%$ of all educational activities as reflected by the number of credit hours allocated to the different courses in the curriculum. The students are exposed to the community at an early stage of their education, starting from the first semester and continue to be exposed throughout the curriculum.

Community based education serves two main functions for the faculty. First it provides opportunities for collaboration with the community and the government, what is now called "university-community-govemment partnership". This partnership is one of the strategies for translating the school's objectives regarding community orientation into real activities for the well-being of the community. This partnership is an important instrument for responding to community health needs. Second, CBE prepares students for a community-oriented career in the future. CBE provides a chance for students to work in an environment similar the one they are going to face in the future, in particular in undeserved and rural communities.

The community is indeed a unique environment for the implementation of certain educational strategies and the attainment of certain objectives. The specific objectives set for these educational activities are: 
(1) To demonstrate the impact of disease on the family and the community, (2) to facilitate perception of patients as part of the family and the community, (3) to clarify how the health system and health team work, (4) to acquire skills in research methodology, problem solving, communication, decision making, manual clinical skills, leadership, organization and team work (5) to provide a setting for teaching of the behavioral sciences, including medical sociology, psychology, anthropology, economics, etc.

These objectives are tackled to varying degrees by different courses at different stages in the curriculum. These courses are:

\section{Introduction to medicine and the study of medicine (Semester one).}

This is the first exposure of students to the community. The students work in small groups to collect data on health problems from different working and living environments, with the objective of recognizing major health and other health-related problems. The ultimate goal is for the students to appreciate the importance of a holistic and multidisciplinary approach to health. The course also intends to introduce students to the curriculum and the instructional methods used and the rationale behind adopting a community-oriented, community-based and problem-solving approach to medical education.

\section{Interdisciplinary field training, research and rural development} programme (Semester four, six and eight).

During this course small groups of students from different faculties are assigned to various villages. This course is run in three phases in three consecutive summers. In the first phase, students identify problems using various investigation tools including questionnaires, interviews, observations and qualitative methods, such as focus group discussion. The second phase is an implementation phase in which the students execute a project through full community participation to solve one of the priority problems identified in the first phase. In the last phase students study to what extent the measures implemented in the previous phase have been successful (Hamad, 1982). The following is a summary of a report written by a group of third year medical students of the FMUG which explain the kind of activities carried out in this course.

"We are a group of ten medical students, assigned to village 18 in the Elrahd area, $60 \mathrm{~km}$ south to the university campus. In the furst phase we collected data using various investigations tools. A high illiteracy rate was identified as a high priority problem. Through the community we managed to get funds from the Dutch Embassy to establish a community development centre in the village, with the aim of raising the literacy rate, particularly among women, in addition to 
other activities including the promotion of handcrafts, health and nutrition education and income-generating projects to raise the income of families, such as raising poultry and establishing backyard gardens. The community offered the building and the university provided technical support in the form of training. Six trainers were selected by the community and a training course was conducted for them in Wad Medani, the State capital. The trainers trained the rest of the women in the village and they took the responsibility of implementing the different activities set by the programme in the village. An evaluation was conducted, which showed that all the goals of the projects were reasonably well achieved. A remarkable finding was the conspicuous community and self satisfaction about the outputs of this project. For us it was a spectacular experience which we will never forget and we learned a lot from it".

3. Primary health care centre practice and family health. (Semesters four to eight).

This course continues for four semesters. Each student is assigned to a family to visit every other week, with the objective of recognizing the course of health problems at the family level and to acquire the skills of responding to family problems through a holistic approach. In addition, students work in small groups in primary health care units. During this course students participate in health service delivery and identify major health problems at the family and community levels using a problem solving approach. In addition, the students are exposed to the practical experience of working in the health system with the objective of understanding its function and to appreciate the importance of working in a team including different health professions. (Mirghani et al, 1988).

\section{Doctor and society (Semester four).}

This course mainly deals with communication skills, doctor-patientcommunity relationships and the determinants of health within a context of family and the society. During this course the students work in small groups. They interview patients, community members and different health cadres with regard to their attitudes and experiences with the doctor-patientcommunity relationship. The collected information is used as learning material in a series of students' seminars.

\section{Rural residency course (Semester seven).}

Following semester seven in which the students have completed the system courses, each student is assigned to a single-doctor rural hospital and lives in that locality for four weeks. The student participates in all hospital activities, practices clinical procedures and analyze community problems in 
a multidisciplinary approach under the supervision of the resident doctor ( Magzoub et al, 1992).

\section{Primary health care clerkship (Semester nine).}

This is a three-week course during which senior students consolidate their previous knowledge and skills in primary health care. In addition, they will have a practical exposure to health management and the function of the health system (Rahim et al, 1987).

It is obvious from this brief description of the community-based courses, that this kind of education attempts to foster certain competencies and skills, essential to graduate a community-oriented physician responsive to the needs of the community, he is serving. These competencies include the ability to interact with the community, communication skills, decision making skills, leadership skills, organization skills, problem-solving skills and the know-how to perform these competencies. The methods of assessment should be tailored to reflect the level of attainment of these competencies by the student in both direction and magnitude. The FMUG uses a comprehensive approach including eight instruments to assess these competencies. The following is a description in some detail of the eight methods applied to assess students in community settings.

\section{Methods employed for assessment of community-based courses}

\section{Peer evaluation}

Following discussion with tutors and students, it was felt that students were in a better position, compared to tutors, to evaluate each other on four factors of interest. Each of these factors needs continuous and intimate observation. Consequently, a peer evaluation rating scale was developed, which included those four factors. The four factors were (1) Effort: 8 items reflecting the inputs of students in the different activities carried out during the course. (2) Interaction with the community: 6 items, reflecting the students' ability to communicate with the community to facilitate data collection and consent to advice. This skill is considered to be important for the future work of the physician and for developing a doctor-patientcommunity-relationship. (3) Leadership: 4 items were developed, reflecting aspects such as leading a group discussion, decision making and division of labour. This is a very important skill for doctors in the Sudan, because they work as health-team leaders when they are assigned to work in rural hospitals. Objective assessment of this skill is important if one wishes to graduate doctors who are able to respond to community health needs in this respect. (4) Use of knowledge or subject matter contribution: 4 items, reflecting the student's ability to utilize his gain knowledge to help the 
group progress towards the course objectives. The items included in the rating scale can be found in Table 1. The mean of each factor of all group members' ratings on a five points scale is computed for each student.

Table 1

Items included in the peer evaluation rating scale.

\section{Factor (1): Peer evaluation of effort}

1. Contribution to the design of forms for data collection

2. Contribution to data collection in the village

3. Participation in the assigned activities in the village

4. Problem identification

5. Participation in report writing

6. Contribution to the group activities concerning, living, accommodation and housing in the village

7. Participation in preparation for the group seminar

8. Physical attendance in announced group activities

\section{Factor (2): Peer evaluation of community interaction}

9. The terminology used by the student was understandable for the community members

10. He was always responding to community members' questions in a clear way

11. He is a good listener to community problems

12. His advice and suggestions seem to convince the community

13. He was frequently present in the community

14. He was able to befriend community members

\section{Factor (3): Peer evaluation of leadership}

15. He was able to contact community leaders

16. He was a good leader of group discussion

17. He was able to divide labour equally among group members

18. He is a good decision-maker

Factor (4): Peer evaluation of subject-matter contribution

19. He gave useful information to the group

20. His suggestions and thoughts were helpful to the group's work

21. He formulated good questions

22. He made use of references and other resources 
There are several advantages of peer assessment reported in the literature. De Volder and De Grave (1984) suggest that the advantages of peer evaluation are most clear in the areas of skills acquisition and attitude learning. Peer evaluation is best suited for the evaluation of humanistic qualities, such as integrity, compassion, respect and the ability to build and maintain interpersonal relations (Jennet et al, 1990).

Peer ratings are preferred over other types of peer assessment, such as peer ranking and peer nomination, because peer ratings are most useful for feedback purposes and because this approach considers each individual on his own right without forcing students to rank-order other students. However, a potential disadvantage is its generally low reliability and validity compared to the other methods of peer assessment (Love, 1981).

In the FMUG, peer evaluation contributes to $10 \%$ of the total score. The method is found to be reliable, reasonably valid and acceptable to students. (Magzoub et al, 1994)

\section{Community leaders feedback}

Community leaders play major roles in the planning and implementation of community-based activities. The success of these programme is measured by the extent to which the community participates in all decisions concerning the running of these programmes (Magzoub \& Schmidt, 1993). Active participation is a condition for ensuring sustainability of these activities and also provides political and moral support for the organizing training institute. The school felt that the community's role could be extended to contribute to programme and student assessment. This conviction was reinforced by the fact that students get in close contact with community members during their posting, particularly community leaders, who are responsible for their accommodation and feeding and who are to facilitate for the students the conditions necessary to attain their objectives. Community involvement in community-based programmes has led to different reactions. First, community members when requested to rate students directly, were reluctant to comment on students performance. They tended to inflate students grades as part of their hospitality to students. The school, therefore, decided to try out another approach, using the indirect interview method by tutors to gather information on community attitudes towards student work in the field. Subsequently, the collected information is used for the purpose of student and programme assessment. The guidelines for the interview are based on the following model (Figure 1). 


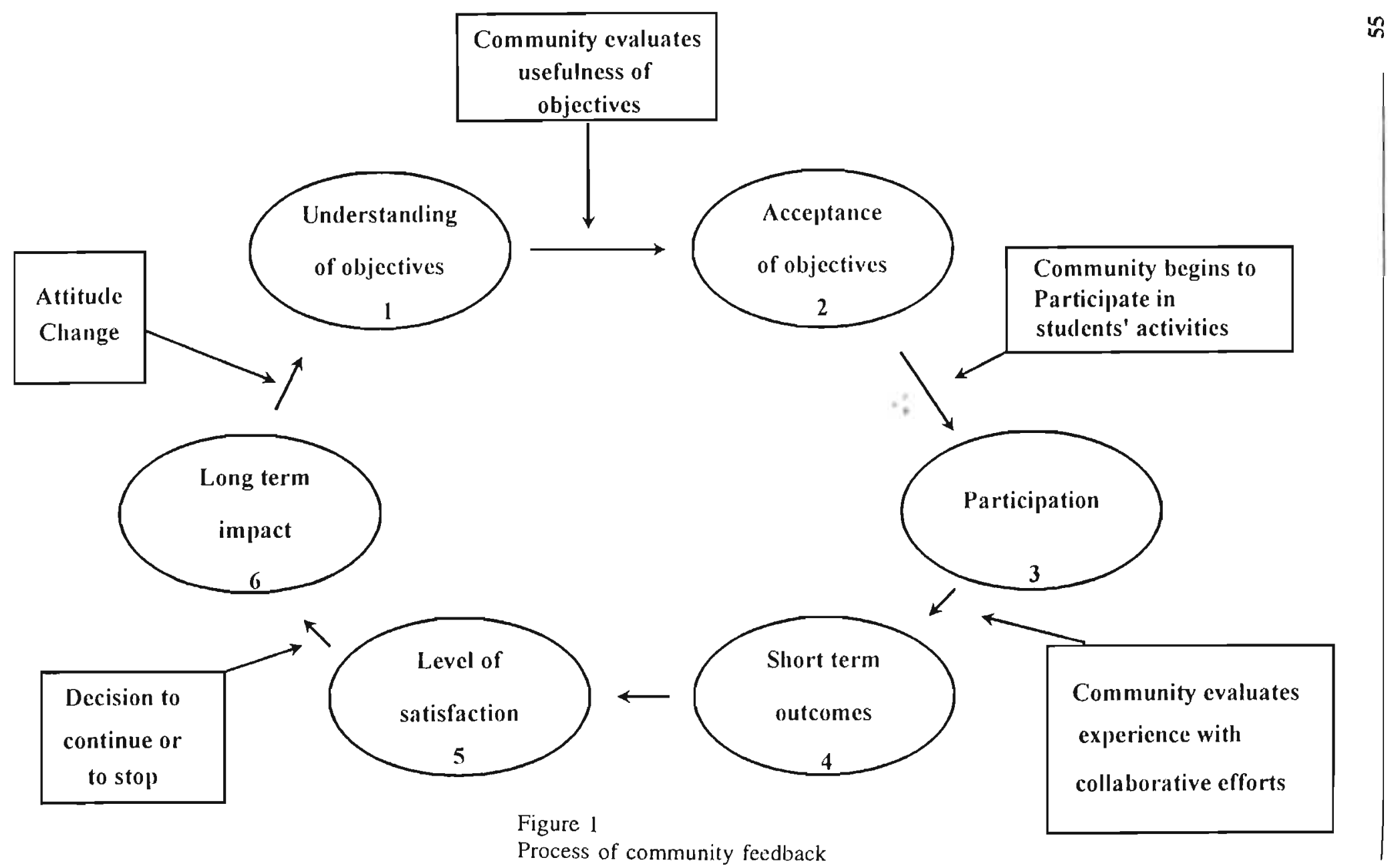


In fact, community feedback is a process involving several steps. The first step is the community understanding of the objectives of students' posting. Usually information about the objectives is delivered to community members by tutors. However, students play an important role in communicating these objectives to make the community understand them.

In the second step the community evaluates the usefulness of these objectives and the activities that will be carried out in their locality. Based on a positive evaluation the community accepts to collaborate with the students. Then, the community begins to participate in student activities, for instance, by guiding them through the village and introducing them to families for data collection. Based on this experience, the community may participate in further student activities, e.g., prioritization of problems and implementation of village projects. This is the third step. Subsequently, community members evaluate their experience of collaboration with students. participation may lead to short-term outcomes such as health education sessions conducted and projects implemented (step five). Also, active participation and the resulting outcome may lead to community satisfaction (step six). Built on this experience the community decides to continue or stop. Longer periods of participatory effort may induce a long term impact, for instance, improvement of health indicators such as reduction in morbidity level. Consequently the long term impact may lead to a deeper community understanding of the CBE programme and its objectives.

This model can be used as a basis for discussion with the community during a supervisory visit, with the aim of identifying the extent to which students and community have passed through all phases of the cycle. Under effective performance conditions the cycle is completed. On the other hand, with poor performance students may not reach beyond step three or four. Also, the level of achievement during the different stages of the cycle can be assessed during this interview. To illustrate this approach we print the following two stories which shows a response of community members when they were requested to give feedback on student performance in their village.

\footnotetext{
"We were visited by ten students in the summer of 1991. (They were able to mention their names M.M.). First we were reluctant to accept their first task of data collection, because of our previous experiences with such visitors, who gathered information from us and then disappear. But the Gezira students were different, they came back with the results of their study. Based on their findings we had a thorough discussion regarding the question which of the problems they identified should have priority. We concluded that malaria ranked as a top priority problem. This problem is mainly caused by
} 
the stagnation of water due to poor drainage as a result of establishing new agricultural canals around the village. This created a good environment for mosquito breeding. Also this problem caused an inconvenience for the villagers because we have to walk about three $\mathrm{km}$., around the stagnant water, to reach the main road leading to the farms. With the help of the students we suggested to establish a drainage bridge. The students helped us to contact government officials. Also, they provided technical support through their university. We accomplished this projects in a time less than expected. Now everyone from the village crossing the bridge is appreciating the marvellous students' achievement. For recognition of their work we call it the "university bridge". We consider this group of students as residents of this village. We believe that when they graduate as physicians, they will be responsive to similar community problems."

"We have been visited shortly by the students who went from house to house to gather information. We facilitated their work in the village through our youth organization who acted as guides and introduced them to families. Also, we arranged their accommodation in the village. The students came back to tell us that our main problem was children diarrhoea. In their opinion, the problem was mainly due to the fact that we have few latrines and our village was not clean. They promised to establish communal latrines in the village. We leamed that they encountered problems in raising funds. Instead, they came for one day to deliver a health education talk, which was poorly attended because of the harvest season. Unfortunately, we did not see them again".

These two examples demonstrating that the cycle is completed in the first and that the students' achievement lead to a better understanding of what the university could do to serve the community. In the second example, the students did not overcome stage three.

The evaluative discussion is conducted with community leaders and those who have close contact with the students, e.g., members a of youth organization. This extensive discussion is conducted by tutors using a focusgroup-discussion methodology. The tutor summarizes the discussion in a report which is analyzed at the university using a checklist consisting of the aforementioned indicators of student performance. The perceived achievement, impact of the work and level of participation by the community is used to rate the group as a whole. This is important to differentiate among the different groups of students. Based on the same report, each individual student is evaluated with respect to community satisfaction and recognition of his achievement and interaction with the 
community. This is helpful to identify differences within each group of students.

Our experiences with this approach have shown that the best-quality information is gathered when the visit is conducted some time after the student posting and preferably following a second posting, when the students have demonstrated some achievement. The method is found to be quite informative with respect to differentiating between different groups of students and less sensitive to differences within groups. Each tutor report is discussed by a committee who decides on the score of each student.

\section{Supervisory checklist}

Supervisors assess students during visits when they are posted in villages, primary health units or rural hospitals. The primary goals of these visits are to assess the extent to which progress has been made to identify potential problems and to help solving these problems. Supervisors perform at least three visits during a students' posting. The school has made use of these visits for the purpose of student assessment. The aim of this assessment is to monitor three important skills essential for students to survive in the community settings. The first skill is the ability to solve problems. In CBE, students are exposed to real-life problems and are required to solve these problems progressing through a number of steps. The steps involved here are: Identification of community problems using different data sources; prioritization of these problems using various criteria; outlining a plan of action to solve one of the priority problems; and suggesting solutions or implementing and evaluating a proposed plan of action. Supervisors assess the students" approach to identifying problems and the criteria they use to prioritize them. In addition, they rate the students' ability to analyze these problems and the approach used to resolve them. The second skill to be monitored is the skill to communicate with individual patients and with the community as a whole. Students are observed while communicating with individuals or while providing health education to an audience. The items to be assessed here are whether the student expresses himself in simple and understandable language; whether he communicates ideas using personal experiences with the local culture and realities; whether he checks to what extent his messages have been understood, and, finally, whether his nonverbal behaviours express an empathic attitude.

The last skill included is organizational ability. Here, the ability of the student to follow a logical sequence in performing his activities is assessed: To what extent does the student have a clear plan for his work in the field; does the student perform regular follow up and daily monitoring; does he have an explicit time schedule to complete a designated activity?. Scoring is performed by the tutor according to a checklist. 


\section{Poster and oral presentation}

At regular intervals students present their work orally in a class seminar or as posters and demonstrations in a students' exhibition. The idea of the latter as a method of learning in community-based education evolved when one of the students commented that it is really unfair to be given only fifteen minutes for oral presentations to present the rich experience of the group in the field. In response to these remarks, students began to prepare posters, photographs and models, for use in their presentation. Following a discussion between the students and the staff, an exhibition was suggested to present everything the student had prepared. This exhibition was open to visitors, including staff members, other students, community members and the expected donors of student projects. These exhibitions became very popular and well attended. Visitors, in particular staff members, were invited to comment in written format with regard to content, clarity of ideas and presentation. These comment are used for assessment purposes as well.

Each student, or representatives of the group, are given fifteen to twenty minutes for presentation followed by discussion. These presentations are attended by the whole class, in addition to the field tutors. Occasionally, students invite community members to attend. During these presentations students use all kinds of aids and sometimes even role play. Following the presentation, each student and tutor is asked to rate the student presentation with respect to content, clarity of ideas, logical sequence, use of audiovisuals and responsiveness to questions. All the students are invited to give score for each item. In some courses, the mean of all ratings is computed for the group as a whole, in other courses, the individual student is rated.

\section{Individual and group report}

Following a field posting, students are asked to write group and individual reports in a comprehensive manner, documenting all their field activities and findings. The report is expected to comply with standards for scientific reporting. It should contain an introduction, a method section, and a results and discussion section. The reporting ability of students is evaluated by tutors using criteria, such as the organization of ideas in a logical sequence; the extent to which scientific methods were applied; thoroughness of discussion of the findings and the presence of executable recommendations. In addition, the general presentation of the report format is evaluated. Scoring is performed by one tutor for all reports.

\section{Physical attendance and performance}

Physical presence in the community setting is essential to attain communitybased learning objectives. Presence of students within a community is an 
important leaming experience. Experience has shown that, although there are not many other options for students when they live in a small village besides carrying out their assigned activities, the level of participation and its impact on learning varies among students. Therefore, absenteeism is not accepted. Students who fail to attend at least seventy percent of course activities will be considered to have failed regardless of their performance on other assessment tools.

\section{Keeping a logbook}

This method is particularly used when students are working in primary health care units or rural hospitals. Students are provided with a log book including a list of certain manual clinical procedures or laboratory investigations they have to perform, assist with, or observe. Tutors in the health centres supervising students (mostly Ministry of Health part-time staff) have to confirm by signature that the student has performed the assigned activities and to comment on the level of performance. Also students are asked to write notes about each patient they have seen, that is; to produce a summary of history, investigations done, provisional diagnoses thought of, final diagnosis, treatment and follow up. The logbook is rated by staff according to the activities achieved and a grade is given to the student.

\section{Short essay questions (SEQs) and multiple choice questions (MCQ- test)}

These methods are applied to test knowledge gains. The main goal of the SEQs is to test student's ability to summarize his ideas in a clear, logical and condensed fashion within a predetermined time frame. The MCQ-test forms a comprehensive test aiming at detecting learning outcomes in the cognitive domain. Usually, MCQ-test consist of 30 questions each including five true/false statements. It is assumed that the two methods test different dimensions of knowledge. Essays and MCQ-test are marked by one tutor for each student.

It is important to mention here, all the above mentioned methods are not applied collectively to each community-based course. The selection of the method depends on the objective and the learning activities in each course. To give an example, in the Primary Health Care Centre Practice and Family Health course, which is mainly conducted in primary health care units assessment methods include logbooks, attendance, student reports MCQ-test and short essay questions. On the other hand in the interdisciplinary Field Training Research and Rural Development course, the assessment methods 
include group report, attendance, community feedback, supervisory checklist and assessment of aral presentation.

\section{Features of the comprehensive approach to student assessment in community settings}

In this section, ten distinctive features of the comprehensive approach to student assessment in community settings are discussed.

First, this approach is carefully considering the process of learning and the different activities carried out in the community, as well as their outcomes. The process starts with inputs from all the partners involved. The community offers, for instance, accommodation to students, moral and political support. Students and faculty provide technical assistance and the government provides financial assistance. Then, certain participatory activities are carried out that lead to the goals set. Through this process, the students learn, the community receives useful services and the school obtains data for research. The assessment tools described take into account all aspects of the learning process: The monitoring of attendance and performance starts at the beginning of, and continues during the whole course. The supervisory checklist, for instance, appraises the students' performance during the process; it measures the quality of the studentcommunity interaction and the effectiveness of the skills used to communicate with individuals and groups in the community. Students' reports measure knowledge gained and provide insight in the extent to which they have acquired the ability to report on their activities. Therefore, emphasis is not only on knowledge gains but also on the growth in other qualities essential for a physician who is really responsive to community health needs.

Second, this approach is considering the effects of community-based activities not only on the students but on the community as well. Via community feedback, information is obtained on the impact of the programme. These data are essential for improving the learning environment of the students and, hence, the attainment of the designated objectives.

Third, this approach to assessment is considered less stressful to students, because the level of performance is monitored throughout the course and not only left to a single exam at the end as is often the case in classroom-based training. By sharing observations of their performance on a continuous basis, students can learn from assessment and improve their skills.

Fourth, this approach provides some measures of students, attitudes that are considered important for future doctors in the Sudan. For instance, the assessment of community feelings towards students and the supervisor visits 
provide indications with regard to the commitment of students to the community and explore their potential for a future community-oriented career, for instance in primary health care.

Fifth, observing the positive effect of their work on the community creates a motivation to learn that goes beyond only passing an exam. For instance, because the community considers students as experts, often questions are raised concerning individual and community health problems, and students are supposed to provide sensible answers. In addition, students conduct health education sessions. These are strong stimulator for students to learn to live up to their status as experts.

Sixth, this approach to assessment is more participatory than is common in most conventional schools. Assessment of students is not only limited to academic staff but involves all those who participate in the instruction; students themselves, community leaders and health workers. For instance, a group of 60 students following their community-based course. will usually be rated by six academic staff, by ten part-time staff from the ministry of health, by 20 community leaders and by their fellow students.

Seventh, our approach assumes that no single instrument is capable of measuring the whole spectrum of learning taking place in the community setting. Therefore, a multi-source evaluation using various instruments that measures the various competencies involved is considered essential. At the University of Gezira at least five tools are applied in each community-based education course, measuring knowledge, communication skills, community interaction styles, reporting ability, effort, leadership and problem solving skills.

Eighth, each instrument is given an appropriate score weight according to the extent to which it covers the objectives of the particular communitybased activity. For instance in the doctor- and-society course, the focus is on communication skills. Therefore, the communication skill assessment may take up to $50 \%$ of the final grade. Also, side effects of a particular assessment tool are taken into consideration. For instance, peer evaluation proved to be a very reliable and reasonably valid (Magzoub et al, 1994). Yet it contributes only $10 \%$ to the final grade so as not to influence the team spirit, which is very essential for achieving the goals of communitybased work.

Ninth, the approach to student assessment described here, is practical and flexible and takes cost-effectiveness into account. In addition, assessment is conducted as part of the learning experience itself, not as a separate and parallel activity. For instance, assessment using the supervisory checklist is performed during supervisory visits of the students by tutors. The main objective of these visits is to make sure things are in order and to help solving students ${ }^{\circ}$ problems in the field. In parallel, assessment takes 
place: Also, during these visits community feedback can be collected. Assessment of students' oral and poster presentation skills is carried out when the students are presenting their work to their class for discussion as part of the ongoing learning during the course. Physical presence is monitored during different course activities by the students themselves. Assessment is flexible in terms of timing; it is not restricted to a definite time period, e.g., the end of the course. On the contrary; it is left to the students and the staff to pick a convenient moment.

Tenth, a last important feature is that this comprehensive approach to student assessment is itself continuously monitored, through discussions during staff meetings and as part of the workshops organized by the programme evaluation committee. Also student feedback and achievement data are used as sources for improving the assessment. In addition, frequent attempts are made to control the quality of the instruments by statistical means; reliability and validity measures are often computed.

In the following section, the presentation of the results of the assessment to student and staff, using the various assessment instruments described, will be discussed. As mentioned above, students' results form an important source for improving the assessment.

\section{Presentation of outcomes of the assessment}

The presentation of the community-based courses outcomes is following a format used at the FMUG, with some modification to accommodate the different nature of community-based courses. The form that is used for presenting results includes the following information: (1) Background data: Name and number of the course, number of credit hours, particular batch, number of students participating in the course and number of students assessed (2) Feedback, which contains: a) Summary of tutors feedback including the extent to which objectives were attained, the running of different course activities and logistic support. b) Summary of students' feedback with regards to course duration, attainment of objectives, field work, learning methods and assessment tools applied. c) Summary of community feedback, including community understanding of programme objectives, acceptance of the programme and the students, students' behaviour and their level of participation. (3) Summary of problems faced during the course and the recommendations to overcome these problems (4) Assessment tools applied in the course, minimum pass level (MPL) for each tool, score weight for each tool, number of students passed/failed on each tool, range of different grade, e.g., A, B, C and F and distribution of students among these grades. (5) Comparison with previous batches in terms of progression or regression. (6) Finally, detailed results for each 
student and the names of students who failed are given. In addition, it is indicated how they will correct for their failing.

These results are discussed in detail in a faculty board meeting including all the staff. The board is the supreme authority in the school responsible for programmes and programme improvement. These meeting are organized every other week, constituting a major activity in the school. The coordinator of the course presents results for discussion. Problems faced during the course are raised. For example, students may comment that the course duration is too short to accomplish the course objectives, or tutors may raise logistic problems. During these meetings proposals to overcome these problems are often decided upon. Students who fail the course constitute the topic of another long discussion. Reasons for failure are discussed. Is the failing due to the student himself? Is it related to the way the programme was implemented or because of the assessment tools applied? How will the student compensate or correct his failure? etc. In brief, these meetings are important occasions for programme improvement, including the tools of assessment.

\section{Discussion}

The comprehensive approach, described above, may have some disadvantages. First, it is a work-demanding endeavour that requires much time and logistic support. This form of assessment requires a strong commitment and motivation of tutors and continuous support from the university. Second, this approach requires the participation of the Ministry of Health staff and community members, who might not be expert in the assessment of students compared to academic staff. Most of them collaborate on a voluntary basis and are less committed to the programme. In addition, their judgement may not be as stable as the university staff's judgement. This demands a continuous series of training and orientation sessions for those collaborating groups. Third, the student may end up with a feeling that he is observed during every activity he is undertaking. This may direct the motivation of some of the students to scoring high marks rather than realizing the primary goals of community exposure. To overcome these disadvantages, measures have been taken to train all participants in the staff and to provide detailed guidelines to be followed in the process. These guidelines describe the purpose of the assessment and how it is to be conducted, the criteria to be used for ratings, etc. Supervisors are concentrating on the leaming process rather than on the assessment during their supervisory visits. In addition, the staff meetings and the workshops are opportunities to reflect on these problems and act accordingly. 
In conclusion, this approach has several advantages, it measures the various competencies needed in the context of community-based work, considers the impact not only on the student but on the community as well; appears to be less stressful to students; provides some measures of attitudes; takes into account cost-effectiveness and is practical. In addition, the assessment methods are continuously monitored. These advantages of our approach contrast with the conventional approaches used, for instance, in departments of community medicine. The latter can be characterized as often being teacher-centred; as using less sources of information; and as concentrating mainly on assessing the learning outcomes in terms of knowledge gains at the end of the course.

The high working load and the time needed for applying this approach, is the price to be paid for conducting a form of assessment that is sensitive to the objectives of community-based education and increases the chances that physicians are graduated who are really responsive to community health needs. 


\section{References}

Abdelrahim I.M., Abdeen A.Z.E., Faki B.A., Mustafa A.E., \& Nadler, S. (1987). Introducing training in primary health care programme management into the curriculum. Medical Education, 21, 288-292.

Abdelrahim I.M. (1989). Six strategies for effective and relevant medical education as adopted in Gezira Medical School. Saudi Medical Journal. 10, 391-5.

De Volder M. \& De Grave W. (1984). Peer evaluation and problem-based leaming, in: Schmidt H. G, De Volder M., (Eds.) Tutorials in problem-based learning. A new direction in teaching the health professions, Van Gorcum, Assen/Maastricht, (1984).

Hamad B. (1982). Interdisciplinary field training research and rural development. Medical Education, 16, 105-107.

Jennet P.A, Van Rosendaa G.M.A.. Lockyer J.M., McDougall G.M., Hunter K. E., \& Schachar N. S. (1990). Peer evaluation in Residency programs, In Bender W., Heimstra, R. J. Scherpheir A. J. J. A., Zwierstre R. P. (Eds). Teaching and Assessing Clinical Competence, Groningen Boekwerk Publications.

Love K.G., (1981). Comparison of peer assessment methods: Reliability, validity, friendship bias and user reaction, Journal of Applied Psychology, 66. No 4, 451-457.

Magzoub M.M.A., Schmidt H.G., Dolmans D. H.J.M. \& Abdel-Hameed A.A. (1994). Assessing students in community settings: The role of peer evaluation. Submitted for publication.

Magzoub M.M.A., \& Schmidt H.G. (1993). The impact of a community-based programme on the community. Submitted for publication.

Magzoub M.E.M.A., Magzoub M.M.A., Saeed A.A., (1992). The rural residency course. Annals of Community-Oriented Education 5, 105-109.

Mirghani O.A., El-Amin E.O., Ali M.E., Osman H.S. \& Hamad B. (1988). A combined course of primary health care practice and family medicine at the university of Gezira. Medical Education, 22(4), 314-316.

Schmidt H. G., Neufeld V. D., Nooman M. Z. \& Ogunbode T. (1991). Network for Community-Oriented Educational Institutions for the Health Sciences. Academic Medicine, 66, No.5, 259-263. 


\title{
A comprehensive Approach to Student Assessment in community settings (2) Measures of Reliability and Validity
}

\begin{abstract}
The faculty of medicine, University of Gezira, a community-based medical school, uses a comprehensive approach to student assessment in community settings. One hundred and five students participated in the present study. The assessment included the use of multiple choice questions, essays, a supervisory checklist, student produced reports, peer assessment and community feedback. The reliability of the methods was tested by computing the alpha coefficient and was found to range between 0.77 to 0.92 . This was considered acceptable. The validity of the instruments was studied using confirmatory factor analysis. In addition, their content validity was reviewed. The results show that the comprehensive approach used is fairly valid. Based on the findings, we suggest that our approach to student assessment provides a successful attempt to solve some of the problems facing student assessment in community settings.
\end{abstract}

\section{Introduction}

Community-based education (CBE) in health professions education is a learning activity, aimed at producing graduates, responsive to health needs of their community. CBE provides a context for leaming that is of a quite different nature than learning in the context of conventional forms of education. Consequently this form of education requires assessment methods adapted to this context and different from those used in class learning or in 
the teaching hospital (Fulop, 1976; Kantrowitz et al, 1987). Many authors have indicated the close relationship between assessment and the kind of learning activities that students actually engage in (Frederickson \& Knox, 1984; Newble, 1988). Generally, assessment objectives should match educational objectives. Developing a valid student assessment system for CBE will help innovative schools to develop assessment procedures supporting student learning (Hassan et al, 1993).

To illustrate why the nature of learning in community-based courses is different, we will take the experiences of a Sudanese doctor graduated by a traditional medical school as an example. This example will be used to identify the tasks of a doctor in a rural setting, and the competencies he has to be equipped with in terms of knowledge and skills, in order to accomplish these tasks successfully. Based on the analysis of these tasks, appropriate methods for assessing the competencies will be discussed.

"I have been required by the Ministry of Health to work in Omshanig rural hospital, which is a single-doctor hospital. The only motivation for me to accept this job, was to fulfil the requirement stated by the ministry to qualify for postgraduate studies. I found the hospital functioning without a doctor for the last two months. This was unfortunate start as there was no possibility to learn from the previous doctor's experience. I discovered that I had to perform responsibilities which I had never expected to be part of my job. Beside my ordinary clinical work in both in-patient and out-patient departments, I had to manage the hospital staff in addition to the finance and the drugs. I found myself committing major mistakes in the management of the staff and finance because I was not familiar with the civil service bylaws. I decided to leave this task to the senior nurse who tumed out to be an exper in this domain. I found that many patients crowding in the outpatient clinic could be treated at the level of primary health care units. if these units were supported and their staff would receive basic training. In addition, 1 found that many problems could be prevented. For instance we had an outbreak of scabies; a problem that would not exist if proper hygiene and health education measures were in operation. Of course, proper implementation of these measures requires community mobilization and participation. In fact, I found myself doing tasks for which I was never prepared during my undergraduate training. And these tasks were taking most of my time and effort. At my medical school, the community medicine course given during my fifth year was not taken seriously by the students, because it was mostly taught in the class. Community-based activities for us were just a tour and a change of environment because it was not at all part of our assessment. Furthermore our assessment was only based on the knowledge gained, not on skill acquired. I really got frustrated, just waiting eagerly to complete the required time in this hardship area (Personal communication with the first author)." 
From this example we can deduce that the tasks required by this doctor are the following. (1) Treatment of patients and referral to the second level. (2) Management of health personnel (3) Supervision and training of primary health care units, (4) Prevention of infectious diseases and control of epidemics (5) health promotion through community participation. It is assumed that, in order to qualify a physician to meet these tasks properly, he should learn in an environment similar the context described, and the learning objectives must consider these tasks (Schmidt et al, 1991). The competencies necessary to accomplish these tasks appropriately are: Management and leadership skills, community interaction skills, manual clinical skills, problem solving, organizational and communication skills. In addition, students have to acquire the relevant knowledge to perform these tasks. Of course, assessment methods should be fit to evaluate these skills objectively. A WHO study group (1987) identified five abilities to be assessed in CBE. These abilities include clinical skills, cognitive, preventive, therapeutic and problem solving abilities. Other abilities reported in the literature entail leadership, community interaction and team work (Hassan et al, 1993; Magzoub et al, 1993).

Since many institutions and health policy makers have become convinced that health professions education should be relevant to the regional needs and that health professionals should be graduated who are really responding to the health needs of the population (Schmidt et al, 1991), schools have started to send students to learn in community settings. The duration of time spent in community settings as compared to other educational activities, may reach $50 \%$ in some institutions (Richards et al, 1990). However, the objective assessment of students in community settings is a real problem, that has not yet been solved satisfactorily. Generally, there is a discrepancy between the activities undertaken by students and the subject of assessment in these contexts.

The following is an example that may give an idea of the nature of this problem, the discrepancy and its consequences. It is a story of a group of second year medical students from the Faculty of Medicine University of Gezira (FMUG) (The first author among them).

During an outbreak of cholera, in 1980, the FMUG decided to expose their second year medical students to the community, to learn the measures taken to control this disease, as cholera is not common in the country. Three students were posted in Mahala village, located $100 \mathrm{~km}$. south of the university campus. The students found the village infected with cholera, to the same extent as the neighbouring villages. They concluded that there must be a common source of infection, and they deduced that the water pond used by these villages must be the most likely source. Therefore they took a sample of water 
for laboratong investigation. The sample was found to be positive for vibrio cholera. Measures were taken to clean the source of water. In addition it was attempted to prevent future contamination through health education and active community involvement to care for their own health. The students participated in all these activities until the problem was over. The students and the community were very satisfied and pleased about their achievement as many lives were saved through these measures. The dean, in addition, presented this experience as an example of the necessity for restructuring medical education to respond to community health needs in a conference organized by the Ministry of Health on the appropriate strategies to realize health for all by the year 2000. However to students' astonishment they got very low marks compared to other groups. They came to know that their marks were only based on the written report, scored with regards to knowledge gains. For most students in the class this was really disappointing and this incident definitely may had an effect on the students attitudes towards community-based courses. For the school, this was one of the reasons to think about improving the assessment system.

Generally, however, it is difficult to assess students reliably and validly in the community setting. The problems facing assessment are felt by both staff and students in institutions adopting community-based education (Hassan \& Ezzat, 1990). These difficulties can be summarized as follows.

In most instances, students work in groups, particularly when they are assigned to villages. Group work is a very important leaming activity in itself. Students leam how to work in a team, are practising leadership skills, begin to understand group dynamics and learn from each other in smallgroup discussions. While assessing group performance, it may be difficult to evaluate the students on an individual basis and to quantify the contribution of each group member. Second, students are assigned to work in different community settings, not only for logistic reasons, but also with the objective of sharing experiences among the different groups. These community settings might be quite different in size, intensity of interaction with the community, socio-economic and cultural differences etc. Yet, students are asked to fulfil the same objectives and carry out uniform activities. This lack of standardization due to field conditions increases the subjectivity of student assessment in these courses. Third, training in community settings involves extensive logistic preparation, e.g., transporting students, arrangement of accommodation and contacts with community leaders. This definitely creates the need for close supervision of students to ensure everything is in order and to assess students and evaluate the programme's well-being. Spending time on these tasks certainly creates a burden for the staff and is quite expensive. Fourth, most of the assessment 
is performed by the staff, health workers, community leaders and the students themselves. This assessment is carried out through direct interviews with the students and in many occasions by "face to face evaluation." This may introduce a "leniency error," i.e., students are given higher scores than they deserve, resulting in inflated grades. In addition, this way of assessing may introduce a second bias, the so called the "halo effect": Both students and staff may carry their impressions about the students in class-based courses in such a way that these impressions influence their ratings of the same students in community-based courses, although these courses may require the exposition of different aspects of one's competencies. A fifth problem is, that many instruments are used and many raters are involved in the assessment. This introduces inter-and intra-rater variability, and also requires training for inexperienced raters (Hassan et al, 1993). Sixth, one of the most important objectives of community-based education is the fostering of attitudinal changes, an objective difficult to assess.

Given these restrictions, how can assessment in the community nevertheless be implemented? By reviewing the fairly limited literature in this area, in addition to the papers presented at the International Symposium on Student Assessment in Community Settings (1993), three main approaches to assessment may be distinguished: (1) Knowledge measurement approaches, essentially pencil and paper methods, that mainly assess the factual recall and, in some cases application of knowledge. Tools applied here include multiple choice questions, essays and reports. This type of assessment is characteristically conducted at the end of the communitybased education activity (Jinadu, 1992; Omatara, 1992). (2) Performancebased approaches. These are (quasi-) observational methods mainly assessing the performance of the students during their field activities. Tools applied here include logbooks (Des Marchais, 1993; Manalo, 1992), supervisory visits (Bollag et al, 1982; Magzoub et al. 1993), peer assessment (Hassan, 1993; Morales Sameneago, 1993) and monitoring of attendance (Magzoub, 1993). (3) Comprehensive approaches which combine (1) and (2) using various tools.

The Faculty of Medicine, University of Gezira (FMUG) uses such comprehensive approach to student assessment in community settings. The various instruments employed are described elsewhere (Magzoub et al 1994).

To our knowledge, no studies are conducted to test the quality of the instruments used in assessing students in community settings i.e., measures of reliability and validity. The aim of this article is to report on the reliability and validity of the comprehensive approach to student assessment in community settings as used at the FMUG. To that end, we measured performance of 105 students of the FMUG with a battery of instruments, 
described previously (Magzoub et al 1993), and intended to cover all competencies required in the community settings. The data were analyzed using confirmatory factor analysis and reliability estimates.

\section{Method}

\section{Subjects and procedure}

One hundred and five students participated in the interdisciplinary field training research and rural development and the family health communitybased courses. Each group consisted of ten to eleven students. These groups were assigned villages to work for three consecutive summers in three phases. During the first phase (August 1991), students identified problems using various investigation tools. In the second phase (September 1992), students implemented projects to solve one of the priority problems identified in the first phase. In the last phase students evaluated their implemented projects. Problems identified and projects implemented can be found in Table 1.

Table 1

Problems and projects implemented in ten villages

Village problem services

Poverty

Scabies

Malaria
Poor utilization of health

Environmental sanitation

High illiteracy rate

Poor water supply

Malnutrition

Environmental sanitation

Poor drainage of rain water
Project implemented

Rehabilitation of the existing primary health unit Health education

Community development centre

Rehabilitation of the slow sand filter Poultry farm

Small-scale soap factory

Establishment of grinding mill

Construction of latrines

Application of insecticides

Establishment of drainage bridge

At the end of the second posting students were assessed using the following measures, the measures include five instruments, each include two to five items.

(1) Community feedback: Two months after the students left the villages, community leaders were interviewed by tutors about their attitudes towards students. The interview included items such as community 
awareness of the purpose of students' visits, awareness of the differcnt activities they carried out. Students' achievement as perceived by community members and, finally, the level of community satisfaction with the students' performance and the student-community-relationship. The interview was summarized by the interviewer in a report. Based on this reports the results for each student were decided upon by a committee.

(2) A group-produced report that intended to measures the reporting abilities of the students as groups. Two aspects were rated: The content of the report, (description of the method followed to collect data, reporting of the results and the presence of executable recommendations) and the form of the report (flow of ideas in a logical sequence, the extent to which scientific method followed and general presentation of the report). All the reports were marked by one tutor.

(3) Knowledge measures which include multiple choice questions (MCQ-test) and essays. MCQ-test measure the factual recall in a comprehensive way. The MCQ-test consisted of 30 items. Each item included five true/false statements. Essays intending to measure the students' knowledge and their abilities to summarize facts within a determined time. The test included four questions which were scored by one tutor.

(4) A supervisory checklist. Supervisors assessed students during their posting on three competencies important in CBE: Problem solving skills, organizational competencies and communication skills. Problem solving skills were defined as the students' abilities to handle community problems. This would include the investigations tools used, criteria for prioritizing problems and approaches to solve the problem. Organizational skills referred to the students planning of activities and the daily monitoring of progress. Communication skills including interaction with both individuals and groups. Assessment would, for instance, be conducted during a health education session. The rating form included, the use of personal experience with the local culture and realities, the use of checking questions, whether ideas were expressed in simple and understandable way etc. The rating for each student is performed by a committee which decides on all the students.

(5) Peer assessment. Each student rated his fellows in the group, on four personal and interpersonal competencies: Effort, which reflected the efforts of students put in the different activities carried out during the course; community interaction, displaying the student's ability to communicate with the community to facilitate data collection and implementation of projects; leadership, reflecting aspects such as leading a group discussion, decision making and division of labour; subject-matter contributions, reflecting the ability of the student to utilize his gain knowledge to help the group work progress. The score for each student on 
each item is computed by averaging the ratings of all judges within the group. The different elements of the comprehensive approach can be found in Table 2.

\section{Analysis}

A reliability study was conducted for each instrument separately and for the total score based on an averages of the scores for each test. The Statistical Package for Social Sciences programme (SPSS) was used to compute the alpha coefficient for each instrument. The hypothesis was that each item belonging to a particular instrument is measuring similar competencies.

A construct validity study was conducted on the variables involved, using confirmatory factor analysis. In the confirmatory factor model as applied in this study, most common factors are correlated, observed variable 1 to five are affected by the first common factor (which we consider knowledge related). Observed variables 6 to 8 are affected by the second common factor (supervisor rating). Variables 9 and 10 are affected by the third common factor (report). Variables 11 to 14 are affected by the fourth common factor (peer rating) and the last three variables are affected by fifth common factor (community feedback). Furthermore, all observed variables are to be affected by a unique factor (error) and no pairs of unique factors are correlated. The Lisrel VII programme (Joreskog \& Sorborn, 1990) was used to determine wether the data confirmed this theoretical model. Additional analysis were carried out with EQS, a structural equations programme (Bentler, 1989). This approach integrates confirmatory factor and path analysis.

An attempt was made to check the content validity of the battery of tests. Content validity describes the extent to which a test samples or 'covers' the area of competencies under assessment. It answers the question: Have most of the importance things been considered (Neufeld, 1984)? In this study the content validity was assessed by reviewing the coverage of objectives of community-based programme described elsewhere (Magzoub et al, 1994) by the different instruments used in assessing student in community settings. The review was conducted by the first author and commented upon by staff from the FMUG, involved in the assessment of students in community settings. The most covered objective by the instrument was indicted by three crosses and the least covered objective was indicated by one cross. 


\section{Results and Discussion}

Discriminating value. The standard deviations in Tables 2 and 3 suggest that the tools used in this comprehensive approach discriminate among students, suggesting that student performance is distributed over a large proportion of the theoretical range for virtually every tool. None of the observations reached ceiling values. Furthermore, for most of the tools the mean for the top ten students is around $80 \%$ and the mean for the bottom ten is around $40 \%$

Table 2

Items included in the rating scale of the comprehensive approach to students assessment in community settings. Mean scores and standard deviations.

Items and factors

Scale Mean SD

Factor (1) Knowledge-related factor

1. MCQ-test

$\begin{array}{rrr}0-40 & 18.92 & 1.94 \\ 0-10 & 5.93 & 1.16 \\ 0-10 & 5.45 & 1.08 \\ 0-10 & 5.55 & 1.22 \\ 0-10 & 5.90 & 1.11\end{array}$

2. Essay 1

3. Essay 2

4. Essay 3

5. Essay 4

Factor (2) Supervisory checklist

6. Communication

$0-10$

7.39

1.40

7. Problem solving

$0-10$

6.93

1.26

8. Organization

$0-10$

6.82

1.21

Factor (3) Report

9. Content of report

$\begin{array}{lll}0-40 & 27.50 & 2.07 \\ 0-40 & 27.55 & 3.18\end{array}$

10. Form of report

\section{Factor (4) Peer evaluation}

11. Effort

12. Community

13. Leadership

$3.44 \quad 0.70$

14. Subject matter contribution

Factor (5) Community feedback

15. Awareness

16. Satisfaction

17. Achievement 
Descriptive statistics for each factor.

\begin{tabular}{|c|c|c|c|c|c|c|c|}
\hline Factors & $\begin{array}{l}\mathrm{N} \\
\text { items }\end{array}$ & Scale & Mean & $\mathrm{SD}$ & $\begin{array}{l}\text { Mini } \\
\text { value }\end{array}$ & $\begin{array}{l}\text { Maxi } \\
\text { value }\end{array}$ & $\mathrm{N}$ \\
\hline MCQS & 1 & $0-40$ & 18.9 & 1.94 & 11.5 & 22.6 & 105 \\
\hline Essays & 4 & $0-10$ & 5.7 & 0.88 & 3.3 & 7.8 & 105 \\
\hline $\begin{array}{l}\text { Superv. } \\
\text { checklist }\end{array}$ & 3 & $0-10$ & 7.1 & 1.21 & 3.3 & 9.0 & 105 \\
\hline Report & 2 & $0-40$ & 27.5 & 4.42 & 22.5 & 31.1 & 105 \\
\hline $\begin{array}{l}\text { Peer } \\
\text { assess. }\end{array}$ & 4 & $1-5$ & 3.5 & 0.59 & 1.6 & 4.7 & 105 \\
\hline $\begin{array}{l}\text { Community } \\
\text { feedback }\end{array}$ & 4 & $0-10$ & 6.4 & 1.34 & 3.7 & 9.0 & 105 \\
\hline
\end{tabular}

Reliability study. Table 4 shows the alpha coefficients for each of the instruments as well as the total score. All the instruments showed a reliability coefficient around the minimally acceptable level. However the total score showed a lower reliability which is 0.62 . Removing the MCQtest from the analysis improved the reliability coefficient to 0.65 . When both MCQ-test and essays were dropped the reliability coefficient of the total score reached 0.69 . On the other hand, skipping the peer assessment decreased the reliability to 0.52 . These results suggest that, the instruments used in this approach are reliable. The total score turned out to reflect a composite of dissimilar competencies as shown by its relatively low reliability and the changing coefficient value when items were dropped.

Table 4

Alpha coefficient for the different tools used in the comprehensive assessment.

Tool

Alpha Coefficient

Essays

0.775

Supervisory checklist

0.829

Report

0.763

Peer assessment

0.917

Community feedback

0.929

Composite score from all items

0.621 
Construct validity.

The construct validity was studied using confirmatory factor analysis. The correlation coefficients between the observed variables varies between 0.49 to 0.59 for the essays, between 0.53 to 0.75 for the supervisory checklist, between 0.66 to 0.78 for the peer assessment between 0.79 to 0.87 for the community feedback, the correlation between the two report items was 0.67 . the correlation between the common factors varied between -0.04 to 0.56 . See table 5 .

Table 5

Correlation between different factors.

\begin{tabular}{|c|c|c|c|c|c|c|}
\hline & $\mathrm{MCQ}$ & Essay & $\begin{array}{l}\text { Super- } \\
\text { visory } \\
\text { checklist }\end{array}$ & Report & $\begin{array}{l}\text { Peer } \\
\text { Assess }\end{array}$ & $\begin{array}{l}\text { Community } \\
\text { feedback }\end{array}$ \\
\hline $\mathrm{MCQ}$ & 1.00 & & & & & \\
\hline Essay & 0.18 & 1.00 & & & & \\
\hline Superv. check. & 0.03 & 0.14 & 1.00 & & & \\
\hline Report & 0.01 & 0.17 & $0.25^{*}$ & 1.00 & & \\
\hline Peer assess. & 0.15 & 0.18 & $0.47 * *$ & $0.29^{*}$ & 1.00 & \\
\hline Comm. feedb. & -.04 & 0.06 & $0.31 * *$ & $0.47 * *$ & $0.56 * *$ & 1.00 \\
\hline
\end{tabular}

$* \mathrm{p}<0.05 \quad * * \mathrm{p}<0.001$

The Chi square is most often used to evaluate the fit of data to a model. A non-significant chi square value is considered a sign of fit. In the present study, chi square was equal to 166.08 with $\mathrm{df}=109, \mathrm{p}=0.00$ This finding suggests that the model does not adequately represent the data. A problem, however with analysis using chi square for an evaluation of model adequacy is that this statistic is quite sensitive to violations of its distribution, in particular in relatively small samples (Bentler, 1989). Therefore other statistics of fit have been developed that are less sensitive to violation of assumptions underlying the chi square distribution. These statistic include the Bentler-Bonnet Normed and Nonnormed Fit indices and the comparative Fit Index (CFI) (Bentler, 1989). Since the CFI takes into account attributes of the unrestricted model relative to the model under test, it will be reported here. For the model tested $\mathrm{CFI}=.84$. A value over 0.90 may be considered an indicator of good fit. Some additional criteria for evaluating the fit of a model such as the one outlined in the analysis section are suggested in the literature (1) The chi-square divided by the degrees of 
freedom should be lower than 2.00 and should have a p-value higher than zero, (2) the root mean square residual should be lower than 0.07 (Saris \& Stronkhorst, 1984). In the present case, the root mean square residuals were 0.074 and the chi square divided by the degrees of freedom is less than two, both of which are considered indicators of reasonable fit (Saris and Stronkhorst, 1984). All this suggest that, although the five factor model significantly differs from the data, the difference is not impressive.

The analysis revealed a low beta-weight for the MCQ-test which indicates that this instrument's variance is not well explained by the knowledge factor. Therefore, a second, somewhat different model was tested, considering the MCQ-test as a separate dimension. This was based on the assumption that MCQ-test may measure an aspect of knowledge different from the four essays. Under this model the essays were considered a separate knowledge application factor. The results displayed a better fit, the CFI was 0.91 , chi square $=200$, with 115 degrees of freedom, $\mathrm{p}=0.001$. However the mean square residuals did not decrease (0.09). This model can be considered as somewhat better fit to the data. Figure 1 graphically displays the results of the analysis. For readability only the significant path coefficients have been displayed. Error terms and all the structural equations resulting from the analysis in standardized format are displayed in Table 6.

Table 6

Structural equations resulting from the confirmatory factor analysis (standardized solution).

\begin{tabular}{|c|c|c|c|c|}
\hline $\mathrm{V} 2$ & $=$ & $0.73 \mathrm{Fl}$ & + & $0.66 \mathrm{E} 2$ \\
\hline V3 & $=$ & $0.70 \mathrm{Fl}$ & + & $0.71 \mathrm{E} 3$ \\
\hline V4 & $=$ & $0.65 \mathrm{~F} 1$ & + & $0.76 \mathrm{E} 4$ \\
\hline V5 & $=$ & $0.63 \mathrm{~F} 1$ & + & $0.77 \mathrm{E} 5$ \\
\hline V6 & $=$ & $0.65 \mathrm{~F} 2$ & + & $0.76 \mathrm{E} 6$ \\
\hline V7 & $=$ & $0.82 F 2$ & + & $0.56 \mathrm{E} 7$ \\
\hline V8 & $=$ & $0.90 \mathrm{~F} 2$ & + & $0.43 \mathrm{E} 8$ \\
\hline V9 & $=$ & $0.67 F 3$ & + & $0.94 \mathrm{E} 9$ \\
\hline V 10 & $=$ & $1.00 \mathrm{~F} 3$ & + & $0.00 \mathrm{E} 10$ \\
\hline Vll & $=$ & $0.86 \mathrm{~F} 4$ & + & $0.49 \mathrm{E} 11$ \\
\hline $\mathrm{V} 12$ & $=$ & $0.81 F 4$ & + & $0.58 \mathrm{E} 12$ \\
\hline V12 & $=$ & $0.88 \mathrm{~F} 4$ & + & $0.48 \mathrm{E} 13$ \\
\hline V 14 & $=$ & $0.87 F 4$ & + & $0.48 \mathrm{E} 14$ \\
\hline V 15 & $=$ & $0.93 F 5$ & + & $0.36 \mathrm{E} 15$ \\
\hline V 16 & $=$ & $0.93 \mathrm{F5}$ & + & $0.35 \mathrm{E} 16$ \\
\hline V17 & $=$ & $0.84 F 5$ & + & $0.53 \mathrm{E} 17$ \\
\hline $\mathrm{F} 1$ & $=$ & $0.19 \mathrm{~V} 1$ & + & $0.98 \mathrm{E} \mathrm{I}$ \\
\hline
\end{tabular}




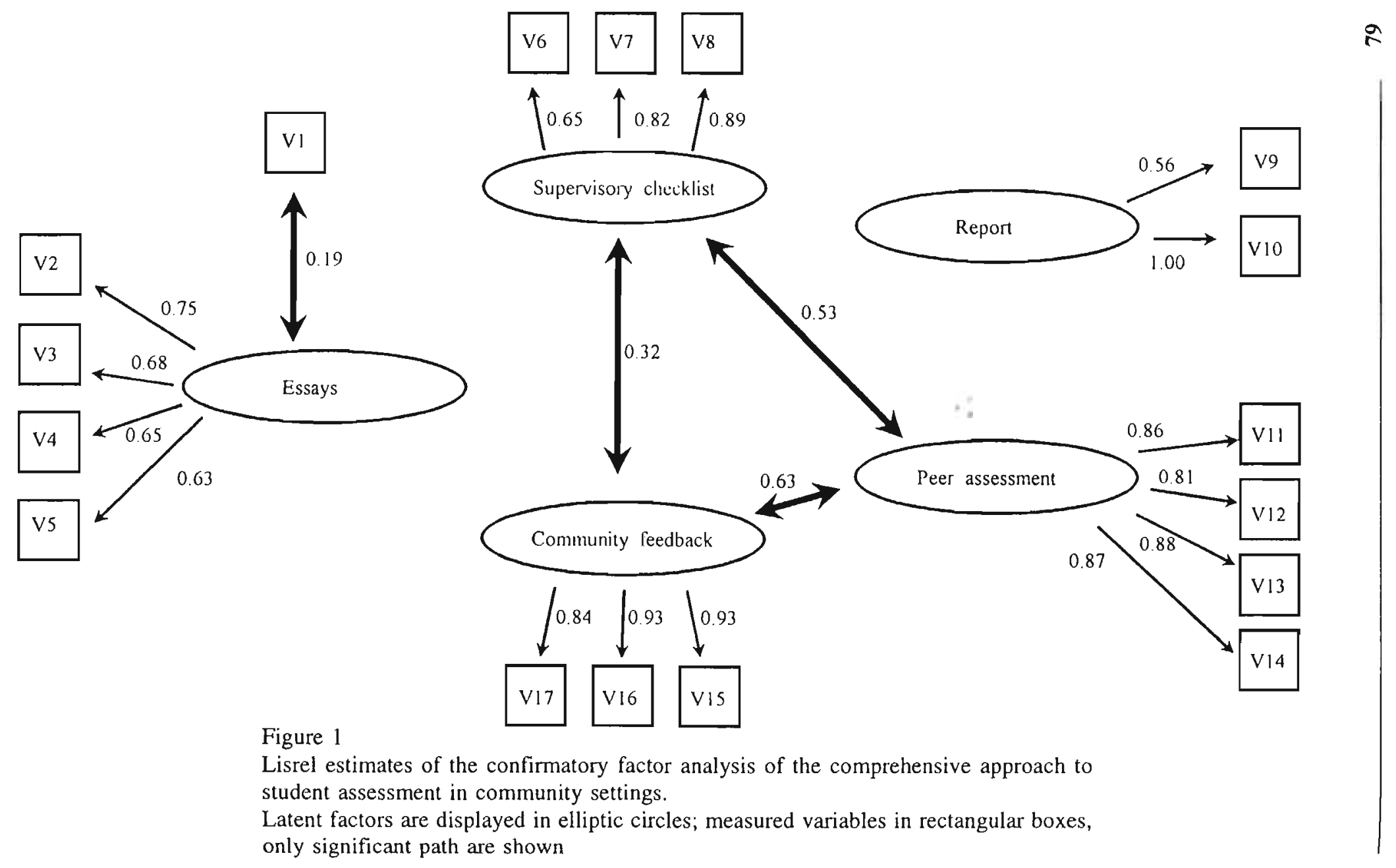


The results suggest that the latent variables F1 to F5 explain the variables involved fairly well. The regression weights, symbolizing the extent to which a measured variable is explained by its latent factor, are generally quite high with one exception. Since $R^{2}=1-E^{2}$, the regression weights in the standardized solution may be interpreted as the correlation or "loading" between the variables and its underlying factor. Further manipulation of the model by entirely removing the MCQ-test form the analysis didn't improve the fit of the model. However, when both the report factor and the MCQtest were skipped, a good fit was found. Chi square $=106.4$ based on 74 degrees of freedom, $\mathrm{p}=0.008, \mathrm{CFI}=0.96$. This may be due to the fact that the reports were assessed such, that each member in the group received an equal score. This limits, of course, the variability between subjects. On the other hand, removing the report factor is detrimental to the content validity of the approach. Assessment of group performance resembles future situations in which students will work. In rural hospitals, for instance, the evaluation is conducted for the management team as a whole. It is also a measure of team work as students in their small groups are encouraged to develop a collaborative spirit, one of the objectives of $\mathrm{CBE}$.

The insignificant correlation between the knowledge-based tools, i.e., essays and MCQ-test and the performance-based tools i,e, community feedback, supervisory checklist and peer assessment, may be explained by the fact that the performance during the field work, with its extensive interpersonal and collaborative elements is only tapping to a limited extent on knowledge. Alternatively the knowledge gains measured by MCQ-test and essays may not properly reflect the actual learning taking place in the community settings. This would call for an approach to MCQ-test and essay question writing that would better reflect the actual learning experiences of students in the field.

In conclusion, the five-factors model does not adequately represent the data. A six factor model in which the MCQ-test was considered as a separate variable showed a better fit. Removal of the report factor and the MCQ-test improves the fit. However, removal of the report variables would limit the content validity of the approach.

Content validity. Table 7 shows that overall the objectives are well covered by the different methods of assessment. Each method is focusing primarily on a specific dimension of the objectives. For example, peer assessment is focusing most on measurement of leadership skills and least on knowledge. Essays are concentrating on knowledge objectives with less focus on performance objectives. 
Table 7

The coverage of objectives by different assessment methods.

Assessment of content validity.

\begin{tabular}{|c|c|c|c|c|c|c|c|c|c|}
\hline $\begin{array}{c}\text { Methods of assessment } \\
\text { Oblecllves }\end{array}$ & $\begin{array}{l}\text { Peer } \\
\text { Evaluation }\end{array}$ & Report & $\begin{array}{l}\text { Community } \\
\text { Feedback }\end{array}$ & $\begin{array}{l}\text { Supervisory } \\
\text { Checkllsi }\end{array}$ & $M G Q s$ & Essay & Log book & $\begin{array}{l}\text { Phyalcal } \\
\text { Altendance }\end{array}$ & $\begin{array}{l}\text { Oral \& } \\
\text { Poster } \\
\text { Present. }\end{array}$ \\
\hline behavioral sclences & $x \times x$ & & & & $x \times x$ & $x \times x$ & & & \\
\hline $\begin{array}{l}\text { Impact of disease on the } \\
\text { lamlly and the communlly }\end{array}$ & $x \times$ & & $x$ & $x$ & $x$ & $\mathrm{x}$ & & & $x$ \\
\hline $\begin{array}{l}\text { Perceptlons of palients as } \\
\text { part of famlly community }\end{array}$ & & & $x \times$ & & & $\therefore$ & $x \times$ & $x$ & $x x$ \\
\hline Function of health system & & $\mathrm{x}$ & & $x x$ & $x$ & $x$ & $x x$ & & $x$ \\
\hline Problem solving & & $x$ & & $x \times x$ & & & $x$ & & \\
\hline Communication skills & & $x$ & & $x \times x$ & & & $x \times$ & $x$ & \\
\hline Clinical skills & & & & $x \times x$ & & & $x \times x$ & $x$ & \\
\hline Research methodologu skills & & $x \times x$ & & $x$ & & & & & $x \times$ \\
\hline Leadershlp skllls & $x \times x$ & & $x$ & $x$ & & & & & $x$ \\
\hline $\begin{array}{l}\text { Organlzallonal skllls } \\
\text { Toam work }\end{array}$ & $x \times x$ & & $x x$ & $x \times x$ & & & & $x x$ & \\
\hline
\end{tabular}


The results of the reliability and validity studies suggested that the comprehensive approach measured the different competencies developing in CBE. The approach seems to give a fair indication of the whole spectrum of competencies acquired. This finding makes informed-decisionmaking possible regarding both students and the programme. For instance, some students may display high achievement on the total score, combined with poor achievement on one of the competencies essential in CBE, leadership, for instance. In this case, a special programme will be developed for these students to help them overcome this weakness. On the other hand, one may find average students with an outstanding performance on some competencies, for instance, problem solving, communication and community interaction skills. Such group may be helpful in assisting staff in organization of $\mathrm{CBE}$ and in the tutoring of junior students, and also can be targeted as future leaders of health services in the country.

The measurement of the different competencies and the intensive follow up to correct weaknesses makes it difficult for students to fail for these courses. In addition, the comprehensive approach enables students to compensate poor performance in one measure with high performance on another. This may be one of the reasons behind the fact that students tend to score higher marks in CBE courses compared to the rest of curriculum as shown in a recent review of examination performance at the FMUG (Abdel-Hameed, 1993). It is interesting to note, from the same review, that there are no significant differences between the performance of females and males students in $\mathrm{CBE}$ course. Community-based education requires community interaction, communication and leadership skills, skills on which females are expected to perform significantly lower particulary in the Arab culture dominant in the area where $\mathrm{CBE}$, as presented here, is conducted. It seems that the learning and assessment methods going on these programmes help female students to match their performance to those of their male peers despite these cultural barriers.

These findings presented in this article have accumulated following fifteen years of experience, during which fourteen batches of students have covered 140 villages for three years each. The assessment model has been greatly improved when graduates of Gezira joined the school as staff. As students they had experienced the pressing problems caused by assessment. Being staff members put them in good position to do something about these problems.

In conclusion, this study advocates a comprehensive approach to student assessment in community settings, using different sources, to assess the different competencies, essential for CBE. The approach tested has been 
shown to be reliable, reasonably valid and has several advantages over the conventional approach. It may be a useful alternative for existing methods of assessment of students and programmes in CBE. 
Abdel-Hameed A.A. (1993). A review of examination performance in the Faculty of Medicine, University of Gezira. Annals of Community-oriented Education, Vol. 6, 291-300.

Bentler P.M. (1989) EQS: Structural Equations Program Manual. Los Anglos, CA: BMDP Statistical Software Inc.

Des Marchais J.E., Dumais B. \& Allard J. Community clinical immersion in first year student and programme evaluation. Paper presented at the International Symposium of Student Assessment (with special emphasis on assessment in community settings) Malaysia, January 10-15 1993. The Network of Community-Oriented Educational Institutions for Health Sciences, Maastricht, The Netherlands.

Frederickson K., Knox J.D.E. (1984). The real test item bias. American Psychologist, 39, 193-202.

Fulop T. (1976). New approaches to a permanent problem. WHO Chronicle, 30, 443441.

Hassan F., Ezzat E. Faris R. \& Fam R. (1993). The development of a valid student assessment system in community-based medical schools: In Bouhuijs P., Schmidt H.G. \& Van Berkel H. J. M. (Eds.) Problem-based learning as an educational strategy, Maastricht, The Netherlands: Network Publications.

Hassan M.H.M. Community and family study programme at the Universiti Sains Malaysia: An experience in peer assessment in the fourth and final year. Paper presented at the International Symposium of Student Assessment (with special emphasis on assessment in community settings) Malaysia, January 10-15 1993. The Network of Community-Oriented Educational Institutions for Health Sciences, Maastricht, The Netherlands.

Jinadu M.K. \& Davies-Adetugbo A. (1992). Ife experience in community-based education for health professionals. Annals of Community-Oriented Education, 5, 5560.

Kantrowitz M., Kaufman A., Menin s., Fulop T., \& Gilbert, J.J. (1987). Innovative tracks at established institutions for the education of health personnel. An experimental approach to change relevant to health needs. WHO offset publications No. 101 Geneva, Switzerland: World Health Organization.

Magzoub M.E.M.A., Abdel-Hameed A.A. \& Ahmed B.O., Assessing group work in community-based learning. Paper presented at the International Symposium of Student Assessment (with special emphasis on assessment in community settings) Malaysia, January 10-15 1993. The Network of Community-Oriented Educational Institutions for Health Sciences, Maastricht, The Netherlands.

Magzoub M.M.A., Schmidt H.G., Mustafa S.E., (1994). A Comprehensive approach to student assessment in community settings, (1) Description of methods. Submitted for publications.

Manalo A.H. Assessment of second year students doing community medicine work in a selected community. Paper presented at the International Symposium of Student Assessment (with special emphasis on assessment in community settings) Malaysia, January 10-15 1993. The Network of Community-Oriented Educational Institutions for Health Sciences, Maastricht, The Netherlands.

Morales-Samaneigo I. Students perception of peer evaluation as an assessment tool in communin activities. Paper presented at the International Symposium of Student 
Assessment (with special emphasis on assessment in community settings) Malaysia, January 10-15 1993. The Network of Community-Oriented Educational Institutions for Health Sciences, Maastricht, The Netherlands.

Neufeld V.R. The design and use of assessment methods for problem-based leaming: In Schmidt H. G. De Volder M. L. (Eds.) Tutorials in problem-based learning: A new direction in teaching the health profession. Van Gorcum, Assen/Maastricht, 1984.

Newble, D. \& Swanson, D. (1988). Psychometric characteristics of the objective structured clinical examination. Medical Education, 22, 325-34.

Norman G.R., Smith E.K.M, Powles A.C.P., Booney P.J., Henry N.L. \& Dodd P.E. (1987). Factors underlying performance in written test of knowledge, Medical Education, 21, 297-304.

Richards R., Fulop T., Bannerman J., Greenholm G., Guilbert j.j. \& Wunderlich M. (1987). Innovative schools for health personnel. Report of ten schools belonging to the Network of Community-Oriented Educational Institutions for Health Sciences. WHO Offset Publication No. 102. Geneva, Switzerland: World Health Organization. Saris W.E., and Stronkhorst L.K. (1984). Causal modelling in nonexperimental research. Amsterdam, The Netherlands: Sociometric Research Foundation

Schmidt H.G., Neufeld V.R., Nooman Z.M., Ogunbode T. (1991). Network of Community-Oriented Educational Institutions for Health Sciences. Academic Medicine, 66, 259-263. 



\section{6}

\section{Assessing Students in Community Settings: The Role of Peer Evaluation}

\section{Abstract}

The assessment of students in community settings faces its own difficulties. Since students are usually posted in small groups in different community settings and since the learning (largely) takes place outside the classroom, assessing student performance becomes an intrinsically complex endeavour. In this article, the proposition is made and tested that peers may be used to assess particular aspects of performance, in particular those which need long and close observation. Examples are: Effort displayed while working in a community, quality of the interaction with that community, display of leadership and subject-matter contributions.

The Faculty of Medicine of the University of Gezira, a community-based medical school, uses peer evaluation to assess these attributes of its students. Three groups of students participated in the present study, totalling 34 students. Goals of the study were to appraise the reliability, validity and acceptability of an instrument designed to measure these characteristics. Reliability was estimated using generalizability theory. A high generalizability coefficient $(\mathrm{G})$ was found when all items were taken into account. In this case, $\mathrm{G}$ equalled 0.97 . Its subscale each had also fairly high G-coefficients: Effort:0.89, Subject-matter contribution: 0.91, Community Interaction: 0.91 , and Leadership: 0.88 respectively. The validity of the instrument was studied using confirmatory factor analysis. The results suggested that the proposed model of peer evaluation is reasonably valid. Finally, the instrument turned out to be quite acceptable to students. 


\section{Introduction}

In the past ten years, a growing number of health institutions have adopted community-oriented, community-based education as a strategy for learning and instruction (Schmidt et al, 1991). Community-based education is defined as a set of instructional activities that uses the community extensively as a learning environment. The community involved may be suburban or rural (Report of WHO Study Group, 1987). A characteristic unique to community-based education (CBE) is that learning inherently takes place outside the class or the university campus. This feature, of course, limits teacher control over leaming and, particularly over student assessment. Because learning in the community partly depends on opportunities that spontaneous arise while being on location, instruction is difficult to plan. In addition, this type of learning often requires that students work in small groups and are posted in different communities. Under these circumstances assessment becomes a formidable task, since it is almost impossible to maintain common standards against which student performance is to be judged. The fact that most community-based programmes aim at fostering the development of high-level skills such as communication skills, leadership qualities and managerial skills, even further complicates the assessment issue, since these skills are not easily assessed through standard procedures. Assessing these skills requires a multi-source approach and probably the involvement of many raters, making student assessment in the community almost impossible to carry out.

The development of relevant methods for student assessment in community settings is a challenge for all institutions adopting CBE, because irrelevant assessment methods will reflect directly on students attitudes towards CBE. Because assessment drives the learning to a large extent, irrelevant assessment will direct students to the pursuit of learning activities that may be irrelevant to the goals of CBE. To solve this problem, different approaches and instruments have been proposed. In general, two main approaches to student assessment in community settings can be distinguished. The most common approach used is measuring student performance on tests at the end of the CBE learning activity. These tests involve instruments measuring knowledge gains or staff judgements regarding student reports of their learning, or both (Jinadu, 1992; Omatara, 1992). The second, less prevalent, approach, is assessment of students during the process of learning. Various instruments have been suggested, among them logbooks (Des Marchais, 1993; Manalo, 1993), supervisory visits (Bollag et al; 1982; Magzoub, 1993) and peer assessment (Hassan, 1993; Morales-Samaneago, 1993). An advantage of the latter, process-oriented approach is that assessment is continuous. Therefore, it is 
helpful for informed decision-making and feedback to students; it happens to be less stressful for students and can more easily tailored to cover the course objectives.

Among the process-oriented methods, peer evaluation has a special attraction for community-based education. As students are working and living together for quite a some time in the community, they are in a good position to judge each other's contributions and the extent of their peer's learning. There are several other advantages of this approach reported in the literature. De Grave and De Volder (1985) suggest that the advantages of peer evaluation over more conventional, paper-and-pencil-based methods are most clear in the areas of in skills acquisition and attitude leaming. Peer evaluation is best suited for the evaluation of humanistic qualities, such as integrity, compassion, respect. and the ability to build and maintain interpersonal relations (Jennet et al, 1990). Presently, three methods of peer assessment are distinguished: Peer nomination. peer ranking and peer rating (Kane \& Lawler, 1978). In peer nomination. each group member is asked to nominate a specified number of group members as being the highest or, alternatively, lowest in the group on a particular characteristics or dimension of performance. In peer ranking, each group member ranks all of the others from best to worst on one or more factors. In peer rating, finally, each group member rates each other group member on a given set of behaviours, using anyone of several kinds of rating scales. Peer rating has several advantages over the other methods, it is most useful for feedback purposes since it considers each individual member in the group in his own right without forcing the judge to rank-order subjects. The disadvantage of peer rating, however, is its potentially low reliability and validity compared to the two other methods of peer assessment (Love, 1981).

For peer assessment to be successful, Kane and Lawler (1978) suggested that three conditions should be met: l) Peers should be in a position to observe unique aspects of each other's behaviours; 2) Peers should be capable of accurately perceiving and interpreting the salient aspects of each other's behaviours; 3) There should be a perceived need to improve the effectiveness with which the characteristics of group members are assessed.

The Faculty of Medicine. Gezira University, Wad Medani, the Sudan, is a community-based, community-oriented school that sends students for posting in rural areas on a regular basis. The students are assigned villages and work in small groups in their selected villages. The students stay in rural areas for periods ranging from one week up to one month. The school, therefore, faces the difficulties in assessing students mentioned earlier. This applies in particular to interaction skills, which require continuous and intimate observation. In order to deal with this problem, the school decided 
to experiment with peer evaluation, using the peer rating method, as part of a multi-source assessment program. The objective of this paper is to report on a series of studies examining the reliability, validity and acceptability of peer assessment as an instrument in assessing students in community settings.

\section{Method}

\section{Instrument}

Following a discussion with tutors and students, it was felt that students were in a better position compared to tutors to evaluate each other on four factors of interest. Each of these factors needs continuous and intimate observation. Consequently, a peer evaluation rating scale was developed which included those four factors. The four factors were: (l) Effort: 8 items, reflecting the input of students in the different activities carried out during this course. (2) Community Interaction: 6 items, reflecting the students' ability to communicate with the community to facilitate data collection and consent to advice. This skill is considered to be important for the future work of a physician and for developing a doctor-patient-community relationship. (3) Leadership: 4 items were developed, reflecting aspects such as leading a group discussion, decision making and division of labour. This is a very important skill for doctors in the Sudan, because they will act as health team leaders when they are assigned to work in rural hospitals. Objective assessment of this important skill is essential if one wishes to graduate doctors who are able to respond to community health needs. (4) Use of Subject matter Knowledge: 4 items, reflecting the student's ability to utilize his gained knowledge to help the group progress towards the course objectives. The items comprising the rating scale can be found in Table 1.

\section{Subjects and procedure}

Three groups of University of Gezira students participated in this study. The first group included 12 students and the second group composed of 11 students, and the third group consisted of 11 students. The rating scale was administered following their rural field training. Students were asked to rate each other on a six-point scale, where 0 represented strong disagreement with the statement and 5 strong agreement. Ratings conducted by 8 raters for each student, were included in the study, because the statistical analysis required equal numbers of judgements per group. 
Items included in the peer evaluation rating scale. Mean scores standard deviations (SD) for each item. $N=272$

Mean

SD

Factor (1): Peer evaluation of effort

$\begin{array}{llll}\text { 1. Contribution to the design of forms for data collection } & 4.23 & 0.95\end{array}$

2. Contribution to data collection in the village

$4.47 \quad 0.76$

3. Participation in the assigned activities in the village

$4.01 \quad 1.14$

4. Problem identification

$3.96 \quad 1.21$

5. Participation in report writing

6. Contribution to the group activities concerning, living, accommodation and housing in the village

7. Participation in preparation for the group seminar

8. Physical attendance in announced group activities

$4.17 \quad 1.16$

\section{Factor (2): Peer evaluation of community interaction}

9. The terminology used by the student was understandable to the community members

10. He was always responding to community members' questions in a clear way

11. He is a good listener to community problems

12. His advice and suggestions seem to convince the community

13. He was frequently present in the community

14. He was able to befriend community members

\section{Factor (3): Peer evaluation of leadership}

15. He was able to contact community leaders

16. He was a good leader of group discussion

17. He was able to divide labour equaliy among group members

18. He is a good decision maker

\section{Factor (4): Peer evaluation of subject-matter contribution}

19. He gave useful information to the group

20. His suggestions and thoughts were helpful to the group's work

21 He formulated good questions

22. He made used of references and resources 


\section{Analyses}

Roliubility studr. Generalizability studies were conducted to estimate the instrument's reliability. One of the advantages of this approach over classical test theory is that it recognizes multiple sources of variability, such as differences among students, item differences and inter-rater differences, instead of only one single undifferentiated error component (Brennan \& Kane, 1979). The object of measurement in this study is students, since the main purpose of assessment in the educational context described is to discriminate between students on the four dimensions measured by the rating scale. Therefore, the largest source of variance is expected to be among students. Both the student and the item sample are treated as "random" since they are both considered to be exchangeable with any other sample of the same size drawn from an imaginary universe (Shavelson \& Webb, 1991). According to generalizability theory, this design is a two-facet design; items and students are considered to be the two facets. This design has five sources of variability: (1) differences between students (S), (2) differences in "item difficulties" (I), (3) differences between raters nested within students (inter-rater differences) (R:S), (4) interaction between students and items (SI), and (5) differences arising both from items crossed with raters within students and from error effects or unidentified events (IR:S,e). Generalizability studies were conducted for the total list and for the separate factors using item scores. The generalizability coefficient is estimated by means of the fraction between the true variance or variance caused by the object of measurement and the true variance plus error variance. The error variance in this study is composed of raters nested within students, the student-by-item interaction, items-by-raterswithin-students interaction and random events. In other words, because differences among students were the topic of interest, only processes influencing the ordering of students are considered as true variance.

Validity study. A confirmatory factor analysis was carried out to assess the adequacy of the latent variables, or factors, underlying the rating scale described above. In the confirmatory factor model as applied in this study, all common factors are correlated, observed variables 1 through 8 are considered to be affected by the first common factor (Effort), observed variables 9 to 14 are affected by the second common factor (Community Interaction), 14 to 18 are affected by the third common factor (Leadership), and the last four items are affected by the fourth common factor (Subject-matter Contribution). Furthermore, all observed variables are assumed to be affected by a unique factor (error), and no pairs of unique 
factors are correlated. The Lisrel VII programme (Joreskog \& Sorborn, 1990) was used to determine whether the data confirmed this model.

Acceptability. Students were interviewed to find out to what extent they accepted the method, whether it was interfering with their activities, and whether they judged it as a valid method of assessment.

\section{Results}

Table 2

Descriptive statistics for each factor

\begin{tabular}{lcccccc}
\hline Factor & $\begin{array}{l}\mathrm{N} \\
\text { items }\end{array}$ & Mean & SD & $\begin{array}{l}\text { Mini } \\
\text { value }\end{array}$ & $\begin{array}{l}\text { Maxi } \\
\text { value }\end{array}$ & $\mathrm{N}$ \\
\hline Effort & 8 & 3.97 & 0.90 & 0.38 & 5.00 & 272 \\
$\begin{array}{l}\text { Community interaction } \\
\begin{array}{l}\text { Leadership } \\
\text { Subject-matter }\end{array}\end{array}$ & 6 & 3.83 & 0.86 & 1.00 & 5.00 & 272 \\
contribution & 4 & 3.52 & 0.97 & 0.25 & 5.00 & 272 \\
Total & 4 & 3.60 & 0.95 & 0.00 & 5.00 & 272 \\
\hline
\end{tabular}

Table 3

Results from G-study for the total list of 22 items (Two-facet Design)

\begin{tabular}{lrrrr}
\hline Source & DF & $\begin{array}{r}\text { Estimated } \\
\text { variance } \\
\text { component }\end{array}$ & $\begin{array}{r}\text { Standard } \\
\text { error }\end{array}$ & $\begin{array}{r}\text { Percentage } \\
\text { of total } \\
\text { variance }\end{array}$ \\
\hline $\begin{array}{l}\text { Students (S) } \\
\text { Items (I) }\end{array}$ & 33 & 0.4435 & 0.1090 & 34.3 \\
Raters within students & 21 & 0.0175 & 0.0078 & 1.4 \\
(R:S) & 238 & 0.0000 & 0.0018 & 0 \\
Student by items (SI) & 693 & 0.2258 & 0.0162 & 17.5 \\
IR:S & 4998 & 0.6058 & 0.0122 & 46.9 \\
\hline
\end{tabular}


Reliability. Table 2 contains the descriptive statistics for each factor, notably means and standard deviations. In Table 3 the sources of variability are summarized for the total list of 22 items. The first source of variance in this table involves students (S), the second source involves items (I), the third source involves raters nested within students(R:S). Other sources listed in this table are the interaction effect between students and items (SI) and the interaction between items on the one hand and raters nested within students on the other (IR:S). The estimated variance component for the student source reflects the magnitude of error in generalizing from one student score to the universe of student scores. The standard error indicates the accuracy of the estimated variance component. The standard error is relatively high, due to the relatively small sample size of students (34) and items (22). As can be seen in the last column of Table 3, the percentage of variance associated with students is 34.3 . This percentage represents the true variance or variance of interest. This percentage is much higher than the percentage of variance for items, which is 1.4. The largest effect, however, is caused by the interaction effect of items by raters within students, and the error effect (46.9 percent). The interaction effect, indicates that the relative standing of students changes from item to item. In other words, students are rank-ordered differently by items.

The generalizability coefficient (or G-coefficient) was found to be 0.97 , which estimates the correlation between student scores on this rating scales and any other randomly selected scale of items and raters measuring the four factors. The G-coefficients for separate factors using item scores are summarized in Table 4

Table 4

G. coefficients and standard errors of measurement (SEM) for the total score and for separate factors using item scores.

Factor

G-coefficient

SEM

Peer evaluation of effort

$\begin{array}{ll}0.895 & 0.2515 \\ 0.887 & 0.2097 \\ 0.881 & 0.2471 \\ 0.910 & 0.2300\end{array}$

Total

0.970

0.1139 
These results show that the G-coefficients for all factors are well above 0.80 ., indicating excellent generalizability both across items and across students. Table 4 also contains the standard error of measurement that correspond with each G-coefficient. The standard error of measurement (SEM) also provides information regarding the reliability of the peer evaluation instrument. The SEM can be used to estimate confidence intervals for individual scores. For example, the 95 percent confidence interval can be computed by multiplying the SEM by 1.96. Taken into account that at least a difference of 0.5 on the rating scale is required to attain practically significant differences between scores, the SEM should be lower than or equal to $0.26(0.5 / 1.96)$. This is true for all factors. Table 5 displays correlation coefficients between the four scales, which are fairly high suggesting that the factors involved are interdependent.

Table 5

Correlation between different factors of peer assessment

Effort

Interaction

Leadership

Subject-matter

Effort

Interaction

Leadership

0.769

$\begin{array}{ll}0.606 & 0.609\end{array}$

0.889

0.709

0.616

All coefficient are significantly different from zero; $p<0.001$

Tables 6 to 9 show the sources of variation for the factors separately. The largest source of variation for most factors is the error component.

Table 6

Results from G-study for effort (Two-facet Design)

\begin{tabular}{lrrrr} 
Source & DF & $\begin{array}{r}\text { Estimated } \\
\text { variance } \\
\text { component }\end{array}$ & $\begin{array}{r}\text { Standard } \\
\text { епror }\end{array}$ & $\begin{array}{r}\text { Percentage } \\
\text { of total } \\
\text { variance }\end{array}$ \\
\hline $\begin{array}{l}\text { Students (S) } \\
\text { Items (I) }\end{array}$ & 33 & 0.5375 & 0.1436 & 38.5 \\
Raters within students & 7 & 0.0000 & 0.0009 & 0.0 \\
(R:S) & 238 & 0.2409 & 0.0266 & 17.3 \\
Student by items (SI) & 231 & 0.2151 & 0.0246 & 15.4 \\
IR:S & 1666 & 0.4021 & 0.0139 & 28.8 \\
\hline
\end{tabular}


Results from G-study for community interaction (Two-facet Design)

\begin{tabular}{lrrrr} 
Source & DF & $\begin{array}{r}\text { Estimated } \\
\text { variance } \\
\text { component }\end{array}$ & $\begin{array}{r}\text { Standard } \\
\text { error }\end{array}$ & $\begin{array}{r}\text { Percentage } \\
\text { of total } \\
\text { variance }\end{array}$ \\
\hline Students (S) & 33 & 0.3475 & 0.0929 & 30.5 \\
Items (I) & 5 & 0.0080 & 0.0046 & 0.0 \\
Raters within students & 238 & 0.0000 & 0.0280 & 0.0 \\
(R:S) & 165 & 0.1883 & 0.0290 & 16.5 \\
Student by items (SI) & 1190 & 0.6040 & 0.0247 & 52.6 \\
IR:S & & & & \\
\hline
\end{tabular}

Table 8

Results from G-study for leadership (Two-facet Design)

\begin{tabular}{lrrrr}
\hline Source & DF & $\begin{array}{r}\text { Estimated } \\
\text { variance } \\
\text { component }\end{array}$ & $\begin{array}{r}\text { Standard } \\
\text { error }\end{array}$ & $\begin{array}{r}\text { Percentage } \\
\text { of total } \\
\text { variance }\end{array}$ \\
\hline Students (S) & 33 & 0.4509 & 0.1226 & 37.4 \\
Items (I) & 3 & 0.0133 & 0.0127 & 0.1 \\
Raters within students & 238 & 0.0266 & 0.0167 & 2.2 \\
(R:S) & 99 & 0.1662 & 0.0326 & 13.4 \\
Student by items (SI) & 714 & 0.5526 & 0.0292 & 45.9 \\
IR:S & & & & \\
\hline
\end{tabular}

Table 9

Results from G-study for subject-matter contribution (Two-facet Design)

\begin{tabular}{lrrrr} 
Source & DF & $\begin{array}{r}\text { Estimated } \\
\text { variance } \\
\text { component }\end{array}$ & $\begin{array}{r}\text { Standard } \\
\text { error }\end{array}$ & $\begin{array}{r}\text { Percentage } \\
\text { of total } \\
\text { variance }\end{array}$ \\
\hline $\begin{array}{l}\text { Students (S) } \\
\text { Items (I) }\end{array}$ & 33 & 0.5374 & 0.1413 & 43.3 \\
Raters within students & 3 & 0.0000 & 0.0043 & 0.0 \\
(R:S) & 238 & 0.0350 & 0.0171 & 2.8 \\
Student by items (SI) & 99 & 0.1254 & 0.0274 & 10.1 \\
IR:S & 714 & 0.5427 & 0.0286 & 43.7 \\
\hline
\end{tabular}


Validity: A validity study was performed using confirmatory factor analysis. The correlation coefficients between the observed variables vary between 0.31 and 0.78 for Effort, 0.49 to 0.80 for Community Interaction, 0.66 to 0.77 for Leadership and 0.59 to 0.78 for Knowledge Use. The correlations between the four common factors varied between 0.61 to 0.89 as shown in Table 5. Although these coefficients are relatively high, a one-factor model did not fit the data. A model is assumed to fit the data if three conditions are met: (l) The Chi square divided by the degrees of freedom is lower than 2 , a p-value higher than zero, (2) the root mean square residual is lower than 0.07 , and (3) the goodness-of-fit index and the adjusted goodness-of-fit index, that takes into account the number of degrees of freedom, is higher than 0.80 (Saris \& Stronkhorst. 1984). A four-factor model in which observed variables 1 to 8 are affected by the first common factor, observed variables 9 through 14 are affected by the second common factor, observed variables 15 to 18 are affected by the third common factor, observed variables 19 to 22 are affected by the fourth common factor differed significantly from the data (Chi-square [ $\mathrm{df}=203$ ] $=472.14, \mathrm{p}=0.00$ ) . The root mean square residual was 0.053 , the goodness-of-fit-index and the adjusted goodness-of-fit-index were respectively, 0.79 and 0.74 . These results suggest that the first condition specified by Saris and Stronkhorst (1984) is not met, the second condition is met and the third condition is also not met, although the actual findings do not deviate far from the minimally acceptable level.

The results of this analysis are graphically presented in Figure 1. Interestingly, a second-order model factor analysis on the correlation matrix of the scale averages revealed an underlying two-factor model that fitted very well: Chi-square $=0.779, \mathrm{df}=1, \mathrm{p}=0.37$, with a goodness-of-fit index of 1.00. This indicates that two correlated latent factors underlie the rating scale as a whole: one explaining the interaction-oriented behaviours and one explaining the effort and subject-matter input behaviours. Nevertheless we prefer to take as the basic measurement model the less well fitting four factor solution. This preference is based on our conviction that these factors should be distinguished for training and assessment purposes. Community interaction and leadership may refer to a similar deeper endogenous trait in students, they should however be distinguished for the sake of training and assessment because they refer to quite distinguished "surface" behaviour that should be trained and assessed separately. If you skip one for the other you take the risk that students would not any longer engage in the relevant behaviours. 


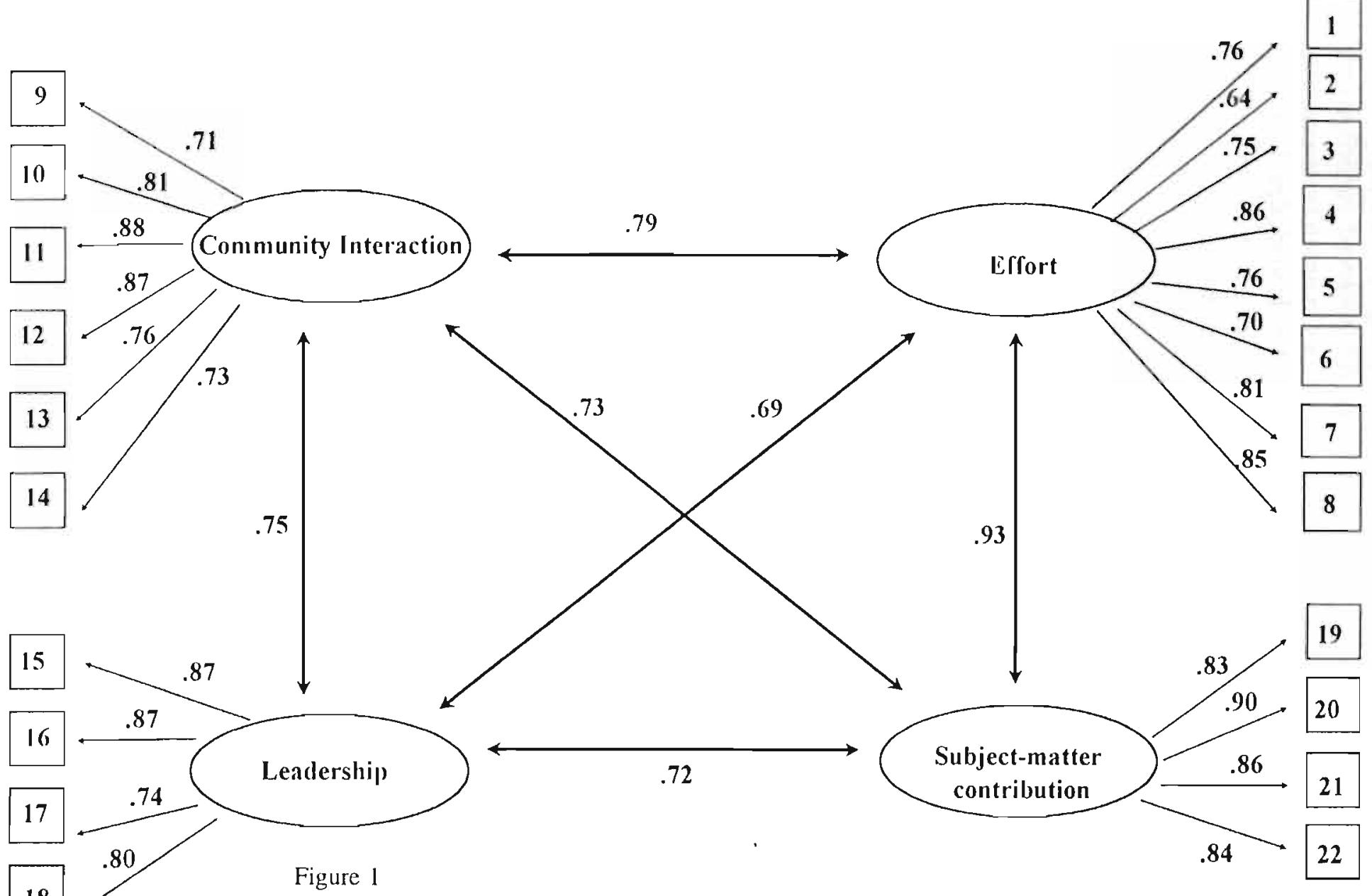

Lisrel estimates of the confirmatory factor analysis of peer assessment.

Latent factors are displayed in elleptic circles; measured variables in square boxes. 
Acceptability. The acceptability interview, revealed that the method was quite acceptable to students. A large majority felt that the instrument measured important characteristics of future physicians. In addition, the students thought that having to judge peers did not interfere with group-related activities. The students proposed the faculty to include peer evaluation in the array of assessment procedures routinely applied at the University of Gezira.

\section{Discussion}

The results of the present study suggest that students are generally able to rate each other reliably, in particular when all items were taken together to generate one index for community-related skills. The G-coefficient found indicates that the findings can be generalized to both other students under similar circumstances and other items measuring the same concepts. The variability among the objects of interest, the students, was sufficiently large compared to other sources of variation to warrant the conclusion that the instrument, taken as a whole, reliably discriminates between subjects of different levels of competence.

As shown in the confirmatory factor analysis, two second-order latent factors underlie the data: one explaining differences in interaction behaviours and one related to effort and subject-matter contributions. We were somewhat surprised to see that subscales in both domains were equally well able to differentiate between students. We expected that cultural influences would moderate the way Sudanese students perceive each other's interpersonal skills. In the Arab culture, dominant in the area in which the present study was done, there is strong emphasis on quality in interpersonal matters. Every member of a group is considered to be contributing to the groups well-being to the same extent and leadership is considered more a collective than an individual good. Therefore, one would expect the interaction subscales to have lower generalizability. In addition, the students involved did not have much experience with evaluating their peers on the attributes on question. It was expected that students become better able to judge their peers reliably only if they have sufficient opportunities to observe and rate their colleagues. Calhoun et al (1990), for instance, showed that senior medical students become more "expert-like" in their peer evaluations in the course of a clerkship.

On the other hand do students accumulate other experiences apart from this particular posting. To judge their peers. as all students are fully boarded and they participate in many voluntary community-based activities through their student organizations almost every other weekend. This may add to the explanation why these students were so good at judging each other. 
It is interesting to note here that our good reliability findings are comparable with most peer-rating studies, and comparable with the best three studies discussed in a recent review by Goldman (1992). In addition, it seems that the measurement procedure fulfil the three criteria for successful use of peer assessment suggested by Kane and Lawler (1978) and mentioned in the introduction to this article. It is, however, clear that attempts should be made to improve on the reliability of the Community-interaction and Leadership scales, if only because they are by no means conceptually less important than the Effort and Subject-matter-contributions subscales. One way of doing this is increasing the number of items measuring the factors in question.

The validity of the model met only one of the three conditions required for the fit of the data. Skipping a few items, notably items 13 and 14 regarding the students presence in the community and the students' ability to befriend community members, did not improve the model's fit. However, skipping these items would be detrimental to the content validity of the instrument. Item 13 is an operationalisation of interaction with the community as indexed by the duration of time spent with community, while the latter is a measure of the outcome of the interaction in the form of increased friendship with community members. The building of friendships is considered an important factor in breaking the barriers between students and the community and, hence, is instrumental in attaining the objectives of learning in and from the community.

Taking into account the above mentioned limitation to the model's fit, the difficulty of measuring the particular behaviours and the fact that this is a first attempt to measure these concepts in a particular student population, the four factor model should be considered as reasonable first approximation to the data. A small sample size may have contributed to a limited fit in addition, a limited sample size may have contributed to a less than satisfactorily fit.

The resulting scores were used as part of a multi-source assessment of student's performance in community-based education. Peer evaluation contributed 10 percent of the total mark given in this course. Other sources included a final report and a written test. In addition, the results were used for formative evaluation. As indicated by the generally low SEM's, the instrument was found to be sufficiently sensitive to distinguish between extremely poor and excellent students. Results of the assessment were immediately communicated to the students and the poor students were advised to improve on their performance. The best students were rewarded. A number of students were performing well in all academic courses as well as on three of the four measures reported here. The exception was Leadership. It should be noted that this is an important skill for future 
doctors in Sudan, because, as has been stated, the student's effectiveness as leader of a health team will depend on this skill. Therefore, a special programme has been developed for these students to help them acquire leadership skills.

Acceptability of the method by students, is a prerequisite for including it in the arsenal of approaches available for assessors. In addition, peer assessment should not interfere with group activities and should not influence the atmosphere in the student team. Team work and group cohesion are vital in community-based education. Interestingly, studies conducted to test the acceptability of the method show contradictory findings. Fenn et al (1993), Epstein (1993), Morales Saminigo (1993), Hassan (1993) and Erickson (1990) found the method to be quite acceptable to students. On the other hand, studies in problem-based learning (Geerligs, 1993) and in a residency programme (Jennet et al, 1990) report that students find the method unacceptable. At the University of Gezira, the students initiated in fact the application of this instrument. They felt that giving equal grades for all group members was not fair. As a result, the idea of using peer evaluation evolved during discussions between tutors and students.

In conclusion, this study can be considered a first successful attempt to measure important skills needed for work in the community settings, that cannot be measured otherwise. The rating scale developed has high reliability and fair validity and its development can be considered a pioneer effort in a field that is still in its infancy. 
Brennan, R.L. \& Kane, M.T. (1979). Generalizability Theon: A Review. New Directions for Testing and Measurement, 4, 33-51.

Crick, JE. and Brennan, R.L. (1983). Manual for Genova: A Generalized Analysis of Variance System. Iowa: American College Testing Program.

De Grave W., De Volder M., (1984). Peer evaluation and problem-based learning In H. G. Schmidt, \& M.L. De Volder (Eds.), Tutorials in Problem-based Learning, Van Gorcum: Assen, The Netherlands.

Des Marchais J.E., Dumais B. \& Allard J. Community clinical immersion in first year student and programme evaluation. Paper presented at the International Symposium on Student assessment (with special emphasis on assessment in community settings). Malaysia, January 10-15, 1993. The Network of Community-Oriented Educational Institutions for Health Sciences, Maastricht, The Netherlands.

Epstein L. C.\& Northrub R. S. The student's role in Assessment: Building a progression in problem-based learning (PBL). Paper presented at the International Symposium on Student assessment (with special emphasis on assessment in community settings). Malaysia, January 10-15, 1993. The Network of Community-Oriented Educational Institutions for Health Sciences, Maastricht, The Netherlands

Erickson G. P., Peer evaluation as a teaching-leaming strategy in baccalaureate education for community health nursing. Journal of Nursing Education for Community Health Nursing. 26, 204-206.

Fenn J. Aurona T., Natu S., Singh T., Natu M. V. \& Zachariah A. Peer assessment of interpersonal Behaviour and its psychological impact. Paper presented to the International Symposium on Student assessment (with special emphasis on assessment in community settings). Malaysia, January 10-15, 1993. The Network of Community-Oriented Educational Institutions for Health Sciences, Maastricht, The Netherlands.

Ferguson, G.A. (1981). Statistical Analysis in Psychology and Education (5th ed.). Auckland: McGraw-Hill.

Galhoun G. J. \& Ten Haken D. J. (1990). Medical students' development of self-and peer-assessment skills A longitudinal study. Teaching and Learning in Medicine, 2, No. 1. 25-29.

Geerligs T. Experience with peer assessment at the Faculty of Health Sciences, University of Limburg. The netherlands. Paper presented to the International Symposium on Student assessment (with special emphasis on assessment in community settings). Malaysia, January 10-15, 1993. The Network of Community-Oriented Educational Institutions for Health Sciences, Maastricht, The Netherlands.

Goldman R.L. (1992). The reliability of peer assessments of quality of care. Journal of the American Medical Association, 267, No. 7, 958-960.

Hassan M.H.M. Community and Family study programme at the Universiti Sains Malavia: An experience in peer assessment in the fourth and final year. Paper presented at the International Symposium on Student assessment (with special emphasis on assessment in community settings). Malaysia January 10-15, 1993. 
The Network of Community-Oriented Educational Institutions for Health Sciences, Maastricht, The Netherlands.

Jennet P.A, Van Rosendaal G.M.A., Lockyer J.M., McDougall G.M., Hunter K. E., \& Schachar N. S. (1990). Peer evaluation in Residency programs, In Bender W., Heimstra, R. J. Scherpheir A. J. J. A., Zwierstre R. P. (Eds). Teaching and Assessing Clinical Competence, Groningen Boekwerk Publications.

Jinadu M.K. \& Davies-Adetugbo A. (1992). If experience in community-based education for health professionals. Annals of Community-Oriented Education, 5, 55-60. Joreskog, K.G., \& Sorbom, D. (1990). Lisrel VII. User's Guide. Chicago: National Educational Resources.

Kane, J.S. \& Lawler. E.E. (1978). Methods of peer assessment. Psychological Bulletin, $85,555-586$.

Love K.G., (1981). Comparison of Peer Assessment Methods: Reliability, Validity, Friendship bias, and user reaction. Journal of applied psychology, 66, No 4, 451-457.

Magzoub M.E.M.A.. Abdelhameed A.A. \& Ahmed B.A. Assessing group work in community-based learning. Paper presented at the International Symposium on Students assessment. Malaysia, January 10-15, 1993. The Network of Community Oriented Educational Institutions for Health Sciences, Maastricht, The Netherlands.

Manalo A.H. Assessment of second year students doing community medicine work in a selected community. Paper presented at the International Symposium on Student assessment (with special emphasis on assessment in community settings). Malaysia, January 10-15, 1993. The Network of Community Oriented Educational Institutions for Health Sciences,Maastricht, The Netherlands.

Morales-Samaneigo I. Students perception of peer evaluation as an assessment tool in community activities. Paper presented at the Intemational Symposium on Student assessment (with special emphasis on assessment in community settings). Malaysia, January 10-15, 1993. The Network of Community-Oriented Educational Institutions for Health Sciences, Maastricht, The Netherlands.

Omatara B. A., Padonu M. K. 0., Passi A. P., Amodu M. 0. (1992). Community-based medical education: The university of Maiduguri experience. Annals of Community-oriented Education, 5, 41-46.

Saris, W. \& Stronkhorst, H. (1984). Causal modelling in non experimental research. Amsterdam, The Netherlands: Sociometric Research Foundation.

Schmidt H. G., Neufeld V. R., Nooman M. Z. \& Ogunbode T. (1991). Network for Community-oriented Educational Institutions for the Health Sciences. Academic Medicine, 66, No. 5, 259-263.

Shavelson, R.J. \& Webb, N.M. (1991). Generalizability Theory. A Primer. London: Sage.

Williams E. (1992). Student attitudes towards approaches to learning and assessment. Assessment and Evaluation in Higher Education, 17, 45-581 
. 


\title{
The Impact of a Community-based Programme on the Community
}

\begin{abstract}
Assessing the impact of community-based education (CBE) is very important both for improving decision making concerning programme improvement and for strengthening the partnership between the organizing university and the community in which the programme is carried out. Unfortunately, the measurement of impact faces serious methodological problems and this may be the reason that, up till now, in the literature no studies are reported in which the impact of a community-based programme on the community is the focus of attention.

The Faculty of Medicine, University of Gezira, Sudan, is a communitybased medical school that sends students on community posting on a regular basis. The school has made a first attempt to measure the effects of its programme on the community. Sixty community leaders were interviewed with regard to their views about the community-based programme of Gezira. The results suggest that the leaders are well aware of the objectives of the programme, consider the Gezira students different from those of other universities, display a positive attitudes towards them and indicate that the presence of the school in the community has provided benefits for the people involved.
\end{abstract}


The following text is an excerpt from a report written by a group of medical students of the Faculty of Medicine University of Gezira, Sudan, as part of their learning during a community posting.

"I.Itamarri village was chosen for us as a site for our field training. The village is located about $35 \mathrm{~km}$ east to the Gezira University main campus. Our first task was to identify the village health and healthrelated problems through community diagnosis.

We designed our investigation procedures for data collection. The procedures developed included questionnaires, interviews, observation instruments, focus group discussion, and anthropometric assessment of the nutritional status of children under five. These procedures were developed with the help of our tutor and senior colleagues. It took us two weeks to collect the data from the village. It was an exciting experience for us to live in the village in the Sheikh's house (The Sheikh was the community leader).

Upon our return to the university campus, we analyzed the data, the village problems were summarized and prioritized according to a number of criteria. including the community perception of the problem, the commonness and the preventability of the problem.

Malnutrition was found to be the top priority problem followed by paediatrics diarrhoea and acute respiratory infection. Six percent of children under five were identified as severely malnourished i.e., less than $60 \%$ of the standard weight for height. Another $25 \%$ displayed mild forms of malnutrition.

We decided to tackle the problem of malnutrition on our next posting through implementation of a nutritional project, which would include therapeutic feeding for the severely malnourished through referral to Omshanig rural hospital. (the nearest hospital to the area), nutrition education programmes for all mothers in the village, and encouragement of families to establish backyard gardens to grow vegetables and raise poultry.

We decided to incorporate our programme in PLAN Sudan, which is a nongovemmental developmental organization working in the same area. PLAN Sudan agreed to offer us transportation to the hospital for the mothers with severely malnourished children. PLAN Sudan also provided vegetable seeds for each family with prepared land as well as chicken for each family with a cage.

We implemented our project through community participation. by encouraging the Sheikh to announce the start, and then by forming a health committee of a group of self-selected mothers. With the help of PLAN Sudan staff and the midwife in the village we trained the mothers to act as trainers for the rest of the women in the village. The programme went off without a hitch, and even in less time than we expected, the planned activities were accomplished. In the last part 
of our community-based course i.e. three years later we evaluated our project, the results showed that the percentage of severe malnutrition, decreased to $3 \%$ and mild malnutrition to $10 \%$.

When we proudly presented our data in the class, one of our tutors noted that, the observed impact, the reduction of the malnutrition percentage, might not be attributed exclusively to our effort. It might be due to other factors including raised socio-economic status, the good harvest during that year which increased food availability, the parallel activities of PLAN Sudan in the area, or a combination of all these factors. At first, this was a very disappointing comment for us. But later, following the review of the literature given to us by our tutor, we learned that the evaluation of health intervention is a problem all over the world. We concluded that we could not be sure that the malnutrition reduction was due to our intervention. But we could be sure that the community and we ourselves were satisfied about our input, and that we learned a lot out of this experience."

This example clearly demonstrates that community-based programmes are opportunities for the university to offer services to the community as well as to realize their primary goal of training professionals. Many communitybased programmes, particularly in developing countries, can be classified as community-based services programme, that provide services through their staff and students. These services are either health intervention, such as curative care in primary care units and preventive activities, e.g., health education and environmental sanitation (Omatara et al, 1992; Jinadu, 1992; Alausa, 1988; Prywes, 1983) or full-fledged community development services through community mobilization (Hamad, 1982; Moses et al, 1990; Nooman et al, 1989). Other community-based programmes are involved in action research to identify problems at the level of health services and the community at large for informed decision making (Magzoub et al, 1992).

One must keep in mind though, that ensuring successful partnership with the community requires active community involvement in all aspects of the programme, including programme evaluation, so that the community feels that the programme is made available to them, rather than being imposed upon them. Unfortunately, not many schools involve the community in the process of programme evaluation.

These activities are all aimed at producing changes in the community. However, the question, then, of course is to what extent these changes contribute to the well-being of these communities. Are the services offered by universities really what the community needs? Are services offered accepted by the community, or do they cause mainly a loss of community time, resources and efforts during the process of learning?

The measurement of the impact of community-based education in the community is important for several reasons. First, demonstrating an impact 
will be reflected on the students enthusiasm as they always feel embarrassed that they are not providing services amounting to what the community offer them. Second, CBE programmes in many universities are supported by external funds. Establishing an impact is helpful in attracting more support for these programmes. Third, measuring impact will help in refining objectives and improving decision making concerning the programme implementation. Finally, and most important, measuring impact will serve as feedback to the community, the latter which is expected to strengthen the community and university partnership.

A recent report of the World Health Organization (1993) showed that, the evaluation of innovations in the education of health professionals has commonly concentrated on the effects on students and teachers, with less attention paid to the effect of education on practice patterns and very little attention to the effect on health in the community (Report of a WHO study group, 1993).

To our knowledge. studies that have attempted to measure the impact of a community-based programme on the community are not yet available. One of the reasons may be that it is difficult to measure that impact on the health of the population. These studies face vigorous methodological problems, such as the ones described by the students in the above example. It is obvious that universities are not the only health providers in the community, and that while health outcome is very complex and many factors are interacting to produce ill health (Mosley, 1983). This difficulty is well recognized in the evaluation of health intervention programmes (Blum \& Feachem, 1985; Tarlov et al, 1989; Mennin et al, 1992).

There are two possible solutions to this problem. The first is to concentrate on measuring process or programme activities, rather than on the impact or outcome on the health status of the community. The underlying assumption is that these activities will lead to the required outcome, so if the activities are carried out properly (which is to be assessed), the desired outcome will emerge. The processes studied mostly include availability, accessibility and utilization rate of the services offered by the intervening institution. This process-oriented approach is often used in health impact evaluation. The second approach is to measure consumer satisfaction with the services provided. This approach is relevant in the case of CBE programme, as satisfaction is a prerequisite to successful and sustainable community participation in the activities undertaken. The University of Gezira Faculty of Medicine a community-based, communityoriented medical school, studied the impact of one of its programme, the Interdisciplinary Field Training Research \& Rural Development Programme, through the second approach i.e., assessing consumer satisfaction. It did so 
by interviewing community leaders. The following is a brief description of this programme.

The Interdisciplinary Field Training Research and Rural Development Programme, intends to provide practical field training for students in rural areas. The aims of this course are to develop students' abilities of problem solving, research, communication and community-interaction skills. It is also a chance for the university to be involved through its staff and students in rural development activities to realize its goals in this respect. Through the application of the idea of interdisciplinary collaboration, the programme foster team work among students from various disciplines.

During this course, which take place in the summer, students from different faculties (medicine, agriculture, science \& technology and economics) work in small groups, of 4 to 6 students supervised by staff members from various disciplines. Each group of students is assigned a village where it takes a responsibility in the development.

In the first summer block, following an introduction to epidemiological and statistical methods, communication, and interviewing techniques, each group of students is posted in their selected village for two weeks to collect data using different methods of data collection. Utilizing the collected data, the students analyze, summarize and prioritize their problems identified, which need not necessarily be health-related. Then students are asked to write a plan of action to face one of the problems identified by specifying a feasible and cost-effective project, to be implemented in the next summer block. The project is designed with maximal community participation.

In the second summer block the students implement the proposed project in the village. This phase usually take four weeks. Then, the students decide on an approach for follow up and determine indicators for evaluation of their project. In the last phase, students evaluate their project and prepare their final report. During the semesters, further discussion is arranged in evening seminars to facilitate exchange of ideas and experiences between different groups (Hamad, 1982).

The aim of this paper is to describe the results of an attempt to asses the impact of this programme on the community, through interviewing 60 community leaders.

\section{Procedure}

Sixty community leaders from eight different villages, that were used as posting sites for student field training were interviewed. Among the community leaders were members of the People Committee, the official community organization responsible for the administrative and political 
issues in each village, traditional leaders and representatives of the Farmers Union in the area. The interviews were conducted, following the three phases of the course, held in the period 1989-1992 in the Eljunaid Sugar Cane Factory catchment area. The data were collected in November 1992, 6 months after the termination of the programme in this area. The data were collected by three medical students (who were not part of the group posted in this area) and a staff member from Gezira University. The investigators used a questionnaire, direct interviews and focus-group discussions to collect data. These methods were designed to elicit information on the following :

1. The community leaders' understanding of the Gezira medical school objectives and strategies.

2. The community leaders attitudes towards students presence in the community.

3. The students impact on the community as envisioned by the community leaders.

4. The community views about, and suggestions for, improvement of the programme.

In addition ten staff members involved in community-based education were interviewed to evoke:

1. Their experience in using community feedback in programme assessment.

2. The items and areas where community feedback could be of assistance for improving the programme and assess students.

\section{Results}

All those interviewed had heard about Gezira University medical school. Table 1 shows that all the major objectives of Gezira University medical school related to their community mission were listed by community leaders, except research. Table 2 shows that the community leaders perceived Gezira student as unique compared to students from other health institutions who also do some community-related work in the particular area. Table 3 shows the community expectation of the university which include most of the objectives of the school. 
Table 1

Objectives of Gezira medical school as mentioned by 60 community leaders interviewed

Objectives

No.

Percentage

1. Care for rural area

22

37

2. Graduation of community-oriented health personnel

12

30

17

28

3. Provision of health education services

16

27

5. Community development

13

22

Table 2

In which respect Gezira University medical students are different from other universities

No. Percent

1. They seek close contact with the community

$\begin{array}{ll}36 & 60.0 \\ 10 & 16.6\end{array}$

2. They care for rural areas

3. They know more about endemic diseases and other community problems

$8 \quad 13.3$

4. They are dedicated and hard workers

$6 \quad 10.0$

5. They communicate well with the community

6. No difference

$10 \quad 16.6$

$4 \quad 6.6$

Table 3

What does the community expect from the university

No. Percent

1. Provision of health education

$41 \quad 68.3$

2. Provision of curative services

$31 \quad 51.6$

3. Control of endemic diseases

4. Inform government about community problems

$9 \quad 15.0$

5. Community development

$9 \quad 15.0$

6. Improvement of environmental sanitation 
Table 4 shows the attitudes of the community leaders towards students. The results indicate that students are well accepted by the community and that, in addition, the community leaders are positive about the extent of cooperation between students and the community.

Table 4

The community leaders attitude towards student presence in the community*

1. The students are well accepted in the community setting

Mean

SD

0.66

2. The students well-behaved in the community setting

3. The community members are co-operative with students

* Community leaders were asked to respond to these questions on a five points scale ranging from 1 to 5 , where 5 represented strong agreement.

Table 5 displays what the community leaders see as new ideas, practices and benefit coming to the community as a result of the students presence. These benefits may be the reasons behind the fact that $98 \%$ preferred frequent visits by the students. Furthermore, $41 \%$ think that the duration of stay of students is too short (nobody indicated that students are staying too long).

Table 5

New ideas, practices and benefits gained by the community as a result of students presence

No. Percent

1. Raising community awareness of prevention and cure of common diseases

2. Improvement of practices conceming home management of prevailing child diseases

3. Provision of health and community development services

4. Increased community understanding of Gezira objectives and strategies 
Almost all the staff members interviewed, except one, had previous experience with using community feedback for decision making purposes, for instance to solve student problems in the field or improve programme operation. They all agreed that it is a very important source of programme evaluation and staff members even suggested that community members could be of assistance in assessing students in the community setting.

\section{Discussion}

Since the establishment of this course in 1981, Gezira University medical school has covered 104 villages. Forty eight of these villages were located in the Gezira and Managil Scheme, where developmental activities have taken place for a number of years, but where still problems exist, mainly water-associated diseases, such as malaria and schistosomiasis. Thirty villages were located in the Rahad scheme where development has recently started, and fourteen villages were located in East Gezira where development has not begun and basic needs like safe water supply and basic health services are not to be found. In each village the programme was in operation for at least three years, and at least one development project was implemented. These projects include a variety of development projects, ranging from strengthening primary health care units through health education and environmental projects, to integrated and comprehensive rural development projects. Thirteen batches, amounting to 650 students (450 of them already graduated), have been a part of this experience.

The vast coverage of the Gezira area made the school well known to the community. Therefore, it is not surprising to find that all community leaders heard about the school and recognized most of its objectives. A few objectives were not recognized by the community. Assessment of the community leaders' understanding about the Gezira University medical school objectives particularly revealed a lack of awareness of research as one of the important tasks of the school. This is despite the fact that students spent one summer in conducting research in their respective community to identify major community problems. The lack of perception of this goal may be due to misunderstandings or underestimation of the importance of research by the community. It may also be due to the fact that students provide some services during their presence in the community that may distract community attention from the (more important) research objective.

On the other hand the fact that the school's objective is to graduate community-oriented doctors is quite known to the community members, as well as the provision of services including health education and preventive 
health services. Somewhat surprisingly, the community leaders did not judge the provision of curative care as a number one priority for the school. It seems that community leaders have started to become aware of the importance of preventive aspects of health and primary health care interventions and the role of the school in this respect. It is also important to mention here, that the community does not expect the university to provide only health services, but rather to participate the solution of other health-related problems as well, including community development problems in a boarder sense. This justifies the multidisciplinary approach to community problems adopted by Gezira University in which the improvement of health is considered part and parcel of the broader developmental issue. Finally, it is expected that the university acts as a catalyst between the community and the government.

The community leaders viewed Gezira students as quite different from students from other institutions, because they have closer contact with the community. This may be explained simply by the fact that they pay more visits to these particular localities than students from other institutions. However, their highly positive rating of students behaviour and its apparent impact on the community, seem to strengthen the community leaders' views that Gezira students are special and unique. It appears that students presence for three consecutive summers has changed the community's expectations of the students and the university.

The community's attitudes towards student presence are impressingly positive; students are welcomed to stay in villages despite the relatively high cost of accommodating them and implementing the projects. The fact that student behaviour is favourably rated by community leaders can be expected to increase co-operation and interaction with the community. The latter realizes one of the most important posting objectives: The acquisition of skills in co-operation and team work, a building block for future cooperation between community and physicians. Even more important, it demonstrates to the community that there are and will be physicians who really care about their problems.

Useful and practical suggestions for improving the programme have been proposed by the community leaders. These suggestions covered matters like the timing of the posting, duration of stay and how information could be collected from families. These suggestions have markedly improved the course's operation.

It is clear that the community can play a major role in giving feedback to the university with regards to the usefulness and operation of community-based programmes. The students tend to worry that they cannot meet community expectations or do not deserve the generous hospitality. This sometimes leads to disappointment among students which may 
seriously affect their interest, enthusiasm and the excitement they experience during the first posting, and consequently may influence the attainment of course objectives. When results of the community feedback, reported in this article, were conveyed to students, it comes as quite a relief for them.

The attitude of staff towards using community feedback is quite favourable. They are all have actual experience in collecting information from community members during supervisory visits. This information is often utilized as a basis for informed decision making conceming student assessment and programme monitoring, so it seems that community feedback can play a constructive role in the improvement of the community-based programme. In addition during their presence in the community staff act as resource for both students and the community and actively participate in service delivery. This realizes another important objective of community-based education, namely to involve staff as well as students in the entire process.

In conclusion, in a developing country with scarce resources, medical schools should aim at relevance of their curriculum through partnership with the community. One way of bringing this into existence is to train students in that community and involving the community in all aspects of that training; the evaluation of programme and students and, perhaps most importantly, the assessment of the impact of student activities on the wellbeing of the community. 


\section{References}

Abdel Rahim I.M., Mustafa A.E. \& Ahmed B.O. (1992). Performance evaluation of graduates from a community-based curriculum: the horsemanship period at Gezira medical school. Medical Education, 26, 223-230.

Alausa O.A. (1988). Community-based medical education in Nigeria: The case of Bayemo university. Annals of Community-Oriented Education, 1, 5-12.

Blum D. \& Feachem R. (1983). Measuring the impact of water supply and sanitation investments on diarrhoeal diseases: Problems of methodology. International Joumal of Epidemiology, 12, 357-65.

Hamad B. (1982). Interdisciplinary Field Training Research and Rural Development. Medical Education 16, 105-107.

Hamad B. (1991). Community-oriented medical education what is it? Medical Education, $25,16-22$

Jinadu M.K. \& Daview-Adetugbo A. (1992). Ife experience in community-based education for health professionals. Annals of Community-Oriented Education, 5, 455-60.

Magzoub M.M.A., Ahmed B.O. \& Salih S.T. (1992). Eleven steps of community-based education at Gezira medical school. Annals of Community-Oriented Education, 5, $11 \cdot 17$.

Mennin S.P., Friedman M. \& Woodward A.C. (1992). Evaluating innovative medical education programme: common questions and problems. Annals of CommunityOriented Education, 5, 123-134.

Moses B.M., Joseph A. \& Rajaratna A. (1990). Co-operation between academic institutions and health care system. The Christian Medical College, vellore model. Annals of Community-Oriented Education, 3 II, 143-144.

Mosley H. \& Chen L.C. (1984). An analytic framework for the study of child survival in developing countries. Population \& Development Review, 10. (suppl) 25-45.

Nooman Z., Refaat A.H. \& Ezzat E.S. (1990). Experience in Community-based education at the Faculty of Medicine. Suez Canal University. In: Nooman, Z. M., Schmidt H. G. \& Ezzat S. E. (Eds.) Innovation in Medical Education: an Evaluation of its Present Status. Springer Publishing Company, New York.

Omotara B.A.. Padonu M.K.O., Bassi A.B. \& Amodu M.A. (1992). Community-based medical education: The university of Maiduguri experience. Annals of CommunityOriented Education. 5, 41-46.

Prywes M.T. (1983). The Beersheeva experience of integration of medical care and medical education. Israel Joumal of Medical Sciences, 19, 775-779.

Seefeldt M., Ahmed B.O., Mustafa A.E., Ali M.M. \& Ali G.M. (1989). The approach and major findings of the programme evaluation of the Gezira University medical sichool innovation, tenth year. Eastem Mediterranean Health Services Joumal, 6, $32-8$.

Tarlov A., Ware Jr.J.E., Greenfeld S., Nelson E.C., Perrin E. \& Zubkoff M. (1989). The medical outcomes study: An application of methods for monitoring the results of medical care. Journal of the American Medical Associanion, 262, 925-930.

World Health Organization (1993). The search for relevance: innovation in education of health professionals. Report of a WHO Study Group, Technical Report Series Geneva, Switzerland: World Health Organization. 


\title{
Problem Facing Graduates from Network Institutions: Experience from Sudan
}

\begin{abstract}
Graduates from the Gezira Medical School face many problems in the present health system. These problems include curative-oriented health care in both teaching hospitals and rural areas. Difficult working conditions which lead many graduates to emigrate. Postgraduate studies which are mainly adapted for international recognition rather than to meet real health needs. These problems make the present health system unattractive for Gezira graduates and hinder their contribution in applying the competencies which they learned in the undergraduate community-based curriculum. These experiences and how graduates from Gezira attempt to influence the health system are discussed.
\end{abstract}

As a graduate from Gezira, a member of the Network, I am not only pleased but rather relieved to see the problems facing graduates as one of the top Network priorities for the next ten years. I think this issue is very vital and has to be considered seriously by the network schools if your schools are to play an influential role in the health services. We have to work jointly schools, graduates and ministries of health, to face this priority problem. 
Although this is a personal experience it is true for most Gezira graduates and probably for graduates of other Network schools, based on interviews and discussions with colleagues from Gezira. We blame traditional schools for focusing on irrelevant knowledge. Yet the same accusation might be raised in our case, that we provide our graduates with competencies which they are unlikely to be able to use in practice, in the present health system.

Graduates from Gezira Medical School receive temporary registration from the Sudan Medical Council and join the Ministry of Health as house officers (residents). In Sudan this appointment is for one year during which the doctor has to spend three months in each of four departments: obstetrics, medicine, surgery and an optional rotation in another department. All medical specialties are offered, except primary health care and public health. Indicators for evaluation of performance by doctors are totally different from what is taught at Gezira. The criteria include how quickly a diagnosis is reached and, more importantly, demonstration of sufficient knowledge to undertake postgraduate studies at internationally recognised medical institutions. All young doctors compete for the opportunity to undertake postgraduate studies as soon as possible. The selection for postgraduate education is through a written examination in the clinical and basic sciences without regard to performance as a doctor. The fundamentals of training at Gezira are not at all relevant in such an environment. Community-based activities are viewed as soft sciences, as side issues, and sometimes as a waste of time and a job to be performed by lazy doctors who failed to join attractive specialties.

Another obstacle is the severe constraint imposed on quality of care by the shortage of doctors, where the house officer is involved in many responsibilities including working in the outpatient department (where patients stand in long queues). admissions, and inpatient follow-up. These duties create severe time constraints and work overload. In such a situation it is not possible for the young doctor to practise all the problem-solving skills, especially when it comes to the underlying problems at family and community levels.

As new graduates we spent one year exclusively in big teaching hospitals without finding any real chance to practise the full range of competencies we had leamed in our medical school. By the end of the year we had succeeded in creating a name for our school, but according to their criteria and not ours. To give an example, during the drought we received a large number of displaced persons in the hospital. We suggested to the hospital authorities that an emergency clinic might be established at the camp to deal with all displaced persons at their camp. We were told that this was not our concern, that it was the job of somebody else in the public health office. We failed to 
do anything through the hospital. Eventually we made contacts through our school where we succeeded to involve students and established an emergency clinic to deal with the problems in the camp itself. Following our full registration by the Sudan Medical Council, many of us chose to work in rural hospitals. We thought that this would suit our training and the skills and knowledge we had acquired. To our surprise the situation in the rural hospital was little better than in the teaching hospital. The health services were rendered independently through vertical programmes. They were supervised by the district inspector, located at the district headquarters. He had no time or facilities to supervise all the primary units in the district, usually more than 100 units. This left the primary health units isolated and with many unresolved problems. Moreover, the financial and administrative responsibilities of the primary health units belonged to the local govermment councils, while the hospital remained under the Ministry of Health. This created a dichotomy in health services delivery. The community expectation of doctors is that they will apply high clinical skills and decide on few referrals, they are not expected to work in Primary Health Care and community based activities. The author was asked to work in a rural hospital in Eastern Gezira. Faced with all these difficulties, he organised a meeting with the community leaders to explain the importance of primary health care as a more appropriate way to face the health problems in the area. He assured the leaders that this work would not be at the expense of his work at the hospital. It took a long time to convince the community. The author made contact with all the health workers in the area. Together with a colleague from Gezira, he started an integrated primary health care programme which included oral rehydration, nutrition and immunization. All the health workers in the area were trained in these interventions and followed this up with implementation. Evaluation demonstrated the success of the programme as measured by the health workers and through community feedback. "Unfortunately, the programme was not strongly supported by Ministry of Health officials in the district and it could not operate within a supportive system: it was left to the enthusiasm of the doctor in charge. As was to be expected, the programme collapsed, due to the disinterest of the doctor in charge.

Another problem that faces all doctors in Sudan is low pay and difficult working conditions. This leads to severe drainage of doctors to the petrol rich countries in the Persian Gulf. Graduates from Gezira are not immune from these problems, and it is not surprising to find more than half the doctors of the first cohort have emigrated to Saudi Arabia. 
The existing postgraduate study programmes are mainly run by traditional medical schools with their own learning strategies and priorities. These programmes, imported from British institutions, are mainly adapted towards international recognition, rather than meeting cornmunity needs and local realities. There is no option for the Gezira graduate but to join these programmes with their own focus and orientation, which are very different from the graduates" basic training at Gezira.

\section{What is the Way out?}

The most important start for the Medical School is to play an influential role in the health services to ensure that the competencies of its graduates are used appropriately. The Gezira experience will serve as an example.

\section{a. Health Area Policy}

As a result of meetings and discussions with the Ministry of Health an area health policy was developed. The aim of this policy was to deliver an integrated primary health care service led by the rural hospitals. Leadership was assumed by a health area management team (HAMT), headed by the doctor and including all Ministry of Health Departments, in addition to the related sectors. The team would be responsible for administration of the entire health services and personnel in the area for planning, implementation and evaluation of all health activities. The team would take charge of logistic support and drug delivery to all primary health units in the area. It would be responsible for the integration of all services, including vertical programmes. It would seek active community participation where necessary. It was hoped that this system would solve the problems of the dichotomy in health services delivery in rural areas and provide a healthy environment and hence attract Gezira graduates to play an influential role in the system.

\section{b. Primary Health Care Management Course}

This policy created a need for trained leaders to guide and manage health areas. Responding to this need the Gezira Medical School has organised a three week PHC management course for doctors prior to their enrolment in rural hospitals. The objective of this course was to prepare the doctor to perform the tasks of the health area management team leader. The methods of training followed the learning strategies of the Gezira Medical School, including problem-based and community-based learning. The course has been run 17 times and has trained 420 participants so far. The training has had a 
magnificent impact on improving the quality of services at the rural hospitals as witnessed by its evaluation through site follow up visits. Moreover, the evaluation reports have shown that this training has demonstrated changes in the doctors' attitudes towards primary and rural health care.

\section{c. Influence of Gezira}

This course has shown that a medical school is able to play a very effective role in attracting to its philosophy doctors who are leaders of health services. This, in turns, may influence the health services. The increasing number of doctors who are choosing public health for their postgraduate studies is attributed by Ministry of Health officials, among other reasons, to the influence of the Gezira course and the influence of Gezira graduates.

The Gezira Medical School has started to influence the health services through its graduates who have taken leading positions in the Ministry of Health. One example is a graduate who is now working as an acting director of the National Control of Diarrhoeal Disease (CDD), a very important department in the Ministry. He caused quite a revolution in the CDD short training courses for doctors and other health workers by incorporating problem-based and community-based learning in these courses. That programme has also moved more towards community participation and involvement which had been neglected in the past.

\section{d. National House Officer Introduction Course}

The Gezira Medical School, in collaboration with the Ministry of Health, has organised one week orientation course for all new graduates in Sudan before they join the Ministry of Health as house officers. This one week course covers primary health care, management curriculum. These short courses have proved that the school can play an important role through training of large numbers of young doctors who are potential leaders of health services in the near future.

In conclusion the problems facing graduates of innovative schools of medical education are numerous and may inhibit the influence of these schools through their graduates in the health system. Fortunately the members of the Network are aware of the problem. and several innovative institutions have started to influence the health system. 


\section{References}

Alausa O.K., \& Enin M.A. (1990). Strategies for collaboration between medical schools and health care system in Nigeria: The Bayerno University Kano Experience. Annals of Community-Oriented Education. 3, (II). 53-62. Maastricht. The Netherlands: Network of Community-Oriented Educational Institutions for Health Sciences.

Anon. Future priorities of the Network. (1991). Newsletter, 15, Maastricht. The Netherlands: Network of Community-Oriented Educational Institutions for Health Sciences.

Nooman Z. (1989). Link with health services: A discussion paper, Annals of CommunityOriented Education. 2. 61-64. Maastricht, The Netherlands: Network of CommunityOriented Educational Institutions for Health Sciences.

Rahim I.M.A. (1990). Is there a role for academic institutions in the primary health care leadership crisis? The Gezira experience. Annals of Community-Oriented Education, 3, (II). 175-182. Maastricht, The Netherlands: Network of Community-Oriented Educational Institutions for Health Sciences. 


\section{Summary and conclusion}

This thesis dealt with aspects of the implementation of community-based education (CBE) at the Faculty of Medicine, University of Gezira (FMUG). The principal feature of community-based medical education is that instruction takes place outside the classroom or the teaching hospital. It is conducted in the community at large where people live and work, in primary health care units, factories, villages, urban and suburban communities. The ultimate goal of such learning activities is to produce physicians responsive to community health needs and able to work in rural and underserved areas. The fact that the community is the learning site makes it difficult to implement and exercise control over student activity compared to classroom teaching. Implementation of $\mathrm{CBE}$ requires at least the followings measures: 1) Clear guidelines of the kind of activities and steps that students will follow in the field. 2) Ensure that these activities have a learning impact on students through the application of appropriate and relevant methods of assessment. 3) The school should provide partnerships with the community and the government and should demonstrate an impact on the community it serves as a result of student learning. 4) Finally, the school should be aware of the kind of problems that its graduates will face when working in the health system and should try to positively influence the health system to allow its graduates to use the competencies learned.

These measures are interrelated in the sense that activities in the community combined with an adequate student assessment system is expected to result in positive impact on student learning and, hence, in the development of positive attitudes towards the community. The learning of the students may, in tum lead to an impact on the community and the health system. 
This thesis was organized around these conceptual premises of communitybased education. Chapters 2 and 3 dealt with activities carried out in the field. Chapters 4, 5 and 6 addressed issues of student assessment in community settings. Chapter 7 discussed the impact on the community, whereas Chapter 8 explored the kind of problems that graduates face in the health system and the measures to be taken by a medical school to influence their situation in a positive way.

Each chapter will be briefly discussed and the major conclusions will be presented.

The first chapter is an introductory one, started with a historical background of $\mathrm{CBE}$ and its definition, then eleven points of its rationale were discussed. Followed by an extensive discussion of the different approaches used all over the world to CBE. In this regard a first approximation towards a taxonomy of $\mathrm{CBE}$ was presented. The taxonomy has three main categories: It distinguishes between programmes that are service-oriented, programmes that are research-oriented and programmes that are training-focused. In addition, it introduces two subclassifications in each category. The taxonomy is based on the nature of activities carried out by the students in the community, in addition, to the level of community and faculty involvement in the programme. To that end $33 \mathrm{CBE}$ programmes were reviewed and distributed to the different categories of the taxonomy. From the same review a number of dimensions were identified that describe the diversities of these programmes. Examples are timing, duration, training site, the level of student and community involvement etc.

\section{Activities in the community: Learning and service}

Chapter 2 addressed a conceptual basis for the actual implementation of community-based learning, describing the concrete steps students follow in community-based education. These steps are characterized by a focus on groups of patients in primary care units, families and the community at large. They follow the management or problem-solving cycle, exposing the students to real-life community problems to which students apply their knowledge and different skills in problem solving. Community participation is considered as an integral part of the cycle. The steps can be tailored according to the available resources and the specific course objectives. The first step consists of the selection of communities from a variety of localities in term of development, size and socio-cultural background. The selection depends largely on the willingness of the community to participate in the programme and the resources available. At this stage, the learning objective is to introduce students to community and family structure and function and its relation to the health of individuals. The second step is the identification of investigation tools. Students identify and design various 
instruments for data collection in their respective communities, thereby working in small groups or individually. At step three, students collect data from their communities and stay in the field for some time. The objective is to try out the data collection techniques in the field and to develop their communication and interviewing skills. At the fourth step, students analyze their data, going through the different stage of analysis, starting from data coding, over data entry and cleaning up, to application of different statistical procedures. They then list all the problems that show up from their data at the fifth step. The learning objective here is to recognize how to classify and present problems. At the sixth step, students prioritize problems using criteria such as commonness of the problem, the community's perception of the seriousness of the problem, etc. At step seven, students write a detailed plan of action to resolve one of the priority problems identified at the previous step. Following discussion with the community, funding agencies are approached to finance their suggested intervention. At the eighth step, students implement their plan with full participation of the community. At the ninth step students follow up on what they have implemented through regular visits to the community. Then, they evaluate the success or failure of what they have implemented during the tenth step, applying different evaluation tools to determine the level of achievement of their primary objectives. At the last step, they write a comprehensive report of their activities. The steps described provide guidelines for implementation of CBE and are a contribution towards a more structured approach to this kind of education.

Chapter 3 provided an example of application of the above steps in the rural residency course, which is offered following the seventh semester at the FMUG, after the students complete studying the body systems in an integrated manner. It is a one-month-duration course, in which each student is assigned to a single doctor rural hospital. The aim of this course is to expose students to an environment similar to the one they will work in in the near future. During this course, the student is expected to observe, assist with, or perform the different activities carried out in the rural hospital and the primary health care units around it. In addition, s/he is required to identify a priority problem, applying a community-based survey, using an appropriate study design and suggest a plan of action to resolve the problem. In order to elicit the attitudes of students and graduates of the FMUG towards this course. A questionnaire was distributed to 80 students and graduates covering matters such as the organization of the course, coverage of objectives, impact on student leaming and impact on graduate performance on rural areas. The results indicated that the course was well received by both students and graduates. Positive educational impact was mentioned by students. Graduates indicated that the course has assisted 
them in improving their performance in rural hospitals as they were already familiar with the rural environment and the nature of problems encountered in rural hospitals before they entered practice. Furthermore, they indicated that they thought their performance was better compared to non-Gezira graduates. A limitation of the study reported in Chapter 2 was that this research only covered students and graduates satisfaction about the course. It did not evaluate the actual performance of graduates in rural hospitals, this being an important area of further research.

\section{Student assessment issues}

A major challenge facing schools adopting CBE strategies as one of their educational tools is, how to assess student in the community setting. Valid and reliable assessment is very difficult for various reasons: First, it is difficult to control the teaching outside the classroom and the teaching hospital. Second, conducting the learning process and application of the assessment methods require heavy logistic support. In addition the lack of standardization of field conditions and having different students' groups posted in different localities make it difficult to evaluate students on an individual basis to find differences between and within various groups. The solutions to these problems are vital. Student assessment is known to be a strong stimulator to student learning; therefore, irrelevant assessment will reflect on student commitment and attitudes towards CBE. Chapters 4, 5 and 6 discuss various aspects of student assessment in the community settings and provided empirical data regarding its application.

Chapter 4 described a comprehensive approach to assessment as applied at the FMUG. In this chapter eight instruments were described. Questions discussed are: What is assessed? Who assesses? How is the instrument applied? What kind of rating scale is used? How does each instrument contribute to the final course score? Each method is concentrating on a specific part of the community-based and contributes to the final grade according to the extent of its coverage of the objectives. Some of the features of the assessment methods are discussed, such as a focus on the process of community-based learning rather than the outcome; taking into account the effect on the community; provision of some measures of student attitudes; having a strong participatory component; being cost-effective; using various sources; being practical and being continuously monitored and improved upon using various sources of information.

Chapter 5 addressed the measures of reliability and validity of the comprehensive approach described in Chapter 4. To that end, data generated by 105 students participating in the interdisciplinary field training, research and rural development course were used. Reliability was calculated by 
computing alpha coefficients for each instrument separately and for the total score. Confirmatory factor analysis was used to test the construct validity of the approach. In addition, its content validity was reviewed. The results indicate that the individual instruments are reliable and the total score turns out to be reflecting different competencies of students rather than one unified skill. Confirmatory factor analysis suggested that at least five different competencies can be distinguished: reporting skills, problem solving skills, community interaction skills, leadership skills and application of knowledge. However, a test of a model including these factors did not fit the data satisfactorily. Removing the report factor in addition to the MCQ-test showed a better fit of the data, however this at the expense of the content validity of the approach. It was concluded that student assessment in the community setting requires a comprehensive approach to measure the various competencies in the community setting. In conclusion the approach tested turned out to be reasonably valid and reliable.

Chapter 6 provided a detailed example of one of the instruments used for student assessment in community settings: The peer assessment method. Peer assessment is believed to be one of the more promising instruments for assessing students in community settings. Since peers are working and living together for quite a long time, they are in a better position to judge each other on certain aspects of performance important in community-based education, such as effort exerted by the student on the community, interaction with that community, subject-matter contribution and knowledge displayed. To that end, 33 students, forming three groups, participated in this study which was undertaken following their community-based activity. Each member of the group judged his fellow peers on four factors comprising 22 items, using a six point scale. A generalizability study was conducted to estimate the reliability of the items and their corresponding scales. A confirmatory factor analysis was carried out to assess the validity of the four-factors model underlying the rating scale. High generalizabilty coefficients were found for all the items of the rating scale as well as for its subscales. The validity study suggested that the proposed model of peer evaluation is reasonably valid. It was concluded that peers are able to assess each other with fair reliability and validity on certain aspects of performance necessary in community-based education.

\section{Impact on the community and the health system}

Community-based education as a learning approach uses the community extensively for learning. Schools involved in such leaming activities must pursue strong collaboration with the community and not consider it as just another type of laboratory. One of the strategies expected to reinforce this collaboration is to demonstrate an impact on that community as a result of 
students' learning. Measuring the impact on the community is important for several reasons. 1) It serves as feedback for programme improvement, 2) it will be reflected on student and staff commitment, and 3) it is expected to strengthen partnership between the community and the university. Studies addressing the measurement of health impact face many difficulties, for instance: What is the appropriate study design to select; and: How to control confounding variables, as universities are not the only health providers in the community? The FMUG attempted an approach which depends on the measurement of activities of students in the community as perceived by community leaders, and community satisfaction with these activities. To that end, 60 community leaders were interviewed, with regard to their views about the community-based programme of FMUG. The interview included community leaders' understanding of the school's objectives and strategies, their attitudes towards students and the perceived impact as a result of students activities. The results suggest that the leaders are well aware of the objectives of the community-based programme and the strategies of the school as a whole; consider Gezira students different from those of other universities; display positive attitudes towards them and indicate that the presence of the student in the community has provided benefits for the people involved. These results have assured students that their efforts were appreciated by the community and also have been of great political and moral support to the university. It was concluded that the measurement of community satisfaction is a useful strategy to assess impact of interventions, because it is more feasible than measurement of improved health indicators. The community leaders were found to be satisfied about their partnership with Gezira University. Of course the study was only based on community leaders assessment. More comprehensive studies are needed to check whether community leaders judgement is a fair estimate of the real impact that students have on the community.

Chapter 8 explored a graduate's experience with the health system. The focus of this chapter was on providing examples of problems facing graduates form innovative schools in health profession education, and on describing the attempts made by the FMUG to influence positively the health system. Problems facing graduates of the FMUG include the following: 1) The present health system is mainly curative-oriented, geared towards serving the population in big cities; 2 ) rural health services are not much better than tertiary hospitals on their emphasis on curing individuals; 3) young doctors are mainly oriented on how to quickly to get an opportunity for specialization in a clinical discipline. In such an environment it is difficult for Gezira graduates to use the competencies learned during their undergraduate training, let alone play an influential role to improve the system. 
The FMLG attempted to influence the health system through a number of measures, such as proposing to the Ministry of Health to implement a health area policy which aims at delivering integrated health services through the rural district hospital. This policy was adopted by the Ministry of Health and implemented in the country as a whole. In addition, this policy created a need for training team leaders of health areas. Responding to this demand the school has developed a short primary health care management course for doctors prior to their enrolment in rural hospitals. This has provided the school with opportunities to influence participants of the course through its educational approach. In conclusion, the problems facing graduates of innovative schools for health profession education are enormous. Schools have to be aware of such problems and seek actively pursue possibilities to influence the health system. The Gezira medical school experience may be looked upon as an example reproducible elsewhere.

\section{Future research}

Research in community-based education is still in its infancy. Most of the available literature is descriptive in nature. The research reported in this thesis addressed priority issues in CBE with regard to programme implementation and student assessment. Further research is badly needed with respect to many aspects of community-based education. The following may serve as guide for priority research in this area.

First, research on programme implementation is required, in particular comparative studies on how different programmes respond to the problem of implantation. This research carries the promise of helping others by providing guidelines on how to implement CBE. Research is also needed on the process of learning taking place in the community and what motivate students to learn in CBE. In this area the development of a theoretical, testable model is a first requirement for community-based education, similar to the one suggested by Schmidt and Gijselaers (1990) for problem-based learning. Such a model should be tested empirically and should provide suggestion for both improvement and evaluation of CBE courses.

More detailed studies on what students leam in community-based education is another area. Examples of questions which need to be answered are: Do students cover the required objectives when they are posted in the community? Do students learn more than what is expected from them by the faculty? How is student achievement affected by posting in different localities?

This thesis presented a first attempt at using a comprehensive approach to student assessment in community settings. Still a lot of further research 
is required in this domain by different schools applying CBE. Which skills need to be assessed in the community settings? What are appropriate methods of assessing these skills? Is it possible to develop reliable, valid and acceptable instruments for this kind of education? Do different programmes in the world need different approaches to assessment or is it possible to establish a universally useful battery of instruments?

In this thesis one approach to the measurement of the impact of a community-based programme is presented. Further research in this domain is essential, because one of the important goals of such educational programmes is to improve the health status of the community and develop the health system. In particular, research is needed on what feasible and cost-effective study designs to measure a change as a result of educational activities in the community. Demonstration of impact on the community, the health system and on graduates' competencies in responding to priority health problems, are important topics for further studies. Graduate selection of a career in primary care career and determinants of choice to work in rural and underserved areas is domain for further research as well.

\section{References}

Schmidt H.G. \& Gijselaers W. H. (1990). Causal model of problem-based leaming. Paper presented at the Annual meeting of the American Research Association, Boston, MA, April 16-22. 


\section{Samenvatting}

In dit proefschrift wordt een aantal aspecten beschreven van de implementatie van community-based education $(\mathrm{CBE})^{1}$ aan de Medische Faculteit van de Universiteit van Gezira in Sudan (MFUG). Het belangrijkste kenmerk van community-based education is dat het onderwijs plaatsvindt buiten het klaslokaal of het ziekenhuis. Het onderwijs wordt uitgevoerd in de community, waarbij community ruim gedefinieerd wordt: het gaat om die plekken waar mensen leven en werken, in de eerstelijns gezondheidszorg, in fabrieken, dorpen, steden en voorsteden. Het uiteindelijk doel van dit type onderwijs is het opleiden van artsen die ontvankelijk zijn voor de behoeften in de verschillende communities en die in staat zijn om in achterstandsgebieden te werken.

Doordat het leren niet plaatsvindt in de gecontroleerde omgeving van een klaslokaal, is het moeilijk om zicht te krijgen en te houden op de activiteiten van de studenten. Dit betekent dat de volgende maatregelen noodzakelijk zijn: 1) duidelijke richtlijnen met betrekking tot het soort van activiteiten dat van studenten in het veld gevraagd wordt, 2) gebruik van passende en relevante methoden van toetsing die ervoor zorgen dat de veldactiviteiten een impact op het leren hebben, 3) afsluiten van overeenkomsten tussen de opleiding enerzijds en communities en de overheid anderzijds, waarbij de opleiding zou moeten laten zien dat de community beïnvloed wordt door de activiteiten van studenten, en 4) bewustwording van problemen die afgestudeerden zullen ondervinden door de structuur van de gezondheidszorg, waarbij de opleiding moeite

De termen Community-based Education en Community laten zich moeilijk vertalen in Nederlandse equivalenten. In dit stuk worden de Engelse termen en afkortingen gebruikt om het scala van onderwijsactiviteiten aan te geven die plaatsvinden in een bepaalde gemeenschap (community). 
moet doen om de gezondheidszorg zodanig te beïnvloeden dat afgestudeerden datgene dat ze geleerd hebben ook kunnen toepassen.

Deze maatregelen vormen een samenhangend geheel. Leeractiviteiten van de studenten in de community die op een adequate wijze getoetst worden, zullen leiden tot betere leerresultaten. Deze zullen op hun beurt positieve attitudes ten op zichte van de community teweeg brengen. Dit zal vervolgens van invloed zijn op de community en het gezondheidszorgsysteem. Deze uitgangspunten hebben als basis gediend voor dit proefschrift.

De hoofdstukken 1 tot en met 3 laten zien wat community-based education is en hoe dit concreet wordt ingevuld. In de hoofdstukken 4 tot en met 6 worden mogelijkheden beschreven om studenten te toetsen. Hoofdstuk 7 gaat over de invloed van het onderwijs op de community. Tenslotte wordt in hoofdstuk 8 beschreven welke moeilijkheden afgestudeerden die werkzaam zijn in de gezondheidszorg zullen ondervinden en welke maatregelen de opleiding kan nemen om tegemoet te komen aan deze moeilijkheden.

Hoofdstuk $l$ is een inleidend hoofdstuk waarin de definitie en rationale van community-based education wordt gegeven en uitgewerkt.

\section{Activiteiten in de community: leren en werken}

In hoofdstuk 2 wordt beschreven welk stappen studenten doorlopen in het community-based education programma. Kenmerkend voor deze stappen is de aandacht voor groepen patiënten in de eerstelijns gezondheidszorg, families en de community als geheel. Studenten doorlopen een cyclus van negen stappen gericht op het hanteren of oplossen van problemen. Dit betekent dat zij naar de community zelf gaan. Hier worden ze geconfronteerd met de alledaagse werkelijkheid van de problemen. Op basis van eerder geleerde kennis en vaardigheden proberen zij deze problemen op te lossen. Deelname aan de community is een wezenlijk onderdeel van de cyclus. Afhankelijk van de specifieke doelstellingen van het onderwijs worden de stappen aangepast. De afzonderlijke stappen hebben betrekking op kennismaking met de community, het vaststellen van een instrument om data te verzamelen en het daadwerkelijk verzamelen van de data. Vervolgens worden de data met statistische technieken geanalyseerd en worden de gesignaleerde problemen op prioriteit ingedeeld. De laatste stappen bestaan uit het opstellen van een actieplan, de implementatie van dit plan en de evaluatie van het geheel. Het gehele proces wordt afgerond met het schrijven van een onderzoeksrapport.

Hoofdstuk 3 geeft een beschrijving van de toepassing van dit stappenplan in een plattelandsstage in het zevende semester van de MFUG. De stage heeft de vorm van een cursus van een maand waarbij elke 
student wordt toegewezen aan een plattelandsziekenhuis waar slechts één arts werkzaam is. Het doel van dit onderwijsblok is het kennis maken met een omgeving die vergelijkbaar is met die waar men in de toekomst zal gaan werken. Van de student wordt verwacht dat hij of zij alle activiteiten in en om het ziekenhuis observeert, bij deze activiteiten assisteert of de activiteiten zelfstandig uitvoert. Daamaast is het vereist dat de student een probleem kiest met een hoge prioriteit, een survey uitvoert en een actieplan opstelt.

De cursus is geëvalueerd door het laten invullen van een vragenlijst door studenten en afgestudeerden. Gevraagd werd onder andere naar de mening van de studenten en afgestudeerden ten aanzien van de organisatie van de cursus, het behalen van de doelstellingen, de impact op het leren van de student en het optreden van de afgestudeerden in plattelandsgebieden. De resultaten laten zien dat de cursus door studenten en afgestudeerden positief beoordeeld wordt. Studenten gaven aan dat ze veel geleerd hadden. De afgestudeerden waren van mening dat de cursus bruikbaar was voor het verbeteren van hun gedrag in plattelandsziekenhuizen, omdat ze door de cursus bekend waren met de situatie en de problemen in een plattelandsgebied alvorens ze werkzaam waren in de praktijk. Ook hadden zij de indruk dat ze beter presteerden dan afgestudeerden van andere medische faculteiten. Een tekortkoming van deze studie is dat alleen gevraagd is naar de waardering van studenten en afgestudeerden voor de cursus en niet naar de feitelijke prestaties van de afgestudeerden in het plattelandsziekenhuis. Onderzoek naar de feitelijke prestaties van de afgestudeerden zou een belangrijk aspect van verder onderzoek kunnen zijn.

\section{Toetsing}

Bij het invoeren van $\mathrm{CBE}$ aan een opleiding, is een van de belangrijkste uitdagingen het ontwerpen van een samenhangend systeem van toetsing van studenten in de community. Valide en betrouwbare toetsing in een dergelijk programma is moeilijk om verschillende redenen. Doordat het onderwijs plaatsvindt buiten het klaslokaal en het ziekenhuis is het moeilijk de toetsafname te controleren. Bovendien vergt de uitvoering van het programma en de daarbij horende toetsing een behoorlijke logistieke ondersteuning. Verder zorgt het gebrek aan standaardisatie van de veldcondities en de verschillende groepen studenten op verschillende lokaties ervoor dat het moeilijk is om de studenten te evalueren op een individuele basis, zodanig dat tussen en binnen groepen verschillen worden gevonden. Aangezien toetsing een sterke stimulans is voor het leren van de student, is voor het slagen van CBE de toetsing van vitaal belang. 
Hoofdstuk 4 geeft een beschrijving van het samenhangend systeem van toetsing dat binnen de MFUG toegepast wordt. Van acht instrumenten wordt beschreven waarvoor ze gebruikt worden en hoe ze gebruikt worden. Elk instrument is gericht op een bepaald onderdeel van het community-based programma. In hoofdstuk 4 wordt een aantal kenmerken besproken van deze instrumenten, zoals de nadruk die gelegd wordt op het meten van het proces in plaats van de uitkomsten, de aandacht die besteed wordt aan het meten van attitudes van studenten, de kostenbesparing van het systeem, het gebruik van verschillende bronnen en de praktische bruikbaarheid van het systeem.

Vervolgens wordt in hoofdstuk 5 ingegaan op het meten van de betrouwbaarheid en validiteit van het systeem van toetsing zoals beschreven in hoofdstuk 4 . Met behulp van alpha coëfficiënten werd de betrouwbaarheid vastgesteld. Een confirmatorische factor analyse werd gebruikt om de construct validiteit te toetsen. Ook werd de inhoudsvaliditeit bepaald. Volgens de confirmatorische factor analyse kunnen vijf verschillende typen vaardigheden onderscheiden worden: rapportage vaardigheden, probleem oplossende vaardigheden, communicatie vaardigheden, leiding gevende vaardigheden en het kunnen toepassen van kennis. Geconcludeerd werd dat het systeem voldoende betrouwbaar en valide is en toetsing in de community een systeem vergt waarin verschillende vaardigheden gemeten worden.

Hoofdstuk 6 gaat in op "peer"2 toetsing. een van de meetinstrumenten die in de community zelf gebruikt worden. Peer toetsing is een van de meest belovende instrumenten om studenten in de community te toetsen. Aangezien de peers geruime tijd samen leven en werken, zijn ze in staat om elkaar te beoordelen op aspecten die belangrijk zijn in community-based education, zoals de inspanning die studenten leveren in de community. de interactie met de community, de inhoudelijke bijdragen en de kennis die getoond wordt. In dit hoofdstuk wordt onderzoek beschreven naar de betrouwbaarheid en validiteit van een beoordelingsinstrument waarbij elke student zijn medestudent op vier factoren beoordeelt. Een generaliseerbaarheidsstudie werd toegepast om de betrouwbaarheid van dit instrument te meten. Bovendien werd een confirmatorische fiator analyse uitgevoerd om de validiteit van dit instrument te onderzoeken. Geconcludeerd werd dat peers in staat zijn om op een tamelijk betrouwbare en valide wijze elkaar op bepaalde aspecten van hun optreden in de community te beoordelen.

Peers behoren tot dezelfde leeftijdsgroep en hebben een vergelijkbare achtergrond. In deze context gaat het dus om medestudenten. 


\section{Impact op de community en het gezondheidszorgsysteem}

Community-based education maakt intensief gebruik van de community voor het leerproces van de studenten. Opleidingen die betrokken zijn bij dergelijke onderwijsactiviteiten moeten het belang van samenwerking met de community onderstrepen en voorkomen dat de community wordt gezien als een soort laboratorium waar data verzameld kunnen worden. Een van de strategieën gericht op het bevorderen van een nauwe samenwerking met de community is het laten zien aan de community wat voor baat $z \mathrm{ij}$ bij het onderwijs van de studenten hebben. Het meten van deze impact op de community is om drie redenen belangrijk. Ten eerste bevat deze informatie feedback voor het onderwijsprogramma. Ten tweede wordt de betrokkenheid van zowel staf als studenten bij het programma vergroot. Ten derde mag men verwachten dat de banden tussen de community en de universiteit versterkt worden.

Onderzoek naar de effecten van CBE op de community is niet eenvoudig. De aanpak van de Medische Faculteit van de Universiteit van Gezira wordt in hoofdstuk 7 besproken. De MFUG heeft gekozen voor een aanpak waarbij de leiders van de communities worden geïnterviewd. Deze leiders zijn immers in staat om aan te geven wat voor activiteiten studenten verricht hebben en hoe deze activiteiten in de community gewaardeerd worden. De uitkomsten van de interviews laten zien dat de leiders in de communities zich bewust zijn van de doelstellingen van het programma en van de doelstellingen van de gehele opleiding. Ook blijkt dat de inspanningen van de studenten gewaardeerd worden. Hieruit volgt dat het meten van de tevredenheid van de community een goede methode is om de impact van interventies van studenten in de community te meten. Bovendien is deze aanpak beter haalbaar dan onderzoek naar verbetering van gezondheidsindicatoren. De leiders waren ook zeer te spreken over de samenwerking met de Universiteit van Gezira.

Ten slotte worden in hoofdstuk 8 de ervaringen van een afgestudeerde met het gezondheidszorgsysteem beschreven. Doel van dit hoofdstuk was om voorbeelden te geven van problemen die afgestudeerden van een innovatieve opleiding te wachten staan. Daarnaast was het doel aan te geven wat de MFUG doet om de gezondheidszorg positief te beinvloeden. Problemen die afgestudeerden tegenkomen hebben te maken met een curatief ingestelde gezondheidszorg voornamelijk gericht op de populatie van grote steden. Gezondheidscentra op het platteland leggen eveneens nadruk op het genezen van mensen. Een ander probleem heeft te maken met het gegeven dat jonge dokters zich zo snel mogelijk klinisch willen specialiseren. Hierdoor is het voor afgestudeerden van Gezira moeilijk die vaardigheden die men geleerd heeft toe te passen. laat staan dat zij de gezondhejdszorg zouden kunnen verbeteren. De 
medische faculteit heeft het Ministerie van Volksgezondheid beïnvloed door een voorstel in te dienen om te proberen een geïntegreerde gezondheidszorg aan te bieden via de streekziekenhuizen. Dit beleid heeft geleid tot een serie maatregelen om uiteindelijk artsen beter voor te bereiden op het werken in streekziekenhuizen. Dit voorbeeld illustreert de noodzaak om niet alleen opleidingen te vernieuwen, maar ook om het gezondheidszorgsysteem te beïnvloeden.

\section{Toekomstig onderzoek}

Het onderzoek in community-based education staat nog in de kinderschoenen. De beschikbare literatuur is voornamelijk beschrijvend van aard. In dit proefschrift is een aantal aspecten van CBE, zoals implementatie en toetsing, nader belicht. Verder onderzoek zou gericht kunnen zijn op het vergelijken van programma's in de wijze waarop zij met implementatie problemen omgaan. Daarnaast is onderzoek nodig op het gebied van het onderwijsleerproces in de community en de motivatie van studenten voor CBE. Belangrijk hierbij is het ontwikkelen van een model dat getoetst kan worden, analoog aan het model ontwikkeld door Schmidt en Gijselaers (1990) voor probleemgestuurd onderwijs. Andere interessante onderzoeksvragen zijn: Wat leren studenten, worden de doelstellingen voldoende gedekt door het programma, leren studenten meer dan hetgeen van hen verwacht wordt? Daarnaast zou onderzoek verricht kunnen worden op het gebied van toetsing: Hoe wordt de toetsing beïnvloed door het gegeven dat studenten verspreid zijn over verschillende lokaties, welke vaardigheden moeten getoetst worden met behulp van welke instrumenten, welke instrumenten zijn voldoende betrouwbaar, valide en aanvaardbaar voor dit type onderwijs?

In dit proefschrift werd een voorbeeld gegeven van de wijze waarop de impact van studenten op de community gemeten kan worden. Het is essentieel dit onderzoek verder uit te bouwen. Het uiteindelijke doel van CBE is immers het verbeteren van de gezondheidstoestand van de bevolking en het leveren van een bijdrage aan het ontwikkelen van de gezondheidszorg. In het bijzonder is onderzoek nodig naar haalbare en rendabele studies om veranderingen in de community te meten die door het onderwijs bewerkstelligd zijn. Daamaast zou onderzoek verricht kunnen worden naar de impact van studenten op de community en de gezondheidszorg in samenhang met de vaardigheden van afgestudeerden om tegemoet te komen aan de behoeften binnen de gezondheidszorg. Tot slot, onderzoek zou gedaan kunnen worden naar de mogelijkheden om afgestudeerden te selecteren voor een werkveld binnen de eerstelijns gezondheidszorg en voor werk in plattelands- en achterstandsgebieden. 


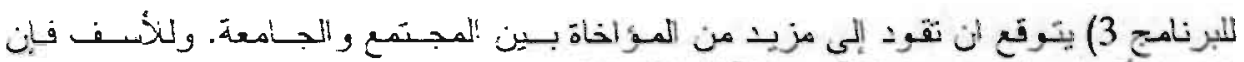

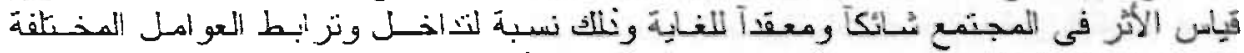

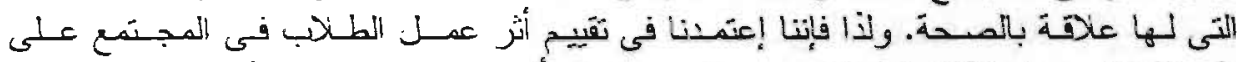

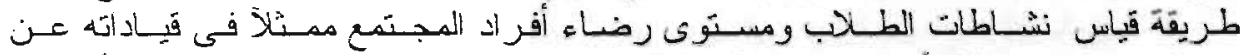

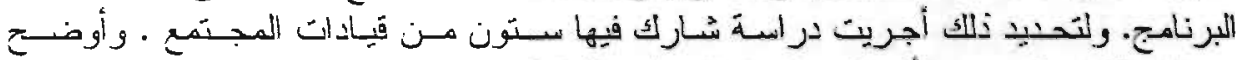

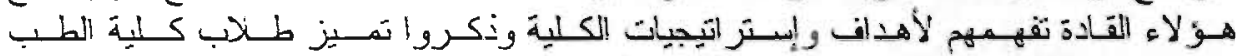

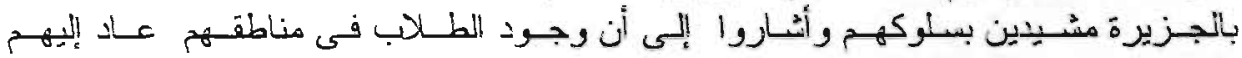

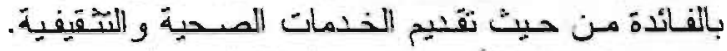

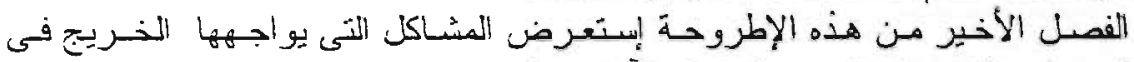

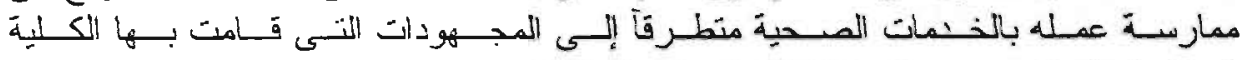

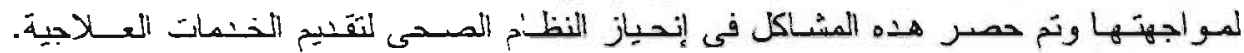

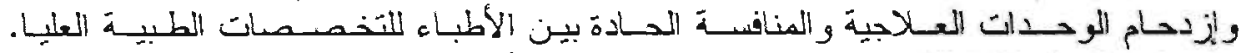

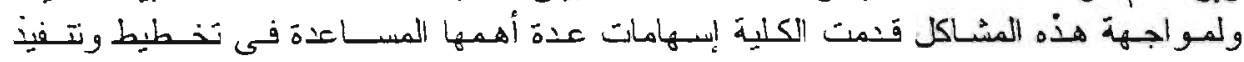

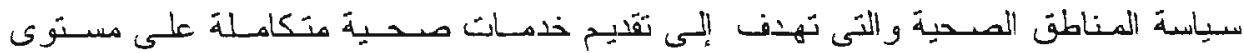

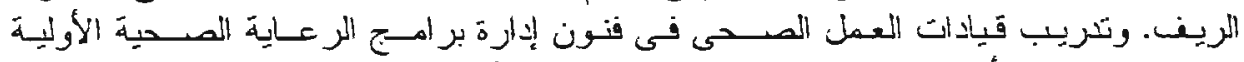

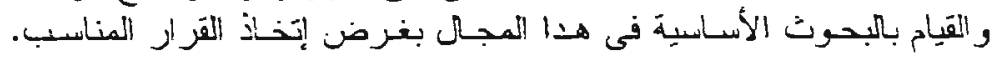

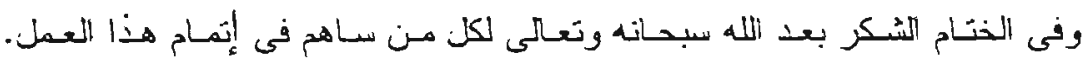

$$
\begin{aligned}
& \text { د. محى الدين محمد عنى مجذوب }
\end{aligned}
$$

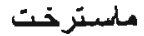

$$
\begin{aligned}
& \text { إكتوبر } 1994
\end{aligned}
$$




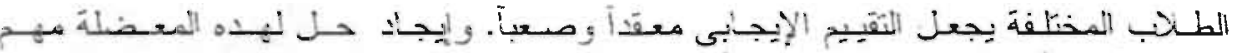

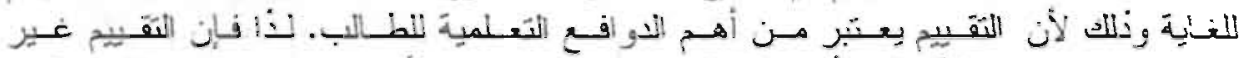

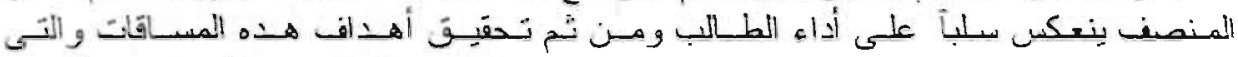

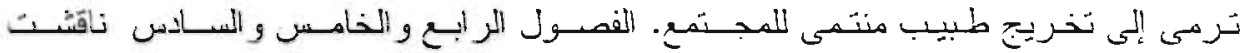

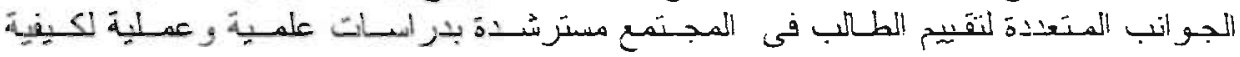
تطبيقه وتتفينه.

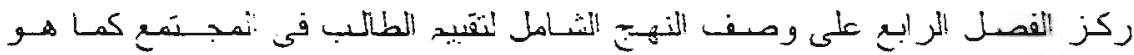

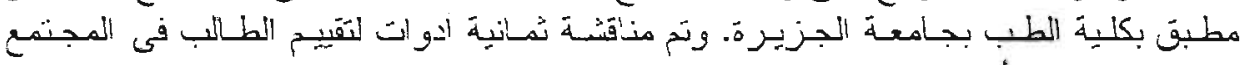

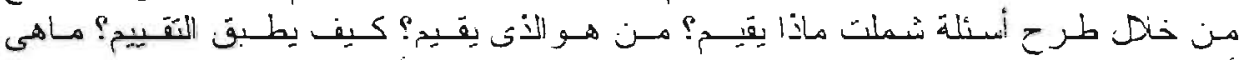

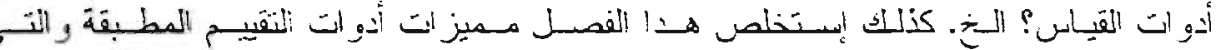

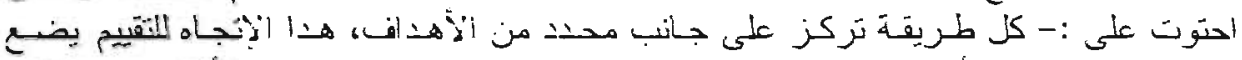

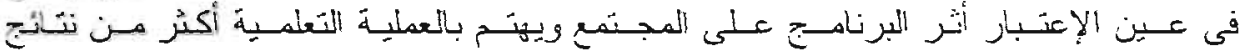

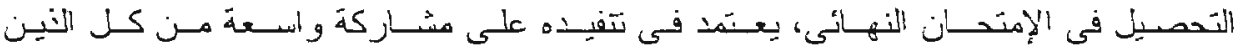

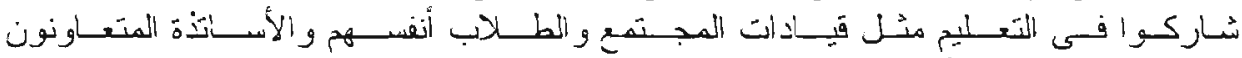

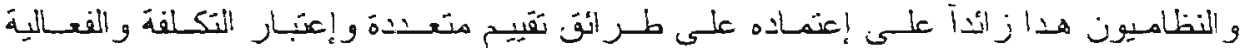

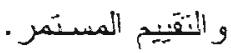

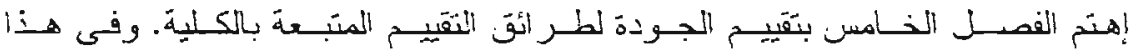

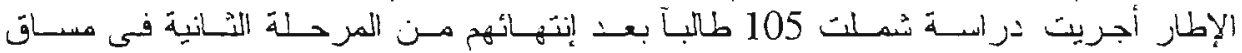

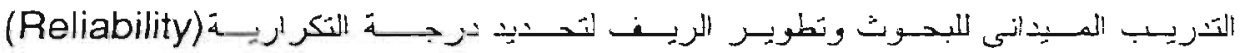

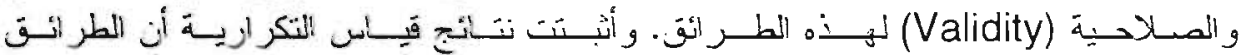

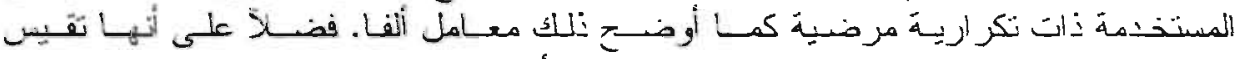

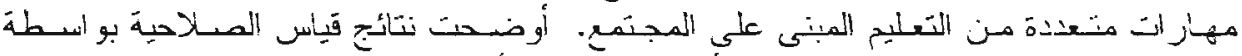

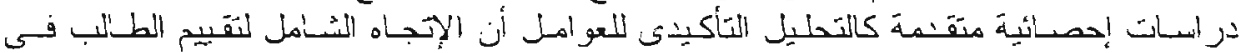

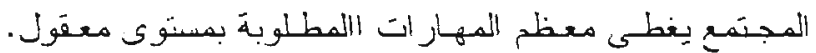

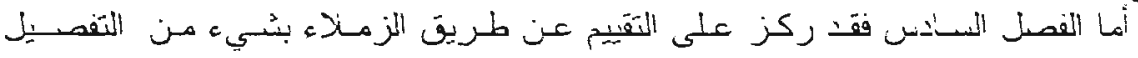

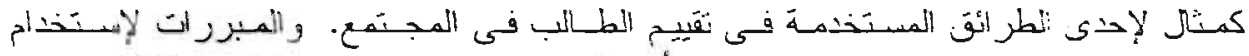

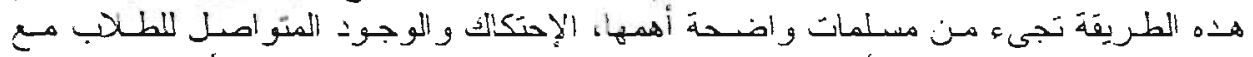

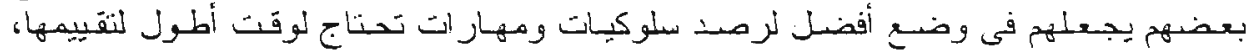

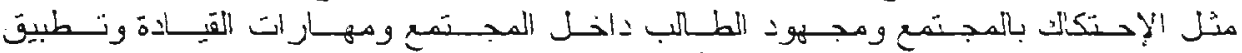

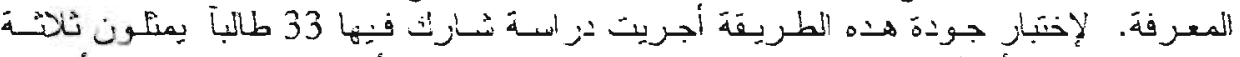

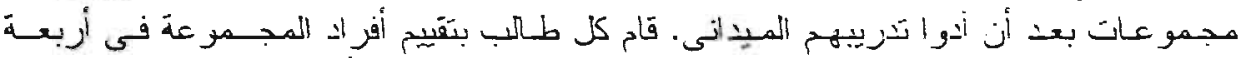

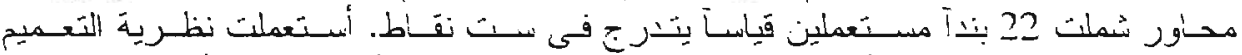

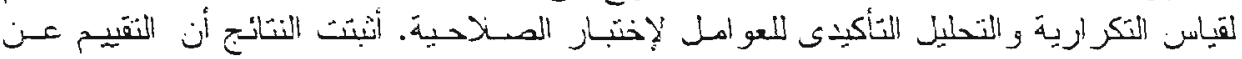

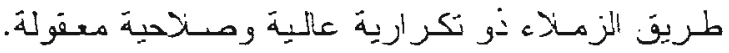

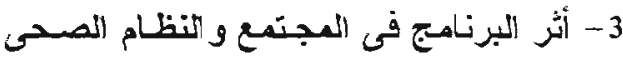

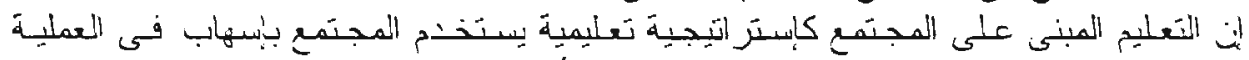

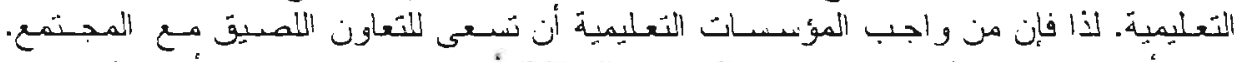

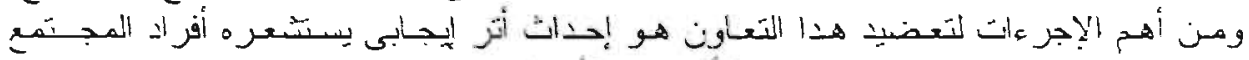

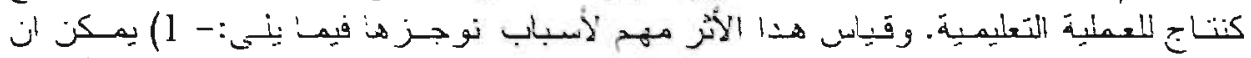

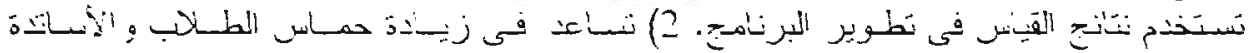




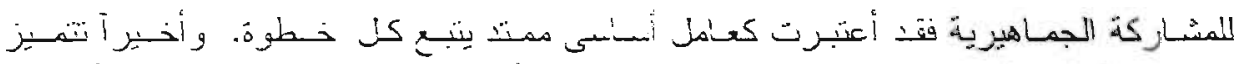

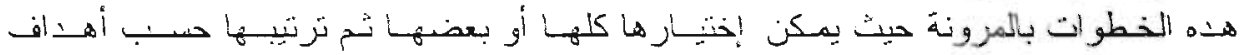
المسباق و الإمكانيات المنتاحة.

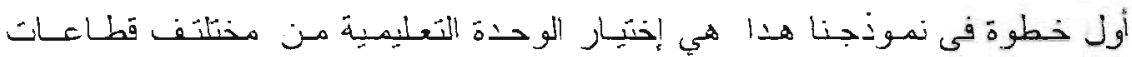

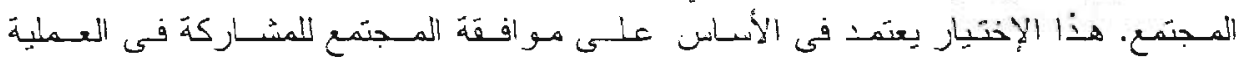

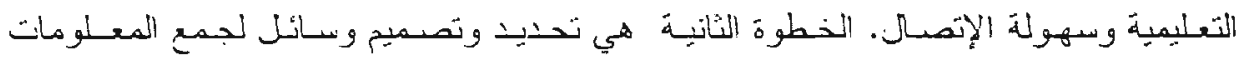

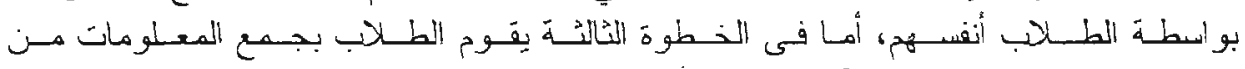

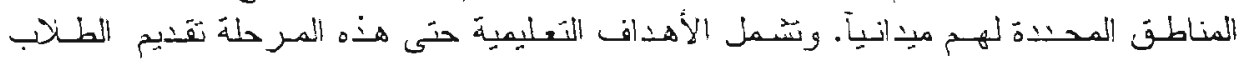

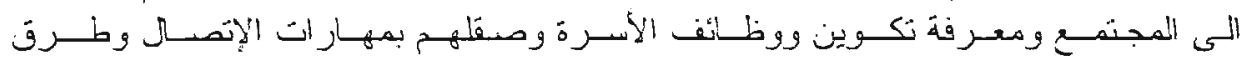

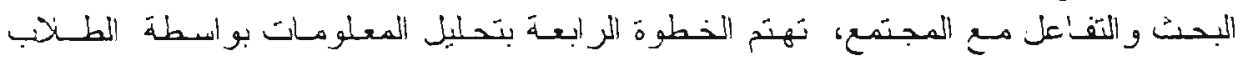

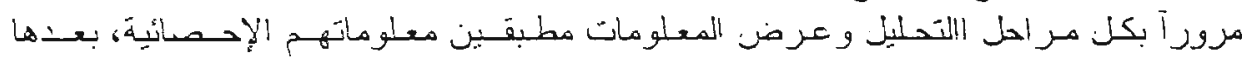

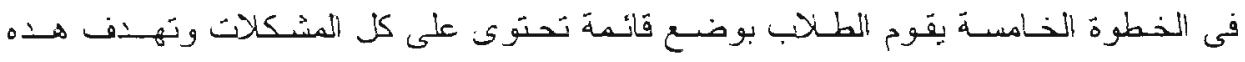

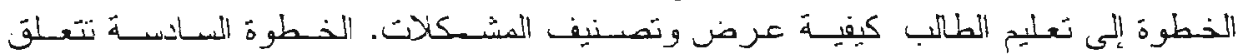

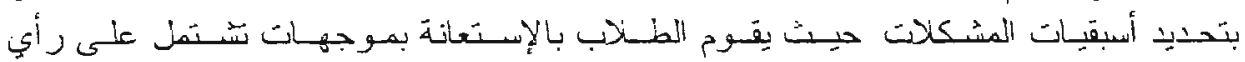

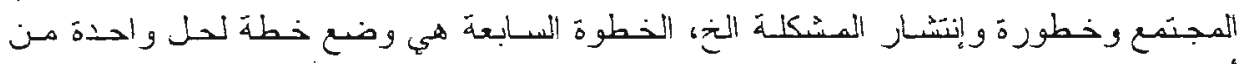

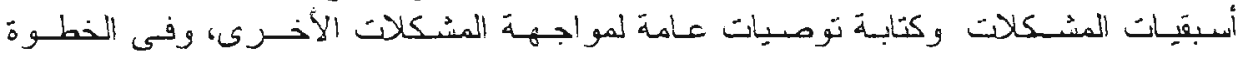

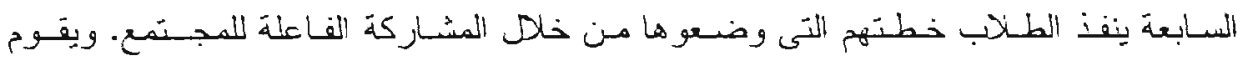

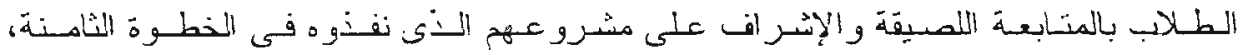

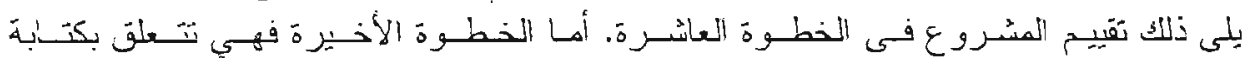

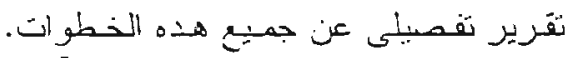

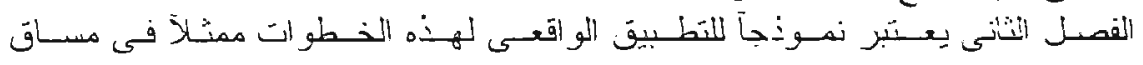

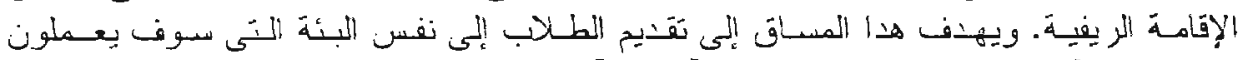

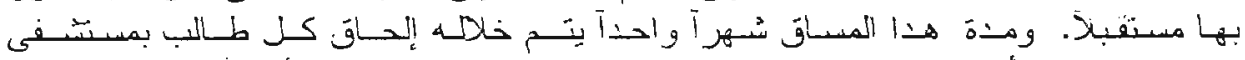

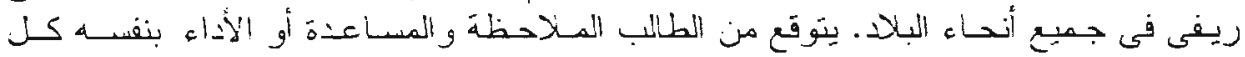

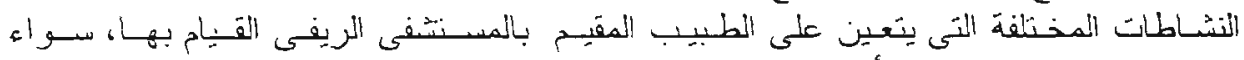

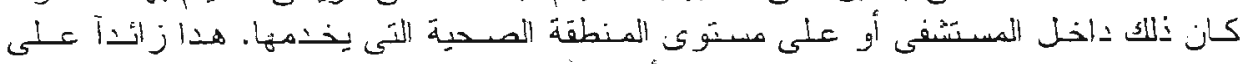

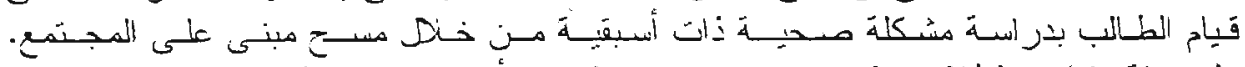

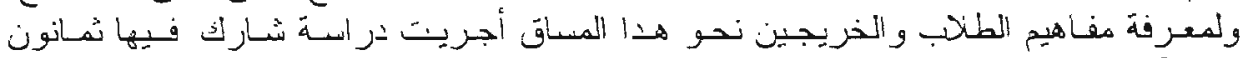

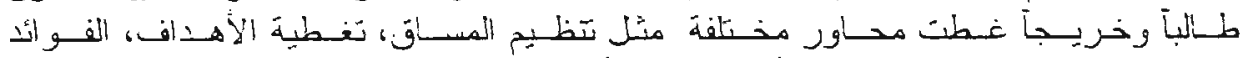

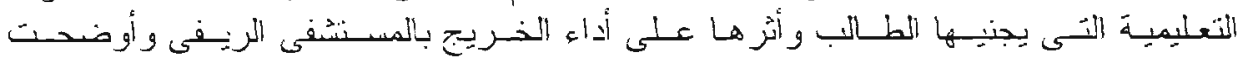

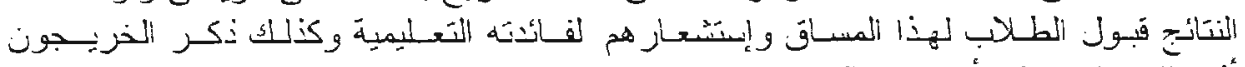

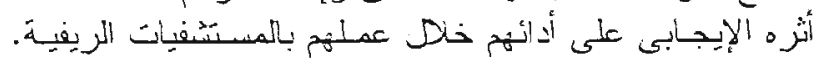

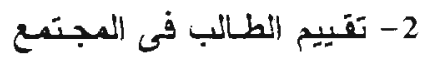

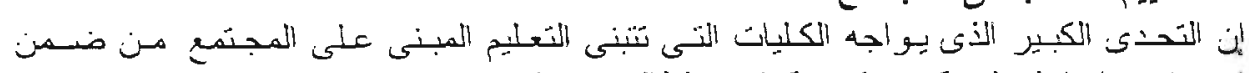

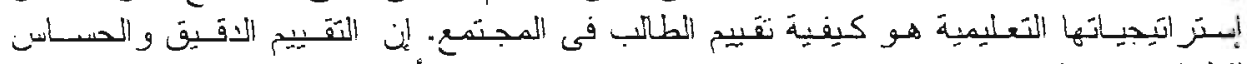

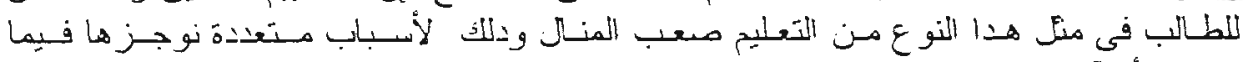

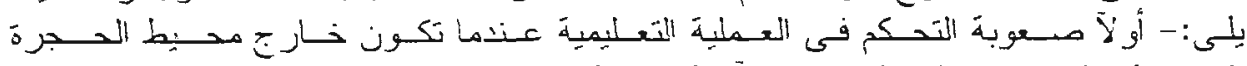

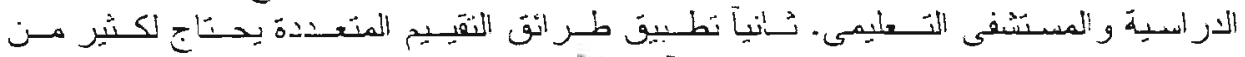

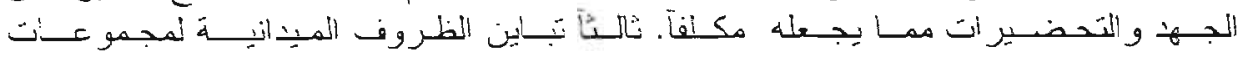




\section{بسم اللـه الرحمن الرحسِ \\ الملخص و الخـلاصنة الرحنة}

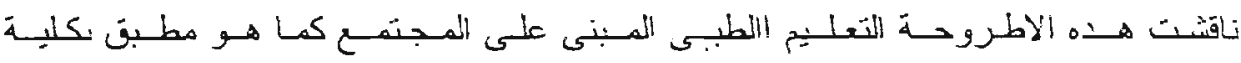

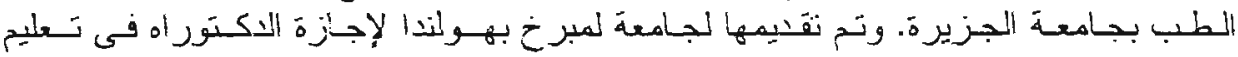

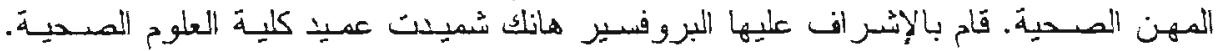

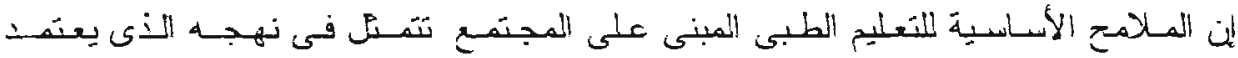

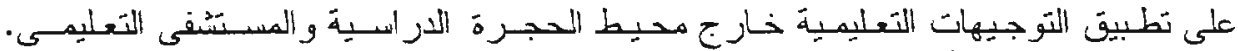

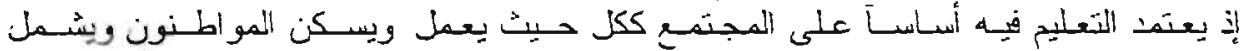

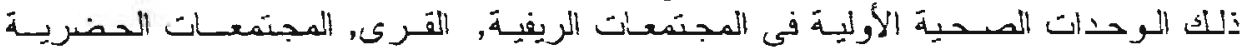

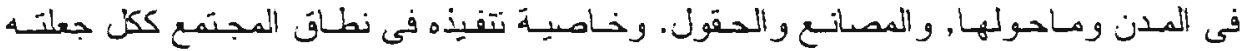

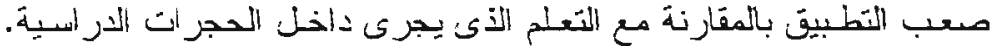

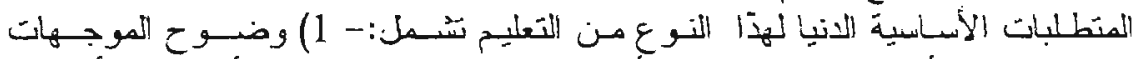

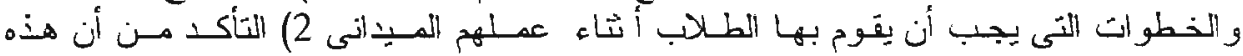

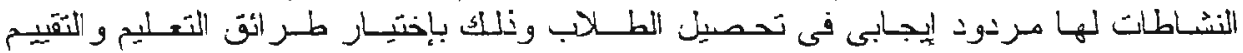

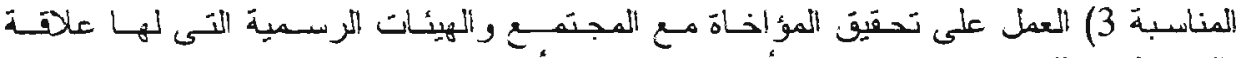

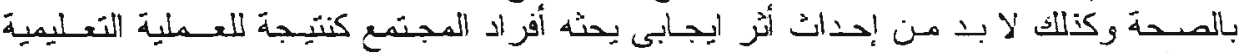

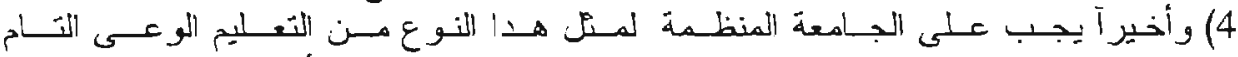

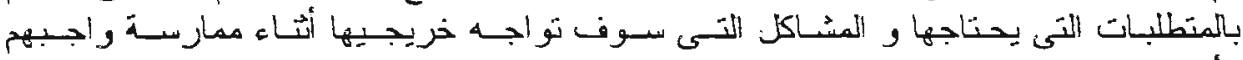

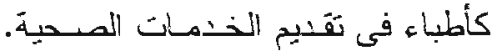

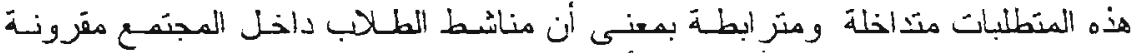

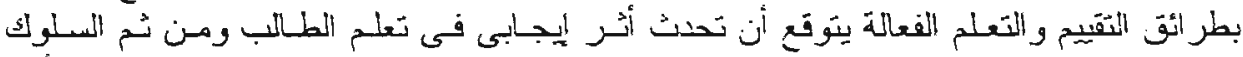

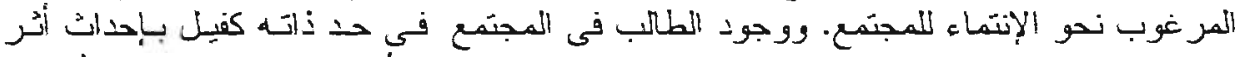

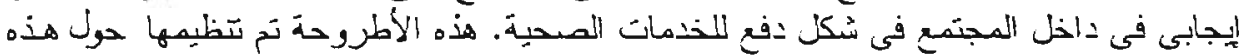

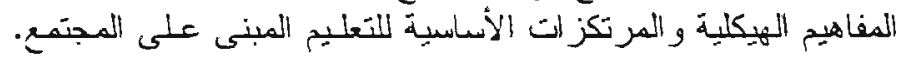

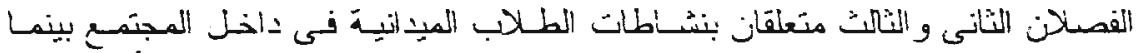

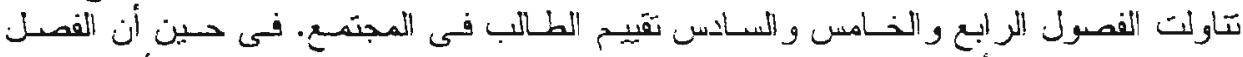

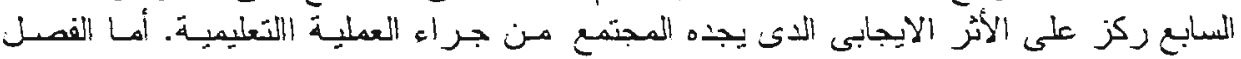

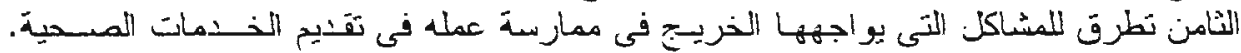

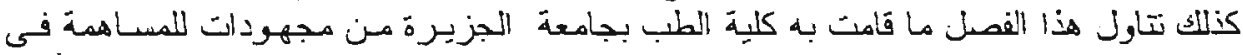

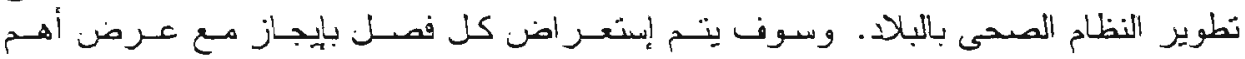

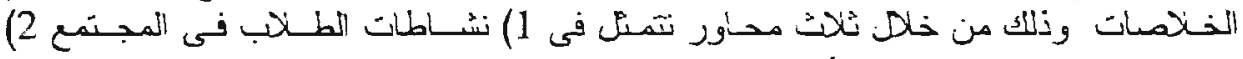

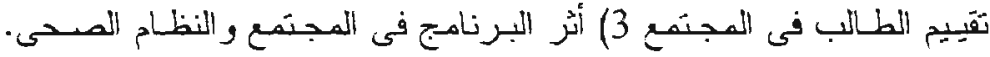

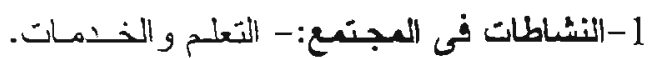

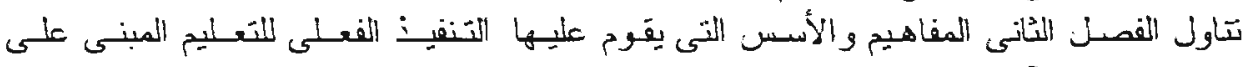

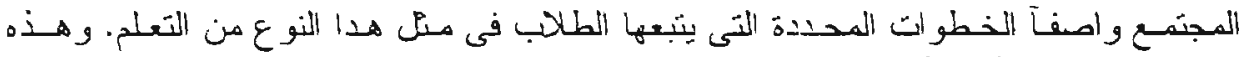

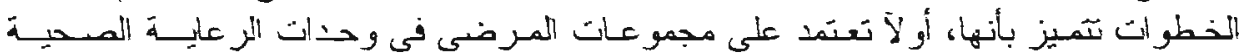

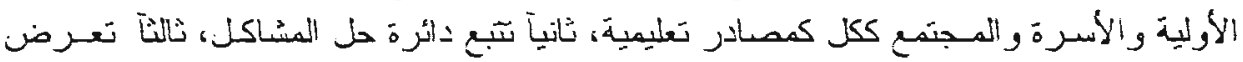

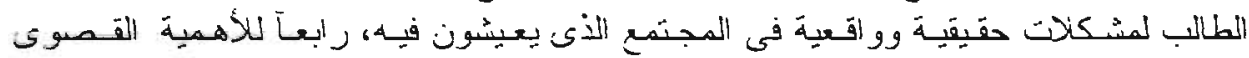




\section{Curriculum Vitae}

Mohi Eldin Mohammed Ali Magzoub was born in Fadasi, Gezira, Sudan on May 17, 1957. Following his graduation at the Faculty of Medicine, University of Gezira (FMUG), Sudan in 1984, he worked in the Wad Medani Teaching Hospital as a houseofficer and then as a medical officer. At the beginning of 1986 he was appointed by the Ministry of Health as a director of Omshanig Rural Hospital in central Sudan. He then joined the Department of Community Medicine, FMUG, at the end of 1986 as a teaching assistant. Following his completion of a Master of Science Programme in Medical Demography at the London School of Hygiene and Tropical Medicine, University of London, in December, 1987, he was appointed as a lecturer by the FMUG. In 1992 he became an associate professor at the Department of Community Medicine, FMUG. Currently he is a member of the Executive Committee of the Network of Community-Oriented Educational Institutions for Health Sciences. 
Druk Uniprint Ontwerp RL design 